\title{
Recent Advances in Pd-Based Membranes for Membrane Reactors
}

\author{
Alba Arratibel Plazaola ${ }^{1,2}$, David Alfredo Pacheco Tanaka ${ }^{2}$, Martin Van Sint Annaland ${ }^{1}$ \\ and Fausto Gallucci ${ }^{1, *}$ \\ 1 Chemical Process Intensification, Department of Chemical Engineering and Chemistry, \\ Eindhoven University of Technology, P.O. Box 513, 5612 AZ Eindhoven, The Netherlands; \\ A.Arratibel.Plazaola@tue.nl (A.A.P.); M.v.SintAnnaland@tue.nl (M.V.S.A.) \\ 2 Tecnalia, Mikeletegi Pasealekua 2, 20009 Donostia-San Sebastian, Spain; alfredo.pacheco@tecnalia.com \\ * Correspondence: f.gallucci@tue.nl; Tel.: +31-402-473-675
}

Academic Editor: Derek J. McPhee

Received: 22 November 2016; Accepted: 20 December 2016; Published: 1 January 2017

\begin{abstract}
Palladium-based membranes for hydrogen separation have been studied by several research groups during the last 40 years. Much effort has been dedicated to improving the hydrogen flux of these membranes employing different alloys, supports, deposition/production techniques, etc. High flux and cheap membranes, yet stable at different operating conditions are required for their exploitation at industrial scale. The integration of membranes in multifunctional reactors (membrane reactors) poses additional demands on the membranes as interactions at different levels between the catalyst and the membrane surface can occur. Particularly, when employing the membranes in fluidized bed reactors, the selective layer should be resistant to or protected against erosion. In this review we will also describe a novel kind of membranes, the pore-filled type membranes prepared by Pacheco Tanaka and coworkers that represent a possible solution to integrate thin selective membranes into membrane reactors while protecting the selective layer. This work is focused on recent advances on metallic supports, materials used as an intermetallic diffusion layer when metallic supports are used and the most recent advances on Pd-based composite membranes. Particular attention is paid to improvements on sulfur resistance of Pd based membranes, resistance to hydrogen embrittlement and stability at high temperature.
\end{abstract}

Keywords: membranes; membrane reactor; pore-filled; palladium membranes; inorganic membranes

\section{Introduction}

When compared with pressure swing adsorption (PSA) and cryogenic distillation, hydrogen permeable Pd-based membranes are a very promising alternative for the separation of pure hydrogen at small- and medium-scales, while concerns about the Pd availability could hamper the exploitation of this kind of membranes at very large industrial scales, such as pre-combustion capture [1-5]. Different combinations of supports, membrane materials and alloys have been investigated with the aim of developing high-flux membranes showing long-term stability at industrially relevant conditions. The early investigations were based on self-supported thick membranes which presented a very high selectivity (required for niche applications such as nuclear), but low permeation rates and extremely high costs. As the U.S. Department Of Energy (US DOE) targets for palladium membranes (used as reference in many countries, including Europe) are getting more demanding every 5 years [6], more efforts have been made toward the development of supported thin films due to the improvements in mechanical stability while maintaining high hydrogen permeation rates. Several techniques are used for the preparation of (dense) supported palladium membranes (electroless plating, electro-deposition, physical vapor deposition and chemical vapour deposition), which were well described by Yun 
and Oyama [7]. Membrane preparation methods were also reported by Paglieri and Way in 2002, who described their application in a membrane reactor, fuel cell, hydrogen isotopes separation and novel applications such as quantification of produced hydrogen by microbes, among others [8].

Before separation, hydrogen is produced mainly by steam reforming (SR) or autothermal (ATR) reactions of different feedstocks, such as methane, higher hydrocarbons, methanol and ethanol; the produced hydrogen can be separated downstream from the exhaust gas stream using hydrogen perm-selective membranes. More interestingly, the separation can be integrated in the reactor (in a membrane reactor-MR) such that the in-situ hydrogen separation will also positively affect the conversion and selectivity of the often equilibrium limited reactions (shift effect according to Le Châtelier's principle).

When using a membrane reactor, the practical configuration can be either in a packed (fixed) bed or as a fluidized bed, where the catalyst is free to move around the membranes. Micro-structured membrane reactors have also been investigated in view of their good heat and mass transfer characteristics [9-13], however, the exploitation of this kind of configuration is hampered by the very active catalytic activity required [10], the extremely high surface area to catalyst volume ratio (in the order $10^{5} \mathrm{~m}^{2} / \mathrm{m}^{3}$ [13]) and by the challenging manifolding and difficulty of accessing damaged channels in a system where hundreds of channels would be required even for smallscale applications.

The advantages of packed-beds lie in its simplicity in construction and well established and validated models for its design and scale-up. Additionally, the catalyst is kept in a fixed position, thus any damage of the membranes due to erosion is circumvented while scratches on the thin membrane surface can only happen when loading and unloading the catalyst from the reactor. On the other hand, the main disadvantages of this kind of reactors are the unavoidable temperature gradients that the reactor (and thus the membrane) is experiencing in both endothermic (steam reforming like) or exothermic (autothermal reforming) reaction systems [14]. More importantly, as thinner membranes are produced with much higher fluxes, the concentration polarization (or better the bed-to-wall mass transfer limitation) prevailing in packed beds will be extremely detrimental for the hydrogen recovery and thus for the overall performance of the membrane reactor [14,15]. These limitations affect fluidized beds to a lesser extent, since they can be operated at virtually uniform temperature and reduced mass transfer limitations. However, much more attention should be paid to possible damages of membranes by erosion. This was already reported in a previous review by Gallucci et al. [16], where the authors showed and discussed in detail different reactor configurations, such as packed-bed (Figure 1 left) and fluidized-bed (Figure 1 right) membrane reactors as well as other concepts.

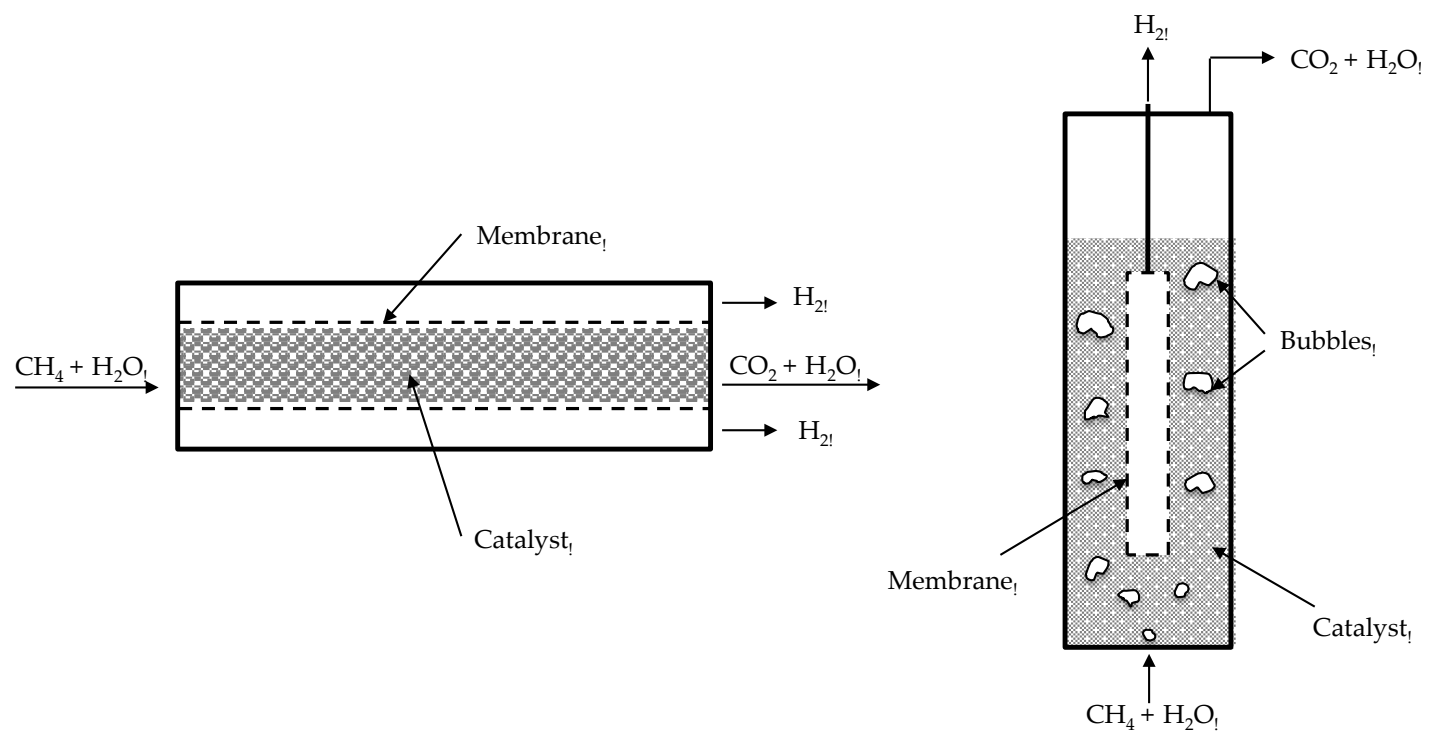

Figure 1. Schematic representation of packed-bed (left) and fluidized-bed (right) membrane reactors. 
A recent paper by Fernandez et al. shows that the integration of membranes in membrane reactors can be also hampered by chemical interaction between the membrane itself and (some component of) the catalyst used in the reactor [17]. For instance they showed that by using a catalyst bed containing $\mathrm{TiO}_{2}$ a strong interaction between this component and the membrane surface made the permeation flux decrease by a factor of 14 within a few $\mathrm{h}$ of experiments under fluidized conditions. Other tests with the same material and powder in a packed bed configuration showed the same effect with an ever higher decrease up to 25 times lower flux (unpublished tests).

Compared with our previous review [16], the present paper reports novel trends by collecting the latest papers published on Pd-membranes and considering the most relevant information for membrane reactor applications. This review is outlined as follows: First, different membrane reactor concepts for hydrogen production and separation from different feedstocks, viz. methane, methanol and ethanol, are reviewed, followed by a discussion of novel concepts to include $\mathrm{CO}_{2}$ capture. Subsequently, the characteristics and properties of the membranes are reviewed, focussing on: (a) effect of the support; (b) resistance of the membrane to embrittlement and poisoning with sulfur (by using palladium alloys); (c) resistance to damage caused by interactions with the catalyst by using cermet or "pore filled" membranes.

\section{Membrane Reactors for Hydrogen Production and Separation}

Integration of hydrogen perm-selective membranes into a catalytic reactor where hydrogen is produced by steam reforming or authothermal reforming of different feedstocks (methane, methanol, ethanol among other hydrocarbons), allows elimination of hydrogen purification units downstream of the reformer together with a reduction of total reactor volume [18]. Another positive aspect of using the membrane reactor concept is based on total capital cost reduction since milder operating conditions are required to achieve the same conversions of conventional systems due to hydrogen extraction through the membranes resulting in shifting of the reaction equilibria towards the products [19-21].

In the review presented by Gallucci et al. [16] the authors reported different configurations of membrane reactors (viz. packed-bed, fluidized-bed and micro-reactor) and the most recent advances obtained in the past 10 years. Since then a number of new works have been published focused on experimental studies for the combination of supported Pd-based membranes in membrane reactors for in situ hydrogen production and recovery. On the other hand, many more theoretical works were reported to confirm the superior performance of membrane reactors (in any configuration) compared with conventional systems [22-31].

As already reported above, the summary of these results show that packed bed membrane reactors (PBMR) are affected by severe mass and heat transfer limitations that result in reduced membrane fluxes (mass transfer limitations) and difficulties in maintaining a uniform temperature close to the membranes (heat transfer limitations) that could also eventually damage the membranes (due to hot spots in case of exothermic reactions). On the other hand, fluidized-bed membrane-reactors (FBMR), have much better heat and mass transfer rates [32], so that the membranes always experience a uniform temperature and the highest hydrogen partial pressure, thus maximizing both membrane flux and lifetime. Additionally, smaller particles can be used in fluidized beds because of the limited pressure drop, and thus any possible internal mass transfer limitation is circumvented. On the contrary, problems with membrane erosion and bubble-to-emulsion mass transfer limitations can affect the performance of the FBMR and the lifetime of the membranes [33]. An alternative to avoid direct contact between particles in constant motion with the membrane surface is to cover the surface with a porous layer with a porosity and pore size sufficiently large to avoid additional mass transfer limitations and small enough to avoid particles entering the pores. The porous structure can be a separate structure but physically attached to the membrane, or it can be part of the membrane itself. The second option can be achieved by using "pore-filled" membranes prepared with a very thin and porous ceramic layer covering the palladium deposited onto nanopores. Nevertheless, these kind of membranes were not yet tested inside a fluidized bed reactor. It should also be reminded that to protect the membrane the 
thin Pd layer cannot be deposited on the inner surface of a porous support (as one might immediately propose), because the large pressure difference used between the reaction zone (the fluidized bed) and the permeation zone (inside the tube) would result in fast delamination of the Pd layer with consequent loss in perm-selectivity.

Finally, Dang et al. [29,34] have also shown that in FBMRs, the application of extremely permeable membranes could lead to formation of densified zones close to the membrane walls in case mild fluidization of small particles is used. They concluded that it may preferable to work at higher fluidization velocities and with somewhat larger particles (in the order of few hundreds of microns), putting stronger targets on the membrane's resistance against erosion.

\subsection{Feedstock for $\mathrm{H}_{2}$ Production in MRs and Required Operating Conditions}

As far as the feedstock for hydrogen production is concerned, most of the recent articles deal with methane and alcohols (methanol and ethanol) as fuel of the membrane reactor. Their conversion to $\mathrm{H}_{2}$, and selectivity to $\mathrm{CO}$ and $\mathrm{CO}_{2}$ depend on the operating conditions (temperature, pressure, reactor configuration and so on). Most of the reactions for hydrogen production (from either $\mathrm{CO}$, methane, ethanol and methanol) are equilibrium limited reaction systems which are endothermic or exothermic depending on the $\mathrm{H}_{2} \mathrm{O} / \mathrm{C}$ and $\mathrm{O}_{2} / \mathrm{C}$ ratios used. In Table 1 the most relevant reactions involving steam reforming for these three feedstocks and their enthalpies have been summarized.

Table 1. Reactions involved in hydrogen production from methane, methanol and ethanol, and their enthalpies [35-41].

\begin{tabular}{|c|c|}
\hline Reaction & $\Delta H_{298 K}\left(k J \cdot \mathrm{mol}^{-1}\right)$ \\
\hline $\begin{array}{l}\text { Water gas shift (WGS) } \\
\mathrm{CO}+\mathrm{H}_{2} \mathrm{O}=\mathrm{CO}+\mathrm{H}_{2}\end{array}$ & -41.1 \\
\hline \multicolumn{2}{|l|}{ Decomposition (Carbon production) } \\
\hline $\mathrm{CH}_{4}=\mathrm{C}+2 \mathrm{H}_{2}$ & 75 \\
\hline $\begin{array}{l}\text { Steam reforming (SR) reactions } \\
\mathrm{CH}_{4}+\mathrm{H}_{2} \mathrm{O}=\mathrm{CO}+3 \mathrm{H}_{2} \\
\mathrm{CH}_{4}+2 \mathrm{H}_{2} \mathrm{O}=\mathrm{CO}_{2}+4 \mathrm{H}_{2} \\
\mathrm{CH}_{3} \mathrm{OH}+\mathrm{H}_{2} \mathrm{O}=\mathrm{CO}_{2}+3 \mathrm{H}_{2} \\
\mathrm{C}_{2} \mathrm{H}_{5} \mathrm{OH}+\mathrm{H}_{2} \mathrm{O}=2 \mathrm{CO}+4 \mathrm{H}_{2}\end{array}$ & $\begin{array}{c}206.2 \\
164.9 \\
49 \\
239.5\end{array}$ \\
\hline $\begin{array}{l}\text { Partial and full oxidation reactions } \\
\mathrm{CH}_{4}+2 \mathrm{O}_{2}=\mathrm{CO}_{2}+2 \mathrm{H}_{2} \mathrm{O} \\
\mathrm{CH}_{4}+\mathrm{O}_{2}=\mathrm{CO}_{2}+2 \mathrm{H}_{2} \\
\mathrm{CH}_{4}+\frac{1}{2} \mathrm{O}_{2}=\mathrm{CO}_{2}+2 \mathrm{H}_{2} \\
\mathrm{CH}_{3} \mathrm{OH}+\frac{1}{2} \mathrm{O}_{2}=\mathrm{CO}_{2}+2 \mathrm{H}_{2} \\
\mathrm{C}_{2} \mathrm{H}_{5} \mathrm{OH}+\frac{1}{2} \mathrm{O}_{2}=2 \mathrm{CO}+3 \mathrm{H}_{2}\end{array}$ & $\begin{array}{c}-14.4 \\
-71 \\
-35.6 \\
-192.3 \\
-14.4\end{array}$ \\
\hline $\begin{array}{l}\text { Autothermal reforming (ATR) reactions } \\
4 \mathrm{CH}_{4}+2 \mathrm{H}_{2} \mathrm{O}+\mathrm{O}_{2}=10 \mathrm{H}_{2}+4 \mathrm{CO} \\
4 \mathrm{CH}_{3} \mathrm{OH}+3 \mathrm{H}_{2} \mathrm{O}+\frac{1}{2} \mathrm{O}_{2}=4 \mathrm{CO}_{2}+11 \mathrm{H}_{2} \\
\mathrm{C}_{2} \mathrm{H}_{5} \mathrm{OH}+2 \mathrm{H}_{2} \mathrm{O}+3 / 2 \mathrm{O}_{2}=2 \mathrm{CO}_{2}+5 \mathrm{H}_{2}\end{array}$ & $\begin{array}{c}339 \\
0 \\
-50\end{array}$ \\
\hline
\end{tabular}

The required temperatures for reforming of every feedstock are related to their endothermicity. In conventional reactors, methane and ethanol reforming require temperature above $800{ }^{\circ} \mathrm{C}$ and $600{ }^{\circ} \mathrm{C}$ respectively, while methanol reforming can be carried out at much lower temperatures of 250-300 ${ }^{\circ} \mathrm{C}[42]$.

These temperatures can be dramatically decreased when using membrane reactors as hydrogen recovery through Pd based membranes drives the reactions toward the products [43]. However, while having a clear energetic benefit, decreasing the reaction temperatures has also the negative effect of increasing the potential formation of carbon deposits on the catalysts. The catalysts for membrane reactors should therefore be more resistant against carbon formation. Alternatively excess of steam with typical molar ratios $\mathrm{H}_{2} \mathrm{O} / \mathrm{C}$ of 3-5, can be used to avoid carbon formation [44]. Finally, to assure a long membrane lifetime the temperature of the reformer unit needs to be below the maximum 
operating temperature of membranes, which in case of Pd-based membranes is around $600{ }^{\circ} \mathrm{C}$ [45]. Indeed at this temperature the MR outperforms the conventional system, while the membrane area for hydrogen recovery is minimized [33].

In the following, the most recent results obtained with membrane reactors with integrated hydrogen perm-selective membranes for hydrogen production are presented by reforming of different feedstocks, viz. methane, methanol and ethanol. Table 2 summarizes the performance and operating conditions of the most recent studies reported in the last years, which are explained in more detail in the following sections.

\subsubsection{Methane as Feedstock}

Methane is the most frequently used (and consequently the most studied) light hydrocarbon for hydrogen production. As methane is a molecule that is difficult to activate, generally the reforming of methane is carried out at temperatures much higher than other hydrocarbons, particularly alcohols. When using natural gas as source of methane, the stream contains small amounts of $\mathrm{H}_{2} \mathrm{~S}$, which poison the surface of Pd-based membranes and may even lead to rupture of the thin membrane layer [46]. On the contrary, other feedstocks such as methanol and ethanol are much cleaner than natural gas, so that the reforming of such fuels is not detrimental for the Pd-membranes behaviour.

Larger conversion levels are achieved at lower temperatures $\left(550-600{ }^{\circ} \mathrm{C}\right.$ ) in the $\mathrm{MR}$, when compared with conventional methane steam reforming (800-900 $\left.{ }^{\circ} \mathrm{C}\right)$. Additionally, the allowed decrease in temperature is also beneficial for the water gas shift (WGS) equilibrium, reducing the CO concentrations in the retentate stream [47].

Nickel-based catalysts represent the most effective option to achieve high conversions of methane at reasonable costs. Generally, these catalysts are supported on porous ceramics (i.e., $\gamma-\mathrm{Al}_{2} \mathrm{O}_{3}[48]$ ). Others noble metals like rhodium were supported on $\mathrm{ZrO}_{2}$ for low temperature ATR of $\mathrm{CH}_{4}$ [10] as well as on YSZ for higher temperature ATR [49]. Noble metal catalysts are generally preferred over Ni-based catalyst for their higher reaction rates, higher stability and lower activity towards carbon formation.

Problems associated to hot-spots in a packed-bed reactor were partially avoided using foam-supported catalysts as reported by Kyriakides et al. [50] in a two coaxial tubes MR. The temperature gradient was reduced from $100{ }^{\circ} \mathrm{C}$ to $25^{\circ} \mathrm{C}$ as catalyst pellets were replaced by foam supported catalysts. Moreover, enhancement of methane conversion was achieved by replacing the catalyst due to better heat transfer: in fact when using commercial pellets up to $18.85 \%$ conversion at 1 bar and $500{ }^{\circ} \mathrm{C}$ average wall temperature $\left(415^{\circ} \mathrm{C}\right.$ in the bed) was achieved, while the conversions observed for the foam-supported catalyst were up to $29.97 \%$ with the wall and bed temperature close to $500{ }^{\circ} \mathrm{C}$.

The use of a catalytic foam in a membrane reactor was recently reported by Patrascu et al. [51]. $\mathrm{A} \mathrm{Pt}_{(3)} \mathrm{Ni}_{(10)} / \mathrm{CeO}_{2}$ coated onto a SiC foam scaffold (high thermal conductivity) was used as a catalyst. The authors obtained $90 \%$ methane conversion and $80 \%$ of the produced hydrogen was recovered at $525^{\circ} \mathrm{C}$ and 10 bar. This high conversion was achieved using $0.7 \mathrm{~L} \cdot \mathrm{min}^{-1}$ of $\mathrm{N}_{2}$ sweep gas.

Integration of membranes into a packed-bed MR was reported by Matsuka et al. [52], where the authors compare three different types of self-supported membranes: 25 and 50- $\mu$ m-thick $\operatorname{Pd}_{77} \mathrm{Ag}_{23}$, 100 - $\mu \mathrm{m}$-thick $\mathrm{V}$ and $\mathrm{V}_{92} \mathrm{Ni}_{8}$ layers coated on both sides with Pd by magnetron sputtering $(1 \mu \mathrm{m})$. Experiments were performed in presence of $10 \mathrm{wt}$. \% nickel catalysts supported on $\mathrm{SiO}_{2}$ while feeding a mixture of $\mathrm{CH}_{4}, \mathrm{O}_{2}, \mathrm{H}_{2} \mathrm{O}$ and $\mathrm{N}_{2}$. The best performance was observed for the Pd coated vanadium membrane, obtaining $\sim 45 \%$ methane conversion at $400{ }^{\circ} \mathrm{C}$ while the permeation flux was $0.09\left(\mathrm{~mol} \cdot \mathrm{m}^{-2} \cdot \mathrm{s}^{-1}\right)$. The membranes were exposed to Fe in a hydrogen environment at $500{ }^{\circ} \mathrm{C}$, evidencing surface degradation of the PdAg membranes due to the formation of pinholes, while the presence of defects in V membranes was lower. EXD analyses on the cross sections showed traces of iron diffusion along the PdAg membrane. On the other hand, interestingly no Fe diffusion through the $\mathrm{Pd} / \mathrm{V} / \mathrm{Pd}$ membrane was detected, while intermetallic diffusion of palladium into vanadium through 10-15 $\mu \mathrm{m}$ in depth was observed. 
Table 2. Performance and operating conditions of several membrane reactors for reforming of methane, methanol and ethanol, reported in the last years

\begin{tabular}{|c|c|c|c|c|c|c|c|c|c|c|c|c|c|c|c|}
\hline \multirow{2}{*}{ Membrane } & \multirow{2}{*}{ Method } & \multirow{2}{*}{$\begin{array}{l}\text { MR } \\
\text { Type }\end{array}$} & \multirow{2}{*}{ Catalysts } & \multirow{2}{*}{$\begin{array}{c}\text { Reaction } \\
\text { Type }^{\mathrm{a}}\end{array}$} & \multirow{2}{*}{$\mathrm{T}\left({ }^{\circ} \mathrm{C}\right)$} & \multirow{2}{*}{$\Delta \mathrm{P}(\mathrm{kPa})$} & \multirow{2}{*}{ Feedstock } & \multirow{2}{*}{$\mathrm{H}_{2} \mathrm{O} /$ Carbon } & \multirow{2}{*}{$\mathrm{O}_{2} /$ Feedstock } & \multirow{2}{*}{$\begin{array}{c}\text { GHSV } \\
\left(\mathrm{h}^{-1}\right)\end{array}$} & \multicolumn{2}{|c|}{ Conversion (\%) } & \multirow{2}{*}{$\begin{array}{c}\mathrm{H}_{2} \text { Recovery } \\
(\%)\end{array}$} & \multirow{2}{*}{$\begin{array}{c}\mathrm{H}_{2} \text { Purity } \\
(\%)\end{array}$} & \multirow{2}{*}{ Reference } \\
\hline & & & & & & & & & & & Equilibrium & MR & & & \\
\hline $\operatorname{PdAg}(4-5 \mu \mathrm{m}) / \mathrm{Al}_{2} \mathrm{O}_{3}$ & ELP & PB & $\mathrm{Pt}_{3} \mathrm{Ni}_{10} / \mathrm{CeO}_{2}$ & SR & 525 & 1000 & $\mathrm{CH}_{4}$ & 3 & & 136 & 65 & 90 & 80 & - & {$[51]$} \\
\hline $\mathrm{Pd} / \mathrm{V} / \mathrm{Pd}(1 / 100 / 1 \mu \mathrm{m})$ & PVD-MS & PB & $\mathrm{Ni} / \mathrm{SiO}_{2}$ & ATR & 400 & & $\mathrm{CH}_{4}$ & $1.25^{\mathrm{e}}$ & $0.3^{\mathrm{e}}$ & - & 26 & $\sim 45$ & - & - & [52] \\
\hline $\mathrm{Pd}(3 \mu \mathrm{m}) / \mathrm{Al}_{2} \mathrm{O}_{3}(\mathrm{HF})$ & ELP & PB & $\mathrm{Ni} / \mathrm{SBA}-15$ & $\mathrm{SR}$ & 560 & - & $\mathrm{CH}_{4}$ & 2 & - & - & 52 & 53 & 43 & - & [53] \\
\hline $\mathrm{Pd}(10.2 \mu \mathrm{m}) / \mathrm{OxPSS}$ & ELP & PB & Fe-Cr oxide & SR & 400 & $2-3$ & $\mathrm{CH}_{4}$ & $1\left(\mathrm{H}_{2} \mathrm{O} / \mathrm{CO}\right)$ & - & 5000 & 32 & 59 & 15 & - & [54] \\
\hline $\mathrm{Pd} / \mathrm{Nao} / \mathrm{PSS}$ & ELP & PB & $\mathrm{Ru} / \mathrm{La}_{2} \mathrm{O}_{2} \mathrm{CO}_{3}$ & $\mathrm{CR}$ & 450 & & $\mathrm{CH}_{4}$ & & 0.3 & - & 35 & 36 & 80 & 99.5 & [55] \\
\hline PdAg & - & $\mathrm{PB}$ & $\mathrm{Ni} / \gamma-\mathrm{Al}_{2} \mathrm{O}_{3}$ & SR & 600 & 100 & $\mathrm{CH}_{4}$ & $2.85\left(\mathrm{CH}_{4} / \mathrm{CO}_{2}\right)$ & - & - & 20 & 35 & 47 & - & [56] \\
\hline Pd/PSS & - & FB & - & $\mathrm{SR}$ & 450 & 1000 & $\mathrm{CH}_{4}$ & $3\left(\mathrm{H}_{2} \mathrm{O} / \mathrm{CO}\right)$ & - & - & - & - & 47 & - & [57] \\
\hline $\operatorname{PdAg}(25 \mu \mathrm{m})$ & - & FB & & ATR & 600 & 2600 & $\mathrm{CH}_{4}$ & $2-3.5$ & 0.3 & - & 29 & 41 & - & & [58] \\
\hline $\mathrm{PdAg}(25 \mu \mathrm{m}) / \mathrm{PSS}$ & - & FB & $\mathrm{NiO} / \mathrm{Al}_{2} \mathrm{O}_{3}$ & $\mathrm{SR}$ & 550 & 900 & $\mathrm{CH}_{4}$ & 3 & - & - & - & 73.1 & - & 99.94 & [59] \\
\hline $\mathrm{PdAg}(25 \mu \mathrm{m}) / \mathrm{PSS}$ & - & FB & $\mathrm{NM}^{\mathrm{b}} / \mathrm{Al}_{2} \mathrm{O}_{3}$ & ATR & 550 & 900 & $\mathrm{CH}_{4}$ & 3 & 0.35 & - & - & 80.9 & - & 99.988 & - \\
\hline PdRu $(5 \mu \mathrm{m}) \mathrm{YSZ} / \mathrm{PSS}$ & ELP & FB & $\mathrm{Ni}$ & $\mathrm{SR}$ & 580 & 2900 & $\mathrm{CH}_{4}$ & 3 & - & 150 & 17 & 90 & 85 & 95.59 & [60] \\
\hline PdAg/Inconel/PdAg & ELP & FB & Noble metal-based & SR & $550-630$ & $350-550$ & $\mathrm{CH}_{4}$ & 3 & - & $0.26^{\mathrm{h}}$ & 72.2 & 83.1 & & $\sim 100$ & [61] \\
\hline $\mathrm{PdAg} / \mathrm{YSZ}-\mathrm{Al}_{2} \mathrm{O}_{3} /$ HastelloyX & ELP & FB & $\mathrm{Ni} / \mathrm{CaAl}_{2} \mathrm{O}_{3}$ & SR & 600 & 300 & $\mathrm{CH}_{4}$ & 3 & - & & 61 & 73 & 27 & 97.6 & [62] \\
\hline $\mathrm{PdAg} / \mathrm{YSZ}_{\mathrm{S}} \mathrm{Al}_{2} \mathrm{O}_{3} /$ HastelloyX & ELP & FB & $\mathrm{Ni} / \mathrm{CaAl}_{2} \mathrm{O}_{3}$ & ATR & 600 & 300 & $\mathrm{CH}_{4}$ & 3 & 0.25 & - & 72 & 82 & 34 & 97.1 & [62] \\
\hline $\mathrm{PdAg} / \mathrm{Al}_{2} \mathrm{O}_{3}$ & ELP & FB & $\mathrm{Ru} / \mathrm{Ce}_{0.75} \mathrm{Zr}_{0.25} \mathrm{O}_{2}$ & SR & 600 & 130 & $\mathrm{CH}_{4}$ & 3 & & - & 89 & 89.3 & 23 & $99.98^{\mathrm{g}}$ & [63] \\
\hline $\mathrm{PdAg} / \mathrm{Al}_{2} \mathrm{O}_{3}$ & ELP & FB & $\mathrm{Ru} / \mathrm{Ce}_{0.75} \mathrm{Zr}_{0.25} \mathrm{O}_{2}$ & ATR & 600 & 130 & $\mathrm{CH}_{4}$ & 3 & 0.25 & - & 93.2 & 96.7 & 35 & $99.95^{\mathrm{g}}$ & [63] \\
\hline $\mathrm{Pd}(7 \mu \mathrm{m}) / \mathrm{Al}_{2} \mathrm{O}_{3}$ & ELP & $\mathrm{PB}$ & $\mathrm{Cu}-\mathrm{Zn} / \mathrm{Al}_{2} \mathrm{O}_{3}$ & SR & 330 & 250 & $\mathrm{CH}_{3} \mathrm{OH}$ & 2.5 & - & 18500 & & 85 & 40 & $\sim 100$ & [64] \\
\hline PdAg $(50 \mu \mathrm{m})$ & Cold-work & $\mathrm{PB}$ & $\mathrm{Cu}-\mathrm{Zn} / \mathrm{Al}_{2} \mathrm{O}_{3}$ & SR & 280 & 250 & $\mathrm{CH}_{3} \mathrm{OH}$ & 3 & - & 1800 & 91 & 100 & $\sim 46$ & $\sim 100$ & [22] \\
\hline $\mathrm{Pd}(7 \mu \mathrm{m}) / \mathrm{Al}_{2} \mathrm{O}_{3}$ & ELP & $\mathrm{PB}$ & $\mathrm{CuO} / \mathrm{ZnO}$ & SR & 300 & 150 & $\mathrm{CH}_{3} \mathrm{OH}$ & 1.5 & - & $0.95^{\mathrm{h}}$ & & 97 & 72 & $\sim 91$ & [65] \\
\hline $\mathrm{PdAg}(5 \mu \mathrm{m}) / \mathrm{Al}_{2} \mathrm{O}_{3}(\mathrm{HF})$ & ELP & PB & $\mathrm{Cu}-\mathrm{Zn} / \mathrm{GaOx}{ }^{\mathrm{c}}$ & SR & 400 & 100 & $\mathrm{CH}_{3} \mathrm{OH}$ & 2 & - & - & 88 & 100 & $\sim 50$ & - & [66] \\
\hline $\mathrm{Pd}(24.3 \mu \mathrm{m}) / \mathrm{PSS}$ & & $\mathrm{PB}$ & $\mathrm{Ni}-\mathrm{Zn} / \mathrm{Al}_{2} \mathrm{O}_{3}$ & $\mathrm{SR}$ & $200-300$ & 345 & $\mathrm{CH}_{3} \mathrm{OH}$ & 1 & - & - & - & $15-78$ & $\sim 30-50$ & - & [67] \\
\hline PdRu & - & PB & $\mathrm{Pt}-\mathrm{Ru}$ & $\mathrm{SR}$ & 450 & . & $\mathrm{C}_{2} \mathrm{H}_{5} \mathrm{OH}$ & 4.5 & - & - & - & $98-99$ & $35-60$ & 99.99 & [40] \\
\hline $\operatorname{PdAg}(75 \mu \mathrm{m})$ & - & $\mathrm{PB}$ & $\mathrm{Rh} / \mathrm{CeO}_{2}$ & $\mathrm{SR}$ & 550 & - & $\mathrm{C}_{2} \mathrm{H}_{5} \mathrm{OH}$ & 5 & - & - & - & 100 & 70 & - & {$[68]$} \\
\hline PdAg $(30 \mu \mathrm{m})$ & - & PB & $\mathrm{Co}\left[\mathrm{Si}_{2} \mathrm{O}_{5}\right](\mathrm{OH}) 2^{\mathrm{f}}$ & $\mathrm{SR}$ & 350 & 1400 & $\mathrm{C}_{2} \mathrm{H}_{5} \mathrm{OH}$ & 3 & - & - & - & 100 & 80 & - & [69] \\
\hline $\mathrm{PdAg}(50 \mu \mathrm{m}) / \mathrm{PSS}$ & - & PB & $\mathrm{Co} / \mathrm{Al}_{2} \mathrm{O}_{3}$ & SR & 400 & 150 & $\mathrm{C}_{2} \mathrm{H}_{5} \mathrm{OH}$ & 9.35 & - & $5.5^{\mathrm{h}}$ & 84 & $94.2-94.5$ & 27 & $\sim 100$ & {$[70]$} \\
\hline $\mathrm{PdAg}(50 \mu \mathrm{m}) / \mathrm{PSS}$ & - & PB & $\mathrm{Co} / \mathrm{Al}_{2} \mathrm{O}_{3}$ & $\mathrm{SR}$ & 400 & 300 & $\mathrm{C}_{2} \mathrm{H}_{5} \mathrm{OH}$ & 9.35 & - & - & - & 100 & 95 & $\sim 100$ & [71] \\
\hline $\mathrm{PdAg}(50 \mu \mathrm{m}) / \mathrm{PSS}$ & - & PB & Co hydrocalcyte ${ }^{f}$ & $\mathrm{SR}$ & 600 & 1200 & $\mathrm{C}_{2} \mathrm{H}_{5} \mathrm{OH}$ & 1.5 & - & - & - & 100 & 85 & - & [72] \\
\hline $\mathrm{Pd}(20 \mu \mathrm{m}) / \mathrm{PSS}$ & ELP & PB & $\mathrm{Co} / \mathrm{Al}_{2} \mathrm{O}_{3}$ & $\mathrm{SR}$ & 400 & 1200 & $\mathrm{C}_{2} \mathrm{H}_{5} \mathrm{OH}$ & 2 & - & - & - & 94 & 舟 & 95 & {$[73]$} \\
\hline $\mathrm{Pd}(4-5 \mu \mathrm{m}) / \mathrm{Al}_{2} \mathrm{O}_{3}$ & ELP & $\mathrm{PB}$ & $\mathrm{Pt}-\mathrm{Ni} / \mathrm{CeO}_{2}-\mathrm{SiC}$ foam & $\mathrm{SR}$ & $340-480$ & $400-800$ & $\mathrm{C}_{2} \mathrm{H}_{5} \mathrm{OH}$ & 1.5 & - & - & - & 100 & 70 & $>99.5$ & [74] \\
\hline $\mathrm{Pd}(8 \mu \mathrm{m}) / \mathrm{Al}_{2} \mathrm{O}_{3}$ & ELP & $\mathrm{PB}$ & $\mathrm{Ni} / \mathrm{CeO}_{2}$ & $\mathrm{SR}$ & 400 & 300 & $\mathrm{C}_{2} \mathrm{H}_{5} \mathrm{OH}^{3}$ & 6.5 & - & 5000 & - & 98 & 70 & 80 & {$[75]$} \\
\hline $\operatorname{PdAg}(60 \mu \mathrm{m})$ & Cold work & $\mathrm{PB}$ & Pt-based $/ \mathrm{Al}_{2} \mathrm{O}_{3}$ & ATR & 450 & 200 & $\mathrm{C}_{2} \mathrm{H}_{5} \mathrm{OH}$ & 5 & 0.5 & - & - & - & $4.01 \mathrm{~d}$ & - & {$[76]$} \\
\hline & ELP & $\mathrm{PB}$ & $\mathrm{Na}-\mathrm{Co} / \mathrm{ZnO}$ & SR & 350 & 100 & $\mathrm{C}_{2} \mathrm{H}_{5} \mathrm{OH}$ & 1.5 & - & 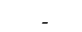 & 50 & 62 & & 99.8 & [77] \\
\hline $\mathrm{Pd}(1.3 \mu \mathrm{m}) / \mathrm{Al}_{2} \mathrm{O}_{3}(\mathrm{HF})$ & ELP & $\mathrm{PB}$ & $\mathrm{Na}-\mathrm{Co} / \mathrm{ZnO}$ & $\mathrm{SR}$ & 360 & 100 & $\mathrm{C}_{2} \mathrm{H}_{5} \mathrm{OH}$ & 6.5 & - & 9800 & 53 & 74 & - & & {$[78]$} \\
\hline $\mathrm{PdCu}(2 \mu \mathrm{m}) / \mathrm{Al}_{2} \mathrm{O}_{3}(\mathrm{HF})$ & ELP & $\mathrm{PB}$ & $\mathrm{Na}-\mathrm{Co} / \mathrm{ZnO}$ & $\mathrm{SR}$ & 360 & 100 & $\mathrm{C}_{2} \mathrm{H}_{5} \mathrm{OH}$ & 6.5 & - & 9800 & 53 & 58 & & & [78] \\
\hline PdAg/YSZ (HF) & ELP & $\mathrm{PB}$ & $\mathrm{NiO} / \mathrm{MgO}_{-} \mathrm{CeO}_{2}$ & $\mathrm{SR}$ & 350 & 100 & $\mathrm{C}_{2} \mathrm{H}_{5} \mathrm{OH}$ & 2.5 & - & & - & & 71 & $\sim 100$ & [79] \\
\hline $\operatorname{PgAg}(30 \mu \mathrm{m}) /$ Inconel & - & $\mathrm{PB}$ & $\mathrm{Pd}-\mathrm{Rh} / \mathrm{CeO}_{2}{ }^{2}$ & $\mathrm{SR}$ & 650 & 1100 & $\mathrm{C}_{2} \mathrm{H}_{5} \mathrm{OH}$ & 3 & - & - & - & 100 & 54 & & [80] \\
\hline $\mathrm{PdAg}(30 \mu \mathrm{m}) / \mathrm{PSS}$ & - & PB & $\mathrm{Pd}-\mathrm{Rh} / \mathrm{CeO}_{2} \mathrm{f}$ & $\mathrm{SR}$ & 600 & 1200 & $\mathrm{C}_{2} \mathrm{H}_{5} \mathrm{OH}$ & 1.6 & - & $60-140$ & - & 100 & 90 & - & [81] \\
\hline
\end{tabular}

a SR. Steam reforming. ATR: Autothermal reforming. b NM: Noble metals. ${ }^{c}$ Catalysts inside pores of hollow fibres; $\mathrm{d}$ Hydrogen yield (produced $\mathrm{H}_{2}$ mol per ethanol mol fed),

e Volume ratio; ${ }^{\mathrm{f}}$ Over cordierite; ${ }^{\mathrm{g}}$ Calculated purities knowing the amount of impurities. ${ }^{\mathrm{h}}$ WHSV: weight hourly space velocity: methane feed flow in $\mathrm{kg} / \mathrm{h}$. relative to catalyst load in $\mathrm{kg} / \mathrm{h}$. 
Methane reforming in a packed bed membrane reactor was also performed by Silva et al. [56] using a $76.2 \mu \mathrm{m}$ thick $\mathrm{Pd}-\mathrm{Ag}$ membrane and a $\mathrm{CH}_{4} / \mathrm{CO}_{2}$ ratio of 2.85 at $600{ }^{\circ} \mathrm{C}$ resulting in $35 \%$ methane conversion, while $47 \%$ of the produced hydrogen was recovered. Larger methane conversions were obtained by Gil et al. [53] using a catalytic hollow fibre membrane reactor were $\mathrm{Ni}(25 \mathrm{wt}$. \%)/SBA-15 catalyst was coated on the inside of an $\mathrm{Al}_{2} \mathrm{O}_{3}$ hollow fibre. A methane conversion of $53 \%$ was reached at $560{ }^{\circ} \mathrm{C}$ and $43 \%$ of the produced hydrogen was recovered through a $3.3 \mu \mathrm{m}$ thick Pd layer deposited on top of the hollow fibre.

Pd membranes deposited by electroless plating $(10.2 \mu \mathrm{m})$ on top of an oxidized porous stainless steel substrate produced by Sanz et al. [54] were evaluated in a WGS membrane reactor. Two configurations were tested employing commercial catalysts consisting of a $\mathrm{Fe}-\mathrm{Cr}$ oxide: a conventional packed bed reactor and a membrane reactor. The membrane was tested in the presence of a methane reformate mixture consisting of $70 \% \mathrm{H}_{2}, 18 \% \mathrm{CO}$ and $12 \% \mathrm{CO}_{2}$. The presence of $\mathrm{CO}$ and $\mathrm{CO}_{2}$ decreased the permeated hydrogen flux due to carbon deposition and $\mathrm{CO}$ adsorption on the membrane surface $[82,83]$. The measured $\mathrm{CO}$ conversions for the membrane reactor at a transmembrane pressure difference of 3 bar were much higher than the obtained conversions in the packed-bed reactor in the temperature range of $350-400{ }^{\circ} \mathrm{C}$, even though the recovered hydrogen through the membrane was less than $15 \%$ in the investigated temperature range and pressure difference of 2-3 bar. Goldbach et al. [84] tested, for 150 days, under WGS reformate mixture $\left(53.9 \% \mathrm{H}_{2}, 28.1 \%\right.$ $\mathrm{H}_{2} \mathrm{O}, 16.3 \% \mathrm{CO}_{2}, 1.1 \% \mathrm{CO}$ and $\left.0.4 \% \mathrm{CH}_{4}\right)$ a $2-4 \mu \mathrm{m}$ thick Pd-membrane at $400{ }^{\circ} \mathrm{C}$ and transmembrane pressure difference of $1800-2000 \mathrm{kPa}$. The hydrogen recovery factor was $98.5 \%$ with a purity of $99.5 \%$. During the experiment the permeability of the membrane was reduced due to coke formation on the surface. In 2015, Brunetti et al. [85] tested for $2100 \mathrm{~h}$ a PdAg membrane ( $3.6 \mu \mathrm{m}$ thick) supported onto an $\alpha-\mathrm{Al}_{2} \mathrm{O}_{3}$ support in a packed bed reactor for WGS. Commercial catalytic pellets based on Fe-Cr were employed at $350-400{ }^{\circ} \mathrm{C}$. The largest $\mathrm{CO}$ conversion $(96.5 \%)$ was achieved at $400{ }^{\circ} \mathrm{C}, 4$ bar transmembrane pressure difference, a $\mathrm{H}_{2} \mathrm{O} / \mathrm{CO}$ ratio of 3.8 and a gas hourly space velocity $2500 \mathrm{~h}^{-1}$ (GHSV). The recovered hydrogen under this condition was around $83 \%$.

A fluidized bed membrane module with a capacity of $1 \mathrm{Nm}^{3} / \mathrm{h}$ of ultra-pure hydrogen production via high temperature WGS was recently demonstrated by Helmi et al. [86]. The performance of the module was tested under different gas mixtures and WGS conditions during $900 \mathrm{~h}$, showing a very stable performance. As shown in Figure 2, the membrane was first activated and the permeation properties were tested. Then a $\mathrm{Pt}-\mathrm{Al}_{2} \mathrm{O}_{3}$ catalyst was integrated in the reactor and a WGS mixture was fed ( 10 vol. $\% \mathrm{CO}, 30$ vol. $\% \mathrm{H}_{2} \mathrm{O}$ and 60 vol. $\left.\% \mathrm{~N}_{2}\right)$. During a long-term test at $400{ }^{\circ} \mathrm{C}$ and 1 bar of transmembrane pressure difference, perm-selectivities up to 21,000 were measured with a $\mathrm{CO}$ concentration at the permeate side below $10 \mathrm{ppm}$. The hydrogen permeance through the $\mathrm{Pd}_{85} \mathrm{Ag}_{15}$ membranes ( $4 \mu \mathrm{m}$ thick) was $3.89 \times 10^{-6} \mathrm{~mol} \cdot \mathrm{m}^{-2} \cdot \mathrm{s}^{-1} \cdot \mathrm{Pa}^{-1}$ under the conditions mentioned above, while $95 \%$ of the CO was converted. As can be seen in Figure 2, as a consequence of an unexpected oven failure, the $\mathrm{N}_{2}$ leakage started increasing due to a high thermal shock and from that moment until the end of the long-term test, the $\mathrm{H}_{2} / \mathrm{N}_{2}$ perm-selectivity decreased. However, the selectivity was still above 12,000 which means that purity of the recovered hydrogen was high enough to feed directly to a fuel cell.

Faroldi et al. [55] compared a commercial Pd-Ag supported membrane with an in-house composite membrane with a $20 \mu \mathrm{m}$ thick Pd layer prepared by electroless plating onto a modified PSS with $\mathrm{NaO}$ zeolite in a fixed-bed MR under different gas mixtures: dry (DRM) and combined reforming of methane (CRM) using Ru as catalyst supported onto $\mathrm{La}_{2} \mathrm{O}_{2} \mathrm{CO}_{3}$. The best results were obtained for the commercial membrane where the recovered hydrogen at $450{ }^{\circ} \mathrm{C}$ was around $80 \%$ with a purity of the produced $\mathrm{H}_{2}$ of $99.5 \%$. Methane reforming was also studied in fluidized bed membrane reactors using Pd based membranes by Chen et al. [58], who reported methane conversions under ATR conditions in the range $26 \%-41 \%$ in a pressure range of $2600 \mathrm{kPa}$ and reaction temperature between 500 and $600{ }^{\circ} \mathrm{C}$, with a hydrogen yield $\left(\mathrm{mol} \mathrm{H}_{2} / \mathrm{mol} \mathrm{CH}_{4}\right)$ ranging from 0.3 to 0.7 . In the work reported by Mahecha-Botero and co-workers [59] $25 \mu \mathrm{m}$ thick Pd-Ag foils (manufactured by Membrane Reactor 
Technologies, Ltd., Vancouver, BC V6C 1S4, Canada) were sealed onto porous metallic substrates modified with a thin ceramic barrier and tested in a FBMR using $\mathrm{NiO}$ and noble metal catalysts supported on alumina for SMR and ATR experiments. Larger methane conversions were obtained under ATR conditions with an $\mathrm{O}_{2} / \mathrm{CH}_{4}$ ratio of 0.35 at $550{ }^{\circ} \mathrm{C}$ and a reactor pressure of $900 \mathrm{kPa}$, having a maximum conversion of $80.9 \%$ while the permeated hydrogen purity was $99.988 \%$. In case of operation under SMR conditions at the same temperature and pressure as the ATR experiments, the obtained methane conversion was $73.1 \%$ with a recovered hydrogen purity of $99.94 \%$.

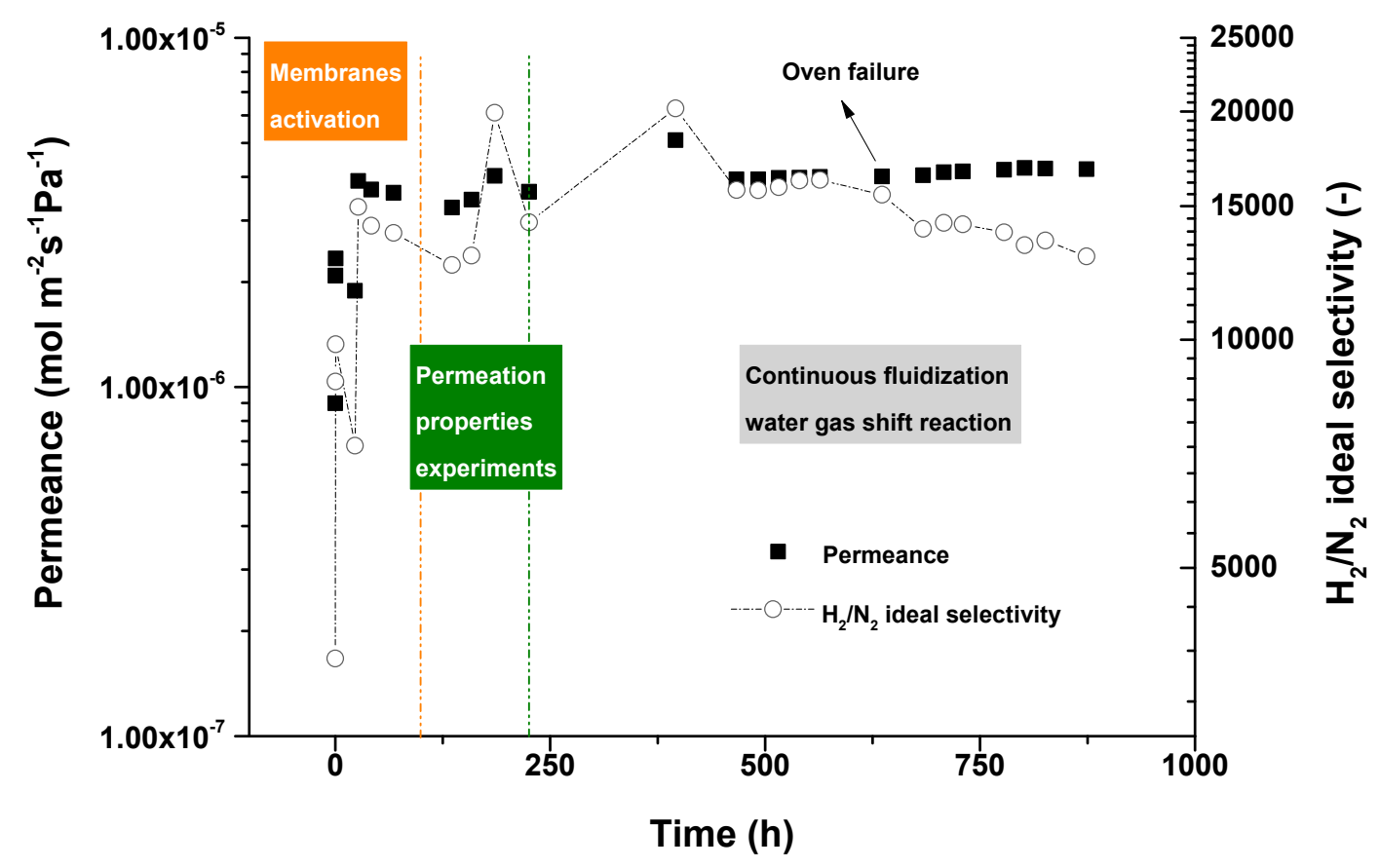

Figure 2. Long-term performance of a fluidized-bed membrane module during $900 \mathrm{~h}$ of continuous operation at high-temperature WGS conditions. Reprinted from [86] with permission from MDPI.

Medrano et al. demonstrated that the absence of interactions between a Pd-Ag membrane and $\mathrm{Ni} / \mathrm{CaAl}_{2} \mathrm{O}_{4}$ catalysts after several reactive tests under SMR and ATR conditions in a fluidized bed membrane reactor [62]. The authors reported methane conversions above $70 \%$ and $80 \%$ under steam and autothermal reforming conditions at $600{ }^{\circ} \mathrm{C}, 3$ bar pressure difference and a $\mathrm{S} / \mathrm{C}$ ratio of 3 . Up to $27 \%$ and $34 \%$ of hydrogen was recovered for steam and autothermal reforming under the conditions used by the authors. The purity of the recovered hydrogen was over $97 \%$, while the ideal perm-selectivity decreased from 574 (before the reactive tests) to 132 (after the SR and ATR experiments). This decrease was attributed to an increase in nitrogen leakages, since the membrane was tested and found stable during $800 \mathrm{~h}$ in the temperature range of $500-600{ }^{\circ} \mathrm{C}$ before the reactive tests.

Fernandez et al. [63] did not find chemical interactions between the $\mathrm{Ru} / \mathrm{Ce}_{0.75} \mathrm{Zr}_{0.25} \mathrm{O}_{2}$ catalysts and the Pd-Ag $(4 \mu \mathrm{m})$ membrane during tests in a fluidized bed MR at 550-600 ${ }^{\circ} \mathrm{C}$. However, pinholes were observed at the membrane surface after 7 days of testing at $600{ }^{\circ} \mathrm{C}$. During experiments carried out under steam methane reforming conditions ( $\mathrm{S} / \mathrm{C}=3$ and 1.3 bar) the authors reported $76.4 \%$ and $89.35 \%$ of $\mathrm{CH}_{4}$ conversion at $500{ }^{\circ} \mathrm{C}$ and $600{ }^{\circ} \mathrm{C}$, respectively. The purity of recovered hydrogen $\left(20 \%\right.$ at $550{ }^{\circ} \mathrm{C}$ and $23 \%$ at $\left.600{ }^{\circ} \mathrm{C}\right)$ was $\sim 99.98$. Small amounts of $\mathrm{CO}$ in the permeate stream (120 ppm and $200 \mathrm{ppm}$ ) were observed. On the other hand, a larger CO concentration (500 ppm) was measured under autothermal conditions at $600{ }^{\circ} \mathrm{C}$, while a higher methane conversion and hydrogen recovery was obtained, $96.7 \%$ and $35 \%$, respectively.

The stability of a $5 \mu \mathrm{m}$ thick Pd-Ru membrane $(0.3 \mathrm{wt} . \%)$ was investigated at $580{ }^{\circ} \mathrm{C}$ in a membrane reactor for methane steam reforming for $1000 \mathrm{~h}$ by Abu El Hawa and coworkers [60]. 
The membrane was tested at $2900 \mathrm{kPa}$ with a steam-to-carbon ratio of 3 using a Ni-based catalyst. During the experiment the recovered hydrogen remained almost equal $(>85 \%)$ with a methane conversion of $80 \%$. The purity of the recovered hydrogen decreased slightly during the test. Nevertheless, it remained above 93\%. Concerning the impurities at the permeate side, the level of $\mathrm{CO}_{2}$ increased from $\sim 2.3 \mathrm{~mol} \%$ to $\sim 5 \mathrm{~mol} \%$. The methane level also increased after $900 \mathrm{~h}$ from $\sim 1 \mathrm{~mol} \%$ to $\sim 2 \mathrm{~mol} \%$. On the other hand, CO levels decreased from $\sim 1.7 \mathrm{~mol} \%$ to almost 0 .

Roses et al. [61] performed steam reforming over a catalytic partial oxidation (CPO) catalyst during $260 \mathrm{~h}$ in a FBMR at temperatures around $550-630{ }^{\circ} \mathrm{C}$ and reactor pressure of $3.5-4.4 \mathrm{bar}$. Double layered PdAg membranes (from REB) used for hydrogen extraction were deposited by ELP onto a porous metal substrate reinforced with Inconel. The authors studied the effect of the WHSV, pressure and temperature on the methane conversion. The conversion reached in the different experiments at higher temperatures was between $65 \%$ and $85 \%$, except for the experiment performed at $550{ }^{\circ} \mathrm{C}$, where a lower methane conversion was achieved $(<50 \%)$. A higher temperature results in a larger hydrogen flux through the membrane, while a higher WHSV results in a lower conversion due to the reduced gas residence time and increased bubble-to-emulsion mass transfer limitations. The GC (resolution >10 ppm) analysis did not show any presence of CO in the permeated hydrogen, which could therefore be directly used as feed to a PEM fuel cell.

\subsubsection{Methanol as Feedstock}

Methanol is an interesting feedstock for hydrogen production, especially as it can be considered as a hydrogen storage medium. Iulianelli et al. [87] recently reported a review on methanol steam reforming performed in different MRs. After this review was published, few more experimental studies were reported. In particular, Liguori et al. [64] reported the use of a supported Pd $(\sim 7 \mu \mathrm{m})$ membrane layer onto a porous $\mathrm{Al}_{2} \mathrm{O}_{3}$ support prepared at Nanjing University of Technology by electroless plating for methanol reforming in a PBMR at $280-330{ }^{\circ} \mathrm{C}$ at low pressures $(150-250 \mathrm{kPa})$. The authors used commercial $\mathrm{Cu}-\mathrm{Zn}$ catalysts supported on $\mathrm{Al}_{2} \mathrm{O}_{3}$ with a steam-to-methanol molar ratio of 2.5. The methanol conversion at $330{ }^{\circ} \mathrm{C}$ increased from $75 \%$ to $85 \%$ when the operating pressure was increased from $150 \mathrm{kPa}$ to $250 \mathrm{kPa}$. At these conditions, the measured hydrogen yield ranged between $57 \%$ and $82 \%$. The permeated hydrogen had a low content of CO (10 ppm), where the hydrogen recovery at $330{ }^{\circ} \mathrm{C}$ was improved from around $25 \%$ at $150 \mathrm{kPa}$ up to $40 \%$ at $250 \mathrm{kPa}$. The same catalyst was employed by Ghasemzadeh et al. [22] in a PBMR using commercial tubular membranes produced by ENEA ( $50 \mu \mathrm{m}$ thick $\left.\mathrm{Pd}_{77} \mathrm{Ag}_{23}\right)$ for recovering hydrogen produced at $280{ }^{\circ} \mathrm{C}$ and 2.5 bar with a steam-to-methanol ratio of 3. A total methanol conversion was achieved with $46 \%$ of produced hydrogen recovered without presence of any impurities. Mateos-Pedredo et al. [65] reported high methanol conversion using in-house $\mathrm{CuO} / \mathrm{ZnO}$ (Ac 375) catalysts in a PBMR and a $7 \mu \mathrm{m}$ thick Pd membrane (Nanjing University of Technology). At $300{ }^{\circ} \mathrm{C} 97 \%$ of the methanol was converted at a transmembrane pressure of 1.5 bar, steam-to-methanol ratio of 2.5 and a WHSV of $2.73 \mathrm{~h}^{-1}$. The authors reported an increase in the hydrogen recovery at $330{ }^{\circ} \mathrm{C}$ from $63 \%$ to $72 \%$ when the space velocity decreased from $2.73 \mathrm{~h}^{-1}$ to $1.37 \mathrm{~h}^{-1}$. The purity of the recovered hydrogen was around $91 \%$ and did not vary with the WHSV.

García-García and coworkers [66] analyzed the performance of two types of $\mathrm{Al}_{2} \mathrm{O}_{3}$ hollow fibres (HF), viz. a catalytic HF micro-reactor (CHFMR) where a $\mathrm{Cu} / \mathrm{Zn} / \mathrm{GaO}_{\mathrm{x}}$ catalyst was located in the finger-like regions and a hollow-fibre membrane reactor (HFMR). The hollow fibres for the MR were coated with PdAg by a sequential electroless plating technique growing a $5 \mu \mathrm{m}$ thick layer followed by annealing in hydrogen at $400{ }^{\circ} \mathrm{C}$ for $24 \mathrm{~h}$. In case of the HFMR, a catalyst was deposited on top of the PdAg layer using a co-precipitation method. A schematic representation of the membrane configurations are presented in Figure 3. The methanol conversion of both membrane configurations were compared the conversion in a fluidized bed reactor (FBR) at temperatures between $150{ }^{\circ} \mathrm{C}$ and $450{ }^{\circ} \mathrm{C}$ and atmospheric pressure. In case of the CHFMR, a low methanol conversion was achieved at $300{ }^{\circ} \mathrm{C}$, around $22.9 \%$, yet much higher than with the FBR, that converted only $4.1 \%$ of the methanol 
fed, producing a four times larger amount of $\mathrm{CO}$ in comparison with the CHFMR. Total methanol conversion was obtained at $321^{\circ} \mathrm{C}$ and $378^{\circ} \mathrm{C}$ in a HFMR and FBR respectively. Those results are related to the presence of the $\mathrm{PdAg}$ layer shifting the reaction towards the products as hydrogen was extracted. The permeated hydrogen through the PdAg HF at $400{ }^{\circ} \mathrm{C}$ was around $50 \%$ of the hydrogen produced during the reaction.
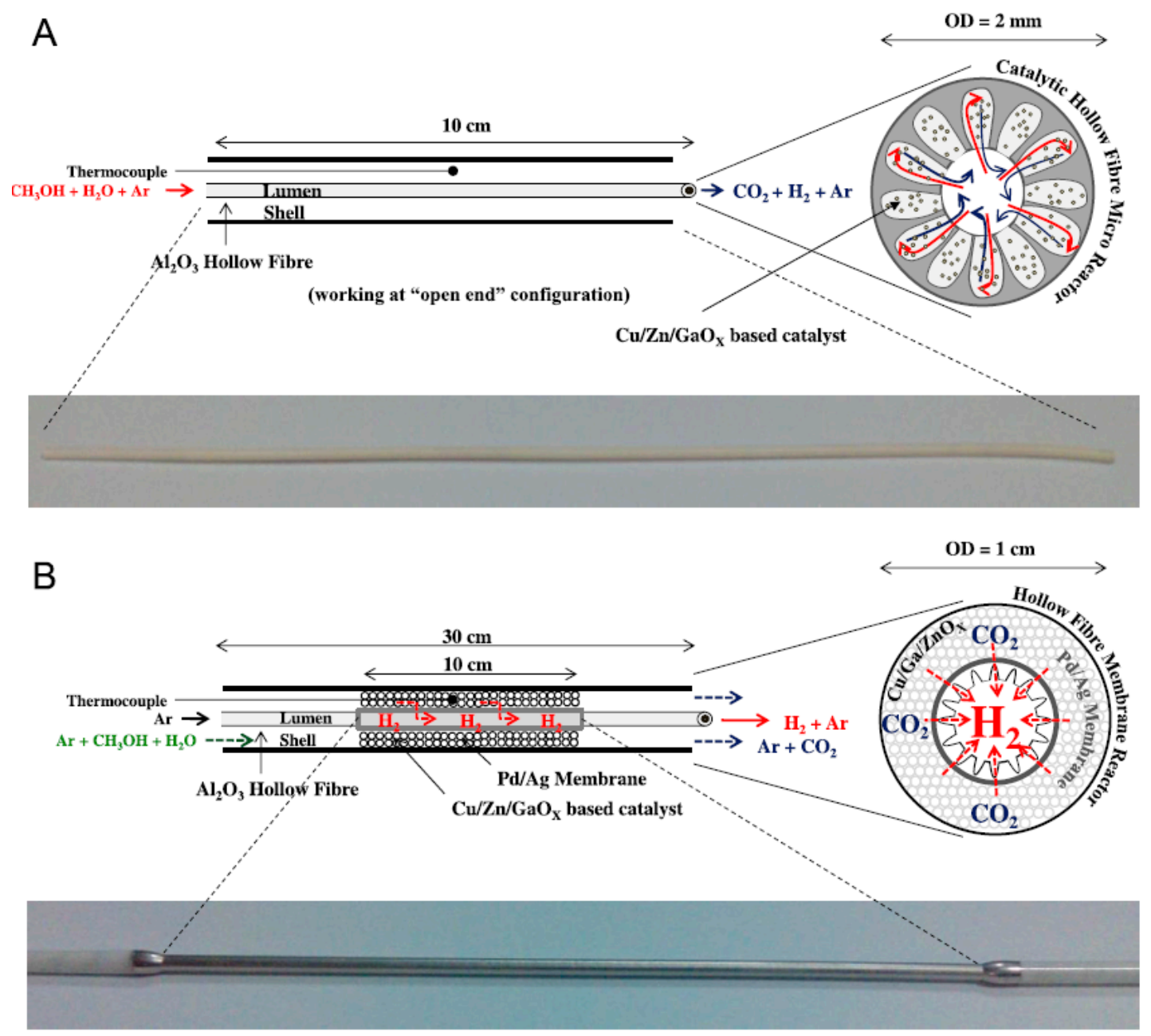

Figure 3. Representation of the catalytic CHFMR (A) and HFMR (B). Reprinted from [66] with permission from Elsevier.

Islam et al. [67] performed their experiments in a fixed bed membrane reactor with a Ni-Zn/ $\mathrm{Al}_{2} \mathrm{O}_{3}$ catalyst. The methanol conversion was $78 \%$ at $300{ }^{\circ} \mathrm{C}$ using a steam-to-methanol ratio of 1 , which was four times higher than at $200{ }^{\circ} \mathrm{C}$. Half of the produced hydrogen was recovered through a Pd/PSS membrane prepared by surfactant induced electroless plating (SIEP) at $300^{\circ} \mathrm{C}$. The authors observed carbon deposition on the membrane after being exposed to steam reforming of methanol during $36 \mathrm{~h}$ at different temperatures $\left(200-300{ }^{\circ} \mathrm{C}\right)$ in batch mode. In addition, the authors also observed embrittlement of the membrane related to the low temperatures employed.

All these studies suggest that methanol reforming can be successfully carried out in membrane reactors at temperatures below $400{ }^{\circ} \mathrm{C}$. At these conditions complete methanol conversion can be achieved, together with a high hydrogen recovery factor and high hydrogen purity. This makes methanol a very good fuel, or better a hydrogen storage medium, for the hydrogen membrane reactor since the produced ultrapure hydrogen can be directly used in PEM fuel cells. 


\subsubsection{Ethanol as Feedstock}

Steam reforming of ethanol requires higher temperatures than methanol due to larger enthalpy (see Table 1), but requires milder conditions than for methane reforming. The main problem associated with ethanol reforming is the production of undesired by-products, such as formaldehyde, methane, ethylene and carbon, which are formed at moderate temperatures [88]. At operating temperatures around $300-500{ }^{\circ} \mathrm{C}$, complete conversion of ethanol can be achieved, although the methane formation decreases the hydrogen production [89]. For this reason, the ethanol reforming is carried out in membrane reactors at higher temperatures than in conventional reactors in order to reduce the methane formation.

Catalysts investigated for ethanol steam reforming are based on groups 8-11 metals. The activity of many metals supported onto alumina were evaluated by Auprêtre et al. [90] at $700{ }^{\circ} \mathrm{C}$ resulting in large conversions in many cases. The best results were obtained with $1 \%$ of rhodium, where the hydrogen yield was $72 \%$ without the formation of methane. Similar values were obtained with supported nickel catalysts. However, the required amount of this metal is at least 10 times larger. On the other hand, the selection of the support is also important to avoid coke formation and prevent undesired deactivation of catalysts, such as for nickel [91]. Usually, gamma-alumina is used as support, but the high acidity catalyses coke formation. Addition of metals from group 3 (yttrium, lanthanum and scandium) increases the basicity of the supports thereby decreasing coke formation [92], where the highest hydrogen yields were obtained with $\mathrm{Rh}$ and $\mathrm{RhNi}$ supported onto $\mathrm{Y}_{2} \mathrm{O}_{3}-\mathrm{Al}_{2} \mathrm{O}_{3}$ without deactivation after $8 \mathrm{~h}$ at $675{ }^{\circ} \mathrm{C}$ realizing ethanol conversions of $97.2 \%$ and $98.2 \%$, respectively. Rh-based catalysts with a high resistance to carbon deposition and a high activity (giving full conversion of ethanol) were reported by da Silva et al. [68]. $\mathrm{Rh} / \mathrm{CeO}_{2}$ showed a high stability even under low steam-to-ethanol ratios attributed to the oxygen storage capacity of ceria. The authors also reported results with a $\mathrm{Rh} / \mathrm{La}_{2} \mathrm{O}_{3}-\mathrm{SiO}_{2}$ catalyst, which exhibited also good resistance against carbon deposition [68], related to the capacity of $\mathrm{LaO}_{x}$ species to generate lanthanum oxycarbonates $\left(\mathrm{La}_{2} \mathrm{O}_{2} \mathrm{CO}_{3}\right)$ [93]. The authors selected $\mathrm{Rh} / \mathrm{CeO}_{2}$ due to the larger ratio of the permeated hydrogen over the ethanol fed [68]. The recovered hydrogen at $550{ }^{\circ} \mathrm{C}$ and a steam-to-ethanol molar ratio of 10 was improved from $15 \%$ to $70 \%$ when the sweep gas flow rate was increased from $15 \mathrm{~mL} \cdot \mathrm{min}^{-1}$ to $130 \mathrm{~mL} \cdot \mathrm{min}^{-1}$.

Nevertheless, cheaper options are required while maintaining a high catalytic activity, such as Co-based catalysts, as suggested by Haga and coworkers [94] who used cobalt supported onto alumina resulting in a high selectivity for ethanol steam reforming.

Dominguez et al. [69] prepared a cobalt talc onto cordierite for ethanol reforming in a PBMR, which was operated at lower temperatures $\left(325-400^{\circ} \mathrm{C}\right)$ favouring the WGS reaction. Total conversion of ethanol was achieved in the temperature range of $350-400{ }^{\circ} \mathrm{C}$ and 8 bar pressure using a S/C molar ratio of 3 (steam/ethanol $=6$ ). The hydrogen was recovered through a $30 \mu \mathrm{m}$ thick PdAg membrane, and the hydrogen recovery was $30 \%$ at $350{ }^{\circ} \mathrm{C}$ and 7 bar operating pressure and increased to $80 \%$ when the pressure was increased to 14 bars.

Iulianelli et al. [70] also reported the use of a $\mathrm{Co}-\mathrm{Al}_{2} \mathrm{O}_{3}$ catalyst for ethanol steam reforming in a PBMR, where the hydrogen was extracted via PdAg $(50 \mu \mathrm{m})$ membranes supported onto a tubular stainless steel module. A 94.2\%-94.5\% ethanol conversion was obtained at $400{ }^{\circ} \mathrm{C}$ in a MR with a retentate pressure of $1.5 \mathrm{bar}$ and a sweep factor of 5.5 (where the sweep factor was defined as the molar ratio between sweep gas $\left(\mathrm{N}_{2}\right)$ and the feed ethanol), whereas in a conventional reactor operated at the same operating conditions a $10 \%$ lower of conversion was achieved. The recovered CO-free hydrogen at the permeate side was around $27 \%$ for the counter-current mode with a hydrogen yield around $17 \%-19 \%$. In a second study [71], the ethanol conversion was improved to $100 \%$ by using a higher sweep factor of 25.2 (in counter-current mode) and a higher pressure ( 3 bar). Most of the produced hydrogen was recovered (95\%) and the hydrogen yield was increased up to $\sim 60 \%$.

Espinal et al. [72] showed full conversion of ethanol in a PBMR using cobalt hydrocalcite catalysts doped with potassium supported on cordierite. The authors investigated the influence of operating 
conditions, such as the temperature, steam-to-ethanol ratio and pressure. The hydrogen was recovered through a $50 \mu \mathrm{m}$ thick PdAg membrane supported onto a porous stainless steel tube. It was observed that the recovered hydrogen increased from $65 \%$ to $82 \%$, when the temperature was increased from $500{ }^{\circ} \mathrm{C}$ to $600{ }^{\circ} \mathrm{C}$ at the same pressure (12 bar) and S/C ratio (3).

In bio-ethanol some traces of glycerol and acetic acid could be present, when it is produced by fermentation. Seelam et al. [73] fed directly a mixture of those compounds with water, in a water/ethanol volume ratio of 4 , to a $\mathrm{PBMR}$ using $\mathrm{Co} / \mathrm{Al}_{2} \mathrm{O}_{3}$ and $\mathrm{Ni} / \mathrm{ZrO}_{2}$ as catalysts. The best results were obtained when using $\mathrm{Co} / \mathrm{Al}_{2} \mathrm{O}_{3}$ catalysts at $400{ }^{\circ} \mathrm{C}$ and 12 bar, where $94 \%$ of the ethanol was converted and $40 \%$ of the produced hydrogen was recovered through a Pd $(20 \mu \mathrm{m}) / \mathrm{PSS}$ membrane with $5 \%$ of impurities in the permeate side. Those results were obtained under a gas-hour-space-velocity (GHSV) of $800 \mathrm{~h}^{-1}$. On the other hand, the $\mathrm{Ni} / \mathrm{ZrO}_{2}$ catalysts showed a higher activity for bio-ethanol conversion at lower pressures (8-10 bar), but the recovered hydrogen was lower than with $\mathrm{Co} / \mathrm{Al}_{2} \mathrm{O}_{3}$.

The production of hydrogen from ethanol reforming using $\mathrm{Pt}-\mathrm{Ni}$ and $\mathrm{Pt}-\mathrm{Ru}$ as catalysts with a low content of the metals ( $0.3 \mathrm{wt}$. \%) supported onto nanodiamonds produced by a detonation synthesis technique (DND) in a PBMR was recently reported by Mironova et al. [40]. Defect-free $\mathrm{Pd}-\mathrm{Ru}$ foils were used as hydrogen membrane. The ethanol conversion achieved at $450{ }^{\circ} \mathrm{C}$ and an ethanol-to-steam ratio of 9 was $98 \%-99 \%$. The obtained hydrogen yield in the MR was $1.5-2$ times higher than in a conventional reactor for the same $\mathrm{C}_{2} \mathrm{H}_{5} \mathrm{OH} / \mathrm{H}_{2} \mathrm{O}$ ratio. The recovered hydrogen through the membranes was around $35 \%-60 \%$ with a presence of $0.01 \%$ of impurities. The produced amount of $\mathrm{CO}$ with the $\mathrm{Pt}-\mathrm{Ru}$ catalysts was negligible at $450{ }^{\circ} \mathrm{C}$, but with an increase in temperature some $\mathrm{CO}$ was produced. A decline in the permeated hydrogen through the membranes was observed after $50 \mathrm{~h}$ on stream (the Pt-Ru catalysts was regenerated every 3-5 h), however, the original hydrogen flux was recovered after a thermal treatment in air at $450{ }^{\circ} \mathrm{C}$.

Full conversion of ethanol was achieved by Murmura et al. [74] with $\mathrm{Ni}(10 \%)-\mathrm{Pt}(3 \%)$ over a $\mathrm{CeO}_{2}$-washcoated $\mathrm{SiC}$ open cell foam in the temperature range of $340-480{ }^{\circ} \mathrm{C}$. The authors obtained full recovery of hydrogen through a $\mathrm{Pd}$ membrane when sweep gas was added over the entire temperature range and pressure difference of 4-8 bar. A small percentage of $\mathrm{CO}_{2}(0.3 \%)$ and $\mathrm{CH}_{4}$ $(0.2 \%)$ was detected in the permeate stream. Iulianelli et al. [75] reached $98 \%$ of ethanol conversion at $400{ }^{\circ} \mathrm{C}, 3$ bar and a GHSV of $5000 \mathrm{~h}^{-1}$ in a PBMR using $\mathrm{Ni}(7.5 \%) \mathrm{CeO}_{2}$ catalysts. The recovered hydrogen $(\sim 70 \%)$ through a $8 \mu \mathrm{m}$ thick Pd membrane had a purity of $\sim 80 \%$. Autothermal reforming of ethanol, also referred to as oxidative steam reforming, is another way to produce hydrogen where a small amount of oxygen is added to the feed which allows to operate the reactor in an autothermal regime (see Table 1). Santucci et al. [95] performed the oxidative steam reforming of ethanol in a membrane reactor using Pd-Ag self-supported tubes from ENEA (with a wall thickness of $60 \mu \mathrm{m}$ ) by feeding water/ethanol/oxygen in a molar ratio of 10/1/0.5, where air was used as oxygen source. The largest hydrogen yield (moles of hydrogen permeated per mol of ethanol fed) obtained at $450{ }^{\circ} \mathrm{C}$ and a pressure of $200 \mathrm{kPa}$ was 4.1. The authors did not report the ethanol conversion, but an increase in ethanol conversion was observed when the ethanol was diluted with water.

Lim et al. [77] obtained interesting results with PdCu membranes deposited by ELP onto $\mathrm{Al}_{2} \mathrm{O}_{3}$ porous supports from Pall modified with boehmite in comparison with $\mathrm{SiO}_{2}-\mathrm{Al}_{2} \mathrm{O}_{3}$ membranes obtained by chemical vapor deposition. The authors prepared $\mathrm{Na}-\mathrm{CO} / \mathrm{ZnO}$ catalysts by co-precipitation which was reported to be stable at moderate temperatures during testing periods exceeding $260 \mathrm{~h}$. The best result obtained with $2 \mu \mathrm{m}$ thick $\mathrm{Pd}_{80} \mathrm{Cu}_{20}$ membranes resulted in an ethanol conversion of $62 \%$ at $350{ }^{\circ} \mathrm{C}$ and $1 \mathrm{~atm}$. The recovered hydrogen contained some impurities, but the obtained $\mathrm{H}_{2}$ purity was around $99.8 \%$. In a study reported later [78], the same authors compared the behaviour of membranes with a $\mathrm{Pd}(1.3 \mu \mathrm{m})$ and $\mathrm{PdCu}(2 \mu \mathrm{m})$ layer deposited onto an $\alpha-\mathrm{Al}_{2} \mathrm{O}_{3}$ hollow fibre by ELP in a PBMR using the same catalyst. Keeping the steam-to-ethanol molar ratio fixed at 13 , the authors observed an ethanol conversion of $\sim 74 \%$ and $\sim 58 \%$ for the $\mathrm{Pd}$ and $\mathrm{PdCu}$ membranes, respectively, at $360{ }^{\circ} \mathrm{C}$ and $1 \mathrm{~atm}$ of pressure. Interestingly, the permeated hydrogen flux 
decreased during the experiments for both membranes, which was attributed to water adsorption on the membrane surface. After $45 \mathrm{~h} 20 \%$ and $60 \%$ of the original values (fresh membranes) where measured for the $\mathrm{Pd}$ and $\mathrm{PdCu}$ membranes, respectively. Additionally, after reactive experiments were carried out, surface damage was observed for both membranes, where larger pinholes appeared on the Pd layer when compared with the PdCu layer. Presence of carbon compounds around the metal was also detected. This study suggested therefore that steam can be interacting with the membrane by adsorption reducing the permeance and concluded that stabilization of the Pd layer (by alloying with other metals) is also required at these moderate temperatures.

Rahman et al. [79] used an YSZ hollow fibre for deposition of a PdAg layer on the shell side by ELP and integrated this into a membrane micro-reactor for ethanol reforming, where a $10 \mathrm{wt}$. \% $\mathrm{NiO} / \mathrm{MgO}-\mathrm{CeO}_{2}$ catalyst was impregnated in the finger like side. The hydrogen yield obtained under atmospheric pressure and $510{ }^{\circ} \mathrm{C}$ was $53 \%$. The recovered pure hydrogen in the shell side decreased from $71 \%$ to $55 \%$ when the temperature was increased from $350{ }^{\circ} \mathrm{C}$ to $550{ }^{\circ} \mathrm{C}$. This result indicated that the membrane area per volume of catalyst was limiting at higher temperatures suggesting that lower amount of catalyst could be used in this micro-reactor.

Noble metals such as $\mathrm{Pd}$ and $\mathrm{Rh}$ over $\mathrm{CeO}_{2}$ have shown a high activity for steam reforming of ethanol. López et al. [80] prepared this catalysts with a small amount of these noble metals $(0.5 \mathrm{wt}$. \%) for ethanol reforming at temperatures around $550-650{ }^{\circ} \mathrm{C}$. Total conversion of the feedstock was obtained at $650^{\circ} \mathrm{C}$ with a steam-to-ethanol ratio of 3 and a reactor pressure of 11 bar. The recovered hydrogen through a PdAg $(30 \mu \mathrm{m}) /$ Inconel membrane under these conditions was $54 \%$. The same catalysts were used by Hedayati et al. [81] in a catalytic membrane reactor. Full conversion of ethanol was obtained at $600{ }^{\circ} \mathrm{C}$. For steam-to-carbon ratio of 1.6, the recovered hydrogen raised from $\sim 17 \%$ to $\sim 90 \%$ when the pressure was increased from 4 to 12 bar. For the same pressure (12 bar) but higher S/C ratio (3), the recovered hydrogen was $\sim 78 \%$.

All these studies have demonstrated that the application of membrane reactors for ethanol reforming have a very positive influence on the reduction of by-products (especially methane) at lower temperatures. In fact, recovery of the hydrogen through the membrane inhibits the formation of methane and therefore higher yields of hydrogen can be achieved at lower temperatures resulting in higher energy efficiencies.

\section{2. $\mathrm{H}_{2}$ Separation and $\mathrm{CO}_{2}$ Capture}

While hydrogen can be considered as a clean energy carrier as its conversion to power produces water as the only by-product, the production of hydrogen itself from fossil fuels results in a large amount of greenhouse gases emissions.

Capture of the emitted greenhouse gases (in particular $\mathrm{CO}_{2}$ ) during hydrogen production and separation is thus an important step to be considered in the life cycle analysis of the hydrogen. Different research groups reported on the possible integration of $\mathrm{CO}_{2}$ capture with the hydrogen production using membrane reactors.

A high degree of process integration is achieved when packed adsorbent-catalyst bed is integrated into a reactor where hydrogen selective membranes are used for hydrogen separation in the so called sorption enhanced membrane reactor (SEMR), as reported by Garcia-Garcia and co-workers [96]. WGS reaction was performed feeding synthetic gas $(86.3 \mathrm{~mol} \% \mathrm{Ar}, 7.8 \mathrm{~mol} \% \mathrm{CO}$ and $5.8 \mathrm{~mol} \%$ steam) in the presence of a $10 \% \mathrm{CuO} / \mathrm{CeO}_{2}$ catalyst, obtaining a $\mathrm{CO}$ conversion close to $90 \%$ at $475{ }^{\circ} \mathrm{C}$. However, the amount of carbon formed at this temperature was quite large $(\sim 17 \%)$. The recovered hydrogen through a Pd-Ag (ELP) hollow fibre membrane was close to $60 \%$, while simultaneous capture of $\mathrm{CO}_{2}(44 \%)$ was attained using a hydrotalcite-derived $\mathrm{Mg}-\mathrm{Al}$ mixed oxides.

Soria et al. [97] reported a hybrid sorption-enhanced membrane reactor (HSEMR) for low temperature WGS. A catalyst $\left(\mathrm{Cu} / \mathrm{ZnO}-\mathrm{Al}_{2} \mathrm{O}_{3}\right)$ and $\mathrm{CO}_{2}$ sorbent $\left(\mathrm{K}_{2} \mathrm{CO}_{3}\right.$-promoted hydrocalcite $)$ were packed inside a self-supported $25 \mu \mathrm{m}$ thick $\mathrm{Pd}_{75} \mathrm{Ag}_{25}$ membrane. Complete $\mathrm{CO}$ conversion was 
achieved at $300{ }^{\circ} \mathrm{C}$ and 5.5 bar. Under these conditions, $37 \%$ of the produced $\mathrm{H}_{2}$ was recovered (with a purity of $100 \%$ ), while the produced $\mathrm{CO}_{2}$ was sorbed by the hydrotalcite.

When one compares the results of the hybrid sorption enhanced membrane reactor with the corresponding single concepts, i.e., the membrane reactor concept and the sorption-enhanced concept, the main benefits are a double shift effect due to the removal of both $\mathrm{CO}_{2}$ and $\mathrm{H}_{2}$ at the same time. This results in: (i) higher conversion degrees compared with the single concepts; (ii) higher hydrogen particle pressure due to the higher conversion and removal of $\mathrm{CO}_{2}$, which results in higher hydrogen fluxes through the membranes; (iii) higher $\mathrm{CO}_{2}$ partial pressure due to the removal of hydrogen and therefore higher $\mathrm{CO}_{2}$ capture rates. However, one should also consider the main disadvantages, being: (i) the membrane should experience higher temperatures during the desorption step; (ii) both hydrogen and $\mathrm{CO}_{2}$ are now produced at lower pressures and therefore two compression units are required, while in the single concepts only one stream is produced at lower pressure.

Another interesting reactor configuration, the $\mathrm{CO}_{2} / \mathrm{H}_{2}$ Active Membrane Piston reactor with $\mathrm{CO}_{2}$ adsorption (CHAMP-SORB), with variable volume batch reactor was proposed and theoretically studied by Anderson et al. [28] for methane steam reforming, where hydrogen is recovered via Pd-Ag membranes and $\mathrm{CO}_{2}$ is adsorbed. A schematic illustration of the four step cycle reactor is shown in Figure 4. Initially, methane and steam are fed into the chamber where the reaction takes place followed by $\mathrm{H}_{2}$ permeation through the membrane and $\mathrm{CO}_{2}$ adsorption on the selected sorbent material. To keep the pressure constant during hydrogen permeation and $\mathrm{CO}_{2}$ adsorption, a piston moves upwards. The chamber is emptied when the methane reforming is complete with the possibility to recycle the remaining gases for heat recovery. This step is followed by $\mathrm{CO}_{2}$ desorption as the piston is moved down resulting on expansion while the temperature is increased to favour the desorption process. Finally, the desorbed $\mathrm{CO}_{2}$ is removed from the chamber, as the piston is up-stroking.

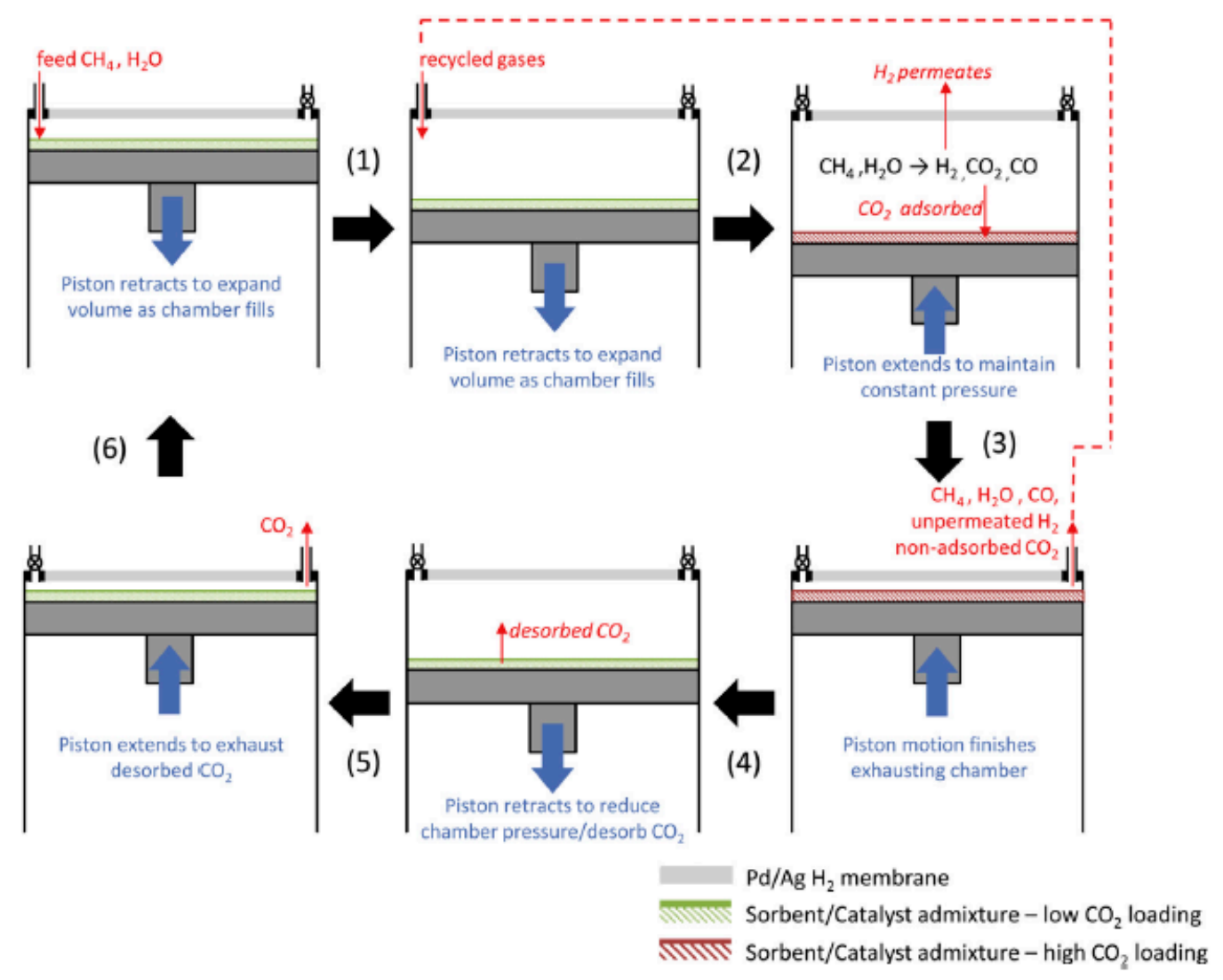

Figure 4. Schematic representation of the CHAMP-SORB reactor for methane SR. Reprinted from [28] with permission from Elsevier. 
The authors claim that this configuration presents several advantages in comparison with more conventional SEMR, since the sorbent regeneration is carried out in the same unit. However, for steady state gas production several units are required in parallel as in a traditional PSA unit. In a study reported later [98], the same authors demonstrated that the SMR process can be executed at $400{ }^{\circ} \mathrm{C}$ with a steam-to-carbon ratio of 2 using a Ni-based catalysts. For hydrogen separation and $\mathrm{CO}_{2}$ adsorption a $50 \mu \mathrm{m}$ thick PdAg layer and $\mathrm{K}_{2} \mathrm{CO}_{3}$ sorbent were used, respectively. The same research group proposed and demonstrated a novel method for portable catalytic reforming of liquid fuels by atomizing the liquid [99]. The so-called CHAMP-Direct Droplet Impingement Reactor (DDIR) was used to generate hydrogen from steam reforming of methanol using a Pd-Ag ( $25 \mu \mathrm{m}$ thick foil) membrane and a $\mathrm{Cu} / \mathrm{ZnO} / \mathrm{Al}_{2} \mathrm{O}_{3}$ catalyst.

For applications where $\mathrm{CO}_{2}$ storage is desired, steam is the most convenient purge gas due to its simple condensation from the gas mixture, as was proposed by Reijers et al. [100] using a hydrotalcite as $\mathrm{CO}_{2}$ sorbent. Nonetheless, the required amount of steam for total desorption is quite large as the required $\mathrm{H}_{2} \mathrm{O} / \mathrm{CO}_{2}$ ratio exceeds $60: 1$. A system analysis should be carried out to find the optimal operating conditions maximizing the energy efficiency of the system.

$\mathrm{Wu}$ et al. [101] reported a dual-enhanced SMR reactor, were hydrogen was removed with a $7.2 \mu \mathrm{m}$ thick membrane, while $\mathrm{CO}_{2}$ was captured using a nano-CaO-NiO/ $\mathrm{Al}_{2} \mathrm{O}_{3}$ sorbent. The $\mathrm{CO}_{2}$ sorption capacity of this complex catalyst was $1.6 \mathrm{~mol} \mathrm{CO} / \mathrm{kg}$ at $600{ }^{\circ} \mathrm{C}$ and a $\mathrm{CO}_{2}$ partial pressure of $20 \mathrm{kPa}$. The highest methane conversion $(98.1 \%)$ was obtained at $600^{\circ} \mathrm{C}$ with a steam-to-methane ratio of 4 . However, since the ideal separation factor $\left(\mathrm{H}_{2} / \mathrm{N}_{2}\right)$ of the membrane was only 9 , the purity of recovered hydrogen was $98.1 \%$ with a CO concentration below $1000 \mathrm{ppm}$.

Another novel hybrid concept for hydrogen production and $\mathrm{CO}_{2}$ capture has been proposed by Medrano et al. [102], referred to as membrane-assisted chemical looping reforming (MA-CLR). This concept is based on the combination of a fluidized bed membrane reactor with chemical looping reforming (CLR), as schematically represented in Figure 5. The energy required for methane steam reforming is supplied via a chemical looping system, where an oxygen carrier (solid supported metal particle) is oxidized in an air reactor via an exothermic reaction with air. The hot solid is fed to the fuel reactor, where it is reduced to metal and releases the heat for the steam reforming. In the fuel reactor membranes are immersed in the fluidized bed resulting in pure hydrogen production, while the exhaust of the reactor only contains $\mathrm{CO}_{2}$ and steam.

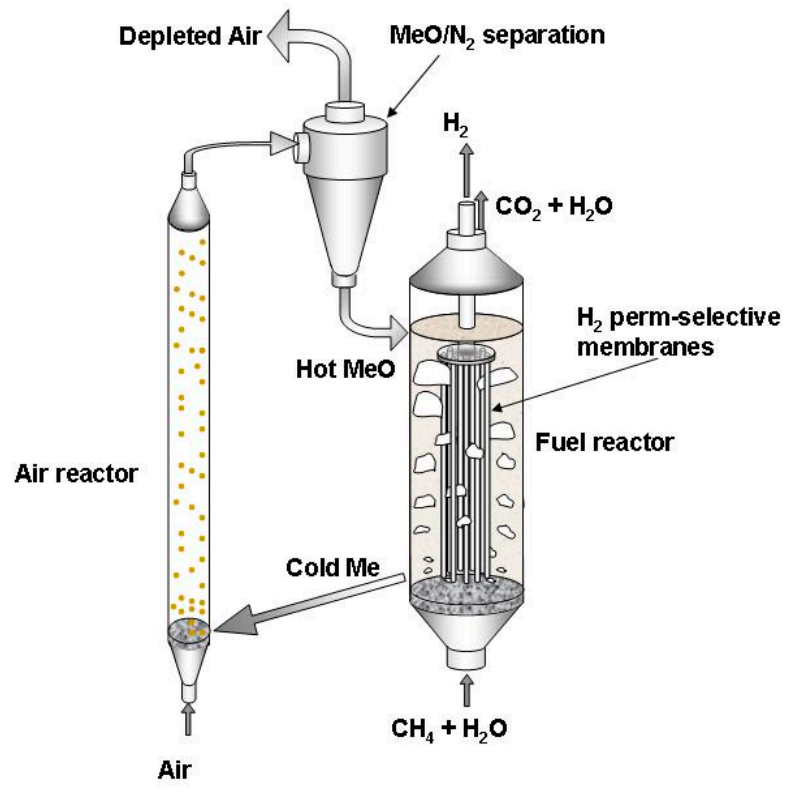

Figure 5. Schematic representation of the MA-CLR system. Reprinted from [102] with permission from Elsevier. 
When compared with the two single systems, i.e., membrane reactor and chemical looping reforming, the new concept presents several advantages: (i) very high efficiency is obtained at low temperatures; (ii) complete conversion is achieved at temperatures below $600{ }^{\circ} \mathrm{C}$; (iii) much less membrane area is required compared with the single membrane reactor; (iv) a very high $\mathrm{CO}_{2}$ capture ratio is achieved because all unrecovered $\mathrm{H}_{2}$ and unconverted $\mathrm{CO}$ are finally converted at the top of the reactor with a gas-solid reaction with the incoming oxygen carrier [102].

Mahecha-Botero et al. [45] reported $\mathrm{CO}_{2}$ capture in a pilot-scale fluidized-bed membrane- reactor using $\mathrm{CaO}$ as sorbent mixed with supported $\mathrm{Ni}$ on alumina as catalysts for reforming of methane. The pilot plant configuration used $25 \mu \mathrm{m}$ thick planar PdAg membranes and catalysts as also reported previously by the same authors [59]. Experiments were carried out at $550{ }^{\circ} \mathrm{C}$ with a reactor pressure of $300 \mathrm{kPa}$ and a steam-to-carbon molar ratio of 3 . The $\mathrm{CO}_{2}$ produced during the reforming was effectively adsorbed by $\mathrm{CaO}$ producing $\mathrm{CaCO}_{3}$. Regeneration of the sorbent was performed by calcination of $\mathrm{CaCO}_{3}$ in the regenerator unit separated from the reformer vessel operated at temperatures up to $950{ }^{\circ} \mathrm{C}$. The largest carbon capture observed during these experiments was around $87 \%$. However, the efficiency of $\mathrm{CaO}$ to adsorb $\mathrm{CO}_{2}$ decreased with time (as expected from the literature on this kind of adsorbent), since the observed levels of $\mathrm{CO}_{2}$ inside the reactor started to increase. During the experiments, the purity of the recovered hydrogen was analysed by GC, giving $99.99 \%$ purity. The authors also reported the effect of the installed membrane area on the hydrogen recovery and methane conversion producing up to $7.47 \times 10^{-4} \mathrm{~mol} \cdot \mathrm{s}^{-1}$ of hydrogen. The authors also reported that abrasion of the membrane surfaces was prevented as the calculated superficial gas velocity was smaller than in conventional reformers.

\section{Characteristics and Properties of Membranes for Hydrogen Separation}

As already reported above, the targets for $\mathrm{H}_{2}$ membranes are generally taken from the targets set by the United States Department of Energy (US DOE) and some targets set for 2015 have been summarized in Table 3. Some of these targets are within reach thanks to the yearly increasing number of research groups devoted to the further development and improvement of hydrogen selective membranes [6]. The target set for the hydrogen flux for 2015 was $1.135 \mathrm{~mol} \cdot \mathrm{m}^{-2} \cdot \mathrm{s}^{-1}$ seems quite achievable especially considering the target of $99.99 \%$ purity.

Table 3. US DOE 2015 target for hydrogen separation membranes [6].

\begin{tabular}{cc}
\hline Performance Criteria & 2015 Target \\
\hline Flux & $1.135 \mathrm{~mol} \cdot \mathrm{m}^{-2} \cdot \mathrm{s}^{-1}\left(300 \mathrm{Scfh} \cdot \mathrm{ft}^{-2}\right)$ \\
Membrane Cost & $<5400 \$ \cdot \mathrm{m}^{-2}\left(<500 \$ \cdot \mathrm{ft}^{-2}\right)$ \\
Durability & $>5$ years \\
$\mathrm{H}_{2}$ recovery & $90 \%$ \\
Hydrogen purity & $99.99 \%$ \\
\hline
\end{tabular}

However, all these criteria are set for membranes working in the presence of impurities like sulfur compounds and $\mathrm{CO}$, which can be challenging for Pd based membranes (especially the sulfur). The flux target is for a hydrogen differential partial pressure of $20 \mathrm{psi}(=138 \mathrm{kPa})$ with a minimum value for the pressure at the permeate side of $15 \mathrm{psi}(=103 \mathrm{kPa})$, and at $400{ }^{\circ} \mathrm{C}$. The cost per square meter of membrane area seems to be achievable for supported membranes. To surpass the high flux DOE 2015 target, very thin dense membranes are required. The required thickness of the membrane can be estimated from Sieverts' law for the membrane flux $[7,103,104]$ :

$$
J_{H_{2}}=\frac{P e_{H_{2}}}{t}\left(p_{H_{2, \text { ret }}}^{0.5}-p_{H_{2, \text { perm }}}^{0.5}\right)
$$

where $J_{\mathrm{H}_{2}}$ is the permeated hydrogen flux, $\mathrm{Pe}_{\mathrm{H}_{2}}$ the hydrogen permeability, $t$ membrane thickness, $p_{H_{2, \text { ret }}}^{0.5}$ and $p_{H_{2, \text { perm }}}^{0.5}$ are the partial pressures of hydrogen in the retentate and permeate sides 
respectively $[7,103]$. To surpass the DOE target, the permeance, defined as the hydrogen flux divided by the driving force, and thus equal to $P e_{H_{2}} / t$, should exceed $3 \times 10^{-3} \mathrm{~mol} \cdot \mathrm{m}^{-2} \cdot \mathrm{s}^{-1} \cdot \mathrm{Pa}^{-0.5}$, or $1 \times 10^{-5} \mathrm{~mol} \cdot \mathrm{m}^{-2} \cdot \mathrm{s}^{-1} \cdot \mathrm{Pa}^{-1}$ in units that are often used in literature for ease of comparison. With a relatively high permeability of $1 \times 10^{-12} \mathrm{~mol} \cdot \mathrm{m}^{-1} \cdot \mathrm{s}^{-1} \cdot \mathrm{Pa}^{-1}$ the required membrane thickness to reach the DOE target is in the order of $0.1 \mu \mathrm{m}$, clearly indicating the necessity to develop ultra-thin Pd membranes or layers on supported membranes.

\subsection{Supported Membranes for High $\mathrm{H}_{2}$ Flux}

\subsubsection{Selection of Porous Support}

For the preparation of very thin and pinhole-free supported membranes the choice of the porous substrate is crucial. Different support configurations and materials are commercially available, however, asymmetric tubular supports are preferred because of their larger surface/volume ratio compared with disk shape substrates. The characteristics of the support determine the required selective layer thickness in order to obtain a defect-free thin layer. Both ceramic and metallic supports have been extensively used. On the one hand, ceramic supports are very interesting because of their suitable surface properties and chemical compatibility with Pd layers. However, their integration in a membrane reactor is more complex and they are mechanically weaker than metallic supports. On the other hand, the thermal expansion of ceramic supports is smaller than metallic supports and is closer to the thermal expansion of Pd and its alloys. The thermal expansion coefficients of some materials used for the preparation of composite membranes have been listed in Table 4 . The most widely used support is alumina, which has smaller thermal expansion coefficient than $\mathrm{Pd}$, which could cause failures in the membranes when used at higher temperatures. This problem can be reduced by using $\mathrm{ZrO}_{2}$ or YSZ (yttria stabilized zirconia), which both have a thermal expansion coefficient closer to that of $\mathrm{Pd}$.

Table 4. Thermal expansion coefficients of some materials used for the preparation of hydrogen selective membranes [105-107].

\begin{tabular}{cc}
\hline Material & Thermal Expansion Coefficient $\left(\mathbf{1 0}^{-\mathbf{6}}{ }^{\circ} \mathbf{C}^{-\mathbf{1}}\right)$ \\
\hline $\mathrm{Al}_{2} \mathrm{O}_{3}$ & $6.5-7.6$ \\
$\mathrm{YSZ}$ & 10 \\
$\mathrm{ZrO}_{2}$ & 10 \\
$\mathrm{CeO}_{2}$ & 11.0 \\
$\mathrm{TiO}_{2}$ & 9.2 \\
$316 \mathrm{~L}$ & 16.0 \\
$\mathrm{Pd}$ & 11.8 \\
$\mathrm{Ag}$ & $18.9-19.7$ \\
$\mathrm{Au}$ & 14.2 \\
$\mathrm{Cu}$ & $16.5-17.0$ \\
$\mathrm{Ni}$ & $11.8-13.3$ \\
\hline
\end{tabular}

The most important characteristics of porous supports for the deposition of very thin pinhole-free selective layers are: (a) small pore size; (b) smooth surface (c) thermal and chemical stability.

Supports with a small pore size are required for thin membranes without defects. Thus, the pore size of the support determines the minimum amount of material required to completely cover them and form a continuous surface. Mardilovich et al. [108] have proven that the thickness required to obtain a dense layer is three times the diameter of the largest pore in the support. The minimum thickness of palladium required to deposit a dense layer on top of a porous support with different pore sizes was found to be much larger, as reported by Uemiya [109] (see Table 5). 
Table 5. Required Pd thickness to cover supports with different pore sizes [109].

\begin{tabular}{cc}
\hline Media Grade of Support $(\mu \mathrm{m})$ & Thickness of Deposited Pd Layer $(\mu \mathrm{m})$ \\
\hline $5 \times 10^{-3}$ & 0.8 \\
0.1 & 2.2 \\
0.2 & 4.5 \\
0.3 & 13 \\
\hline
\end{tabular}

Another property of the porous supports influences the required layer thickness: the surface roughness. High surface quality (small roughness) and controlled porosity can be obtained in ceramic supports. High surface quality (small roughness and pore size) can also be obtained by depositing a meso-porous layer onto porous supports [110-112], which could however reduce the hydrogen permeation because of the induced mass transfer resistance of the additional layer. Additionally, the adhesion between the Pd layer and the additional meso-porous layer could be a problem, which would result in weak Pd membrane. McCool and co-workers [110] improved the surface quality of commercial $\alpha-\mathrm{Al}_{2} \mathrm{O}_{3}$ by deposition of a $5 \mu \mathrm{m}$ thick $\gamma-\mathrm{Al}_{2} \mathrm{O}_{3}$ layer using a slip-casting technique of boehmite. The initial average pore size of the porous support was reduced from $200 \mathrm{~nm}$ to $4 \mathrm{~nm}$, with a final porosity around $40 \%$. Very thin PdAg layers $(163-525 \mathrm{~nm}$ ) with different silver content were deposited by DC sputtering. The best permeation results were obtained for a $117 \mathrm{~nm}$ thick $\mathrm{Pd}_{82.6} \mathrm{Ag}_{17.6}$ layer, for which the measured $\mathrm{H}_{2} / \mathrm{He}$ selectivity and $\mathrm{H}_{2}$ permeance at $300{ }^{\circ} \mathrm{C}$ were $\sim 3800$ and $7.69 \times 10^{-8} \mathrm{~mol} \cdot \mathrm{m}^{-2} \cdot \mathrm{s}^{-1} \cdot \mathrm{Pa}^{-1}$, respectively [110]. Thoen et al. [112] used commercial asymmetric $\alpha-\mathrm{Al}_{2} \mathrm{O}_{3}$ tubes coated with $\mathrm{ZrO}_{2}$ from Pall Corporation with a pore size of $20 \mathrm{~nm}$. A $1.3 \mu \mathrm{m}$ thick $\mathrm{Pd}_{95} \mathrm{Cu}_{5}$ layer was deposited by sequential electroless plating without the presence of EDTA as complexing agent. The permeated hydrogen flux at $365^{\circ} \mathrm{C}$ with a feed pressure of $\sim 435 \mathrm{kPa}(\sim 63 \mathrm{psig})$ was $1.5 \mathrm{~mol} \cdot \mathrm{m}^{-2} \cdot \mathrm{s}^{-1}$. Checchetto et al. [113] deposited a $\mathrm{SiO}_{2}$ nanolayer $(100 \mathrm{~nm})$ on top of an $\mathrm{Al}_{2} \mathrm{O}_{3}$ porous disk with nominal pore size of $200 \mathrm{~nm}$ followed by deposition of $150 \mathrm{~nm}$ of PdAg by pulsed laser deposition, which was not completely defect free since the selectivity observed at $300{ }^{\circ} \mathrm{C}$ was around 600-900 at a pressure difference of 1 bar with a permeance of $1.4 \times 10^{-6} \mathrm{~mol} \cdot \mathrm{m}^{-2} \cdot \mathrm{s}^{-1} \cdot \mathrm{Pa}^{-1}$. Pan et al. [114] modified $\alpha-\mathrm{Al}_{2} \mathrm{O}_{3}$ hollow fibres with an initial pore size of $200 \mathrm{~nm}$ with $1 \mu \mathrm{m}$ thick $\gamma-\mathrm{Al}_{2} \mathrm{O}_{3}$ by dip-coating and finally $2-3 \mu \mathrm{m}$ of Pd were coated by ELP with a final selectivity exceeding 1000 at $400{ }^{\circ} \mathrm{C}$ and a permeance of $1.1 \times 10^{-6} \mathrm{~mol} \cdot \mathrm{m}^{-2} \cdot \mathrm{s}^{-1} \cdot \mathrm{Pa}^{-1}$, which is one order of magnitude smaller than the original support $\left(2.1-2.5 \times 10^{-5} \mathrm{~mol} \cdot \mathrm{m}^{-2} \cdot \mathrm{s}^{-1} \cdot \mathrm{Pa}^{-1}\right)$. Wu et al. [115] and Li et al. [116] modified $\alpha-\mathrm{Al}_{2} \mathrm{O}_{3}(0.1 \mu \mathrm{m}$ pore size $)$ and $\mathrm{Al}_{2} \mathrm{O}_{3}-\mathrm{ZrO}_{2}(0.2 \mu \mathrm{m}$ pore size $)$ supports, respectively, with $\mathrm{TiO}_{2}$ followed by photo-catalytic deposition of Pd thin layers of $100 \mathrm{~nm}$ and $400 \mathrm{~nm}$, respectively. The observed permeance and selectivity are presented in Table 6, which can be compared with other layers deposited onto modified $\mathrm{Al}_{2} \mathrm{O}_{3}$, and $\mathrm{ZrO}_{2}$ supports.

Table 6. Comparison of the hydrogen permeation for various composite membranes.

\begin{tabular}{|c|c|c|c|c|c|}
\hline Membrane/Support & Thickness $(\mu \mathrm{m})$ & Permeance $\left(\mathrm{mol} \cdot \mathrm{m}^{-2} \cdot \mathrm{s}^{-1} \cdot \mathrm{Pa}^{-1}\right)$ & Temperature $\left({ }^{\circ} \mathrm{C}\right)$ & Selectivity $\mathrm{H}_{2} / \mathrm{N}_{2}$ & Reference \\
\hline $\mathrm{Pd}-\mathrm{Ag} / \gamma-\mathrm{Al}_{2} \mathrm{O}_{3} / \alpha-\mathrm{Al}_{2} \mathrm{O}_{3}$ & 0.117 & $7.7 \times 10^{-8}$ & 300 & $\sim 3800 *$ & [110] \\
\hline $\mathrm{Pd}_{95} \mathrm{Cu}_{5} / \mathrm{ZrO}_{2} / \alpha-\mathrm{Al}_{2} \mathrm{O}_{3}$ & 1.3 & $4.5 \times 10^{-6}$ & 365 & 127 & [112] \\
\hline $\mathrm{Pd}-\mathrm{Ag} / \mathrm{SiO}_{2} / \mathrm{Al}_{2} \mathrm{O}_{3}$ & 0.15 & $1.4 \times 10^{-6}$ & 300 & $600-900$ & [113] \\
\hline $\mathrm{Pd} / \gamma-\mathrm{Al}_{2} \mathrm{O}_{3} / \alpha-\mathrm{Al}_{2} \mathrm{O}_{3}(\mathrm{HF})$ & $2-3$ & $1.1 \times 10^{-6}$ & 400 & $>1000$ & [114] \\
\hline $\mathrm{Pd} / \mathrm{TiO}_{2} / \alpha-\mathrm{Al}_{2} \mathrm{O}_{3}$ & 0.1 & $3.3 \times 10^{-6}$ & 450 & 4.7 & [115] \\
\hline $\mathrm{Pd} / \mathrm{TiO}_{2} / \mathrm{Al}_{2} \mathrm{O}_{3}-\mathrm{ZrO}_{2}$ & 0.4 & $4.8 \times 10^{-6}$ & 430 & $83-130$ & [116] \\
\hline
\end{tabular}

Pacheco Tanaka et al. [111] modified tubular $\alpha-\mathrm{Al}_{2} \mathrm{O}_{3}$ substrates with an average pore size of $150 \mathrm{~nm}$ by deposition of a meso-porous $\gamma-\mathrm{Al}_{2} \mathrm{O}_{3}$ layer by vacuum assisted dip-coating followed by a slow drying process at $40^{\circ} \mathrm{C}$ and final calcination at $550{ }^{\circ} \mathrm{C}$. These porous supports were also modified with $\mathrm{YSZ} / \gamma-\mathrm{Al}_{2} \mathrm{O}_{3}$ mixtures, which were calcined at different temperatures (500-1000 ${ }^{\circ} \mathrm{C}$ ) [111]. The nitrogen permeance of the supports calcined at $1000{ }^{\circ} \mathrm{C}$ was close to twice the permeance of those calcined at $600{ }^{\circ} \mathrm{C}$. During the calcination the pore radius decreased, causing larger pore size 
distributions at higher temperatures $(2-9 \mathrm{~nm})$ and a smaller distribution and size at $600{ }^{\circ} \mathrm{C}(1-4 \mathrm{~nm})$. Both modified supports [111,117] were used for the preparation of pore-filled type membranes (which will be discussed in more detail in the Section 3.5.2.

In addition to the pore size (distribution) and surface roughness, the stability of the support material under reductive environments at high temperatures and possible interactions with the material of the selective layer (in particular $\mathrm{Pd}$ ) are two very important aspects to be considered in the preparation of supported membranes. Thermal stability of alumina supports in the presence of hydrogen at different temperatures was evaluated by Okazaki et al. [118]. The authors found that alumina interacts with hydrogen at temperatures above $650{ }^{\circ} \mathrm{C}$ producing aluminium. This diffuses through the Pd layer forming an alloy at the interface as revealed by EDX analysis. In their experiments the hydrogen flux was diminished by a factor two after $50 \mathrm{~h}$. This phenomenon proceeds even faster at higher temperatures, as the hydrogen permeation was totally suppressed after $2-3 \mathrm{~h}$ at $850{ }^{\circ} \mathrm{C}$.

Paglieri et al. [119] observed a similar decrease in the permeated hydrogen flux at $750{ }^{\circ} \mathrm{C}$, where Pd was deposited onto alumina porous supports, with a complete and irreversible flux decay that could not be recovered even after thermal treatment in air or hydrogen in order to restore the hydrogen permeation.

Huang et al. [120] detected diffusion between $\mathrm{Pd}$ and $\mathrm{TiO}_{2}$ used as interdiffusion barrier. In membranes used for 23 days at $600{ }^{\circ} \mathrm{C}$ in the presence of pure hydrogen the authors found diffusion of components of the support (and interdiffusion barrier layer) at a depth of 2-3 $\mu \mathrm{m}$ along the interface. Diffusion was not observed when using $\mathrm{ZrO}_{2}$ and $\mathrm{YSZ}$ interdiffusion barriers. Stability under reductive and oxidative atmospheres is obtained with cubic phase YSZ. Okazaki et al. [121] found that YSZ represents the best choice for high temperature environments, such as for membrane assisted reactors for autothermal reforming. The authors tested a Pd/YSZ membrane during $336 \mathrm{~h}$ at $650{ }^{\circ} \mathrm{C}$ in pure hydrogen observing 10\% reduction in the hydrogen flux during the first $50 \mathrm{~h}$, as shown in Figure 6. After this period, the hydrogen flux reached a plateau without presence of nitrogen leaks. The tested membrane was analysed by cross-section SEM images and it was found that the selective layer did not show presence of $\mathrm{Y}$ and/or $\mathrm{Zr}$. However, when using $\mathrm{Pd} / \mathrm{Al}_{2} \mathrm{O}_{3}$ composite membranes, the hydrogen permeation flux was completely lost after $\sim 125 \mathrm{~h}$.

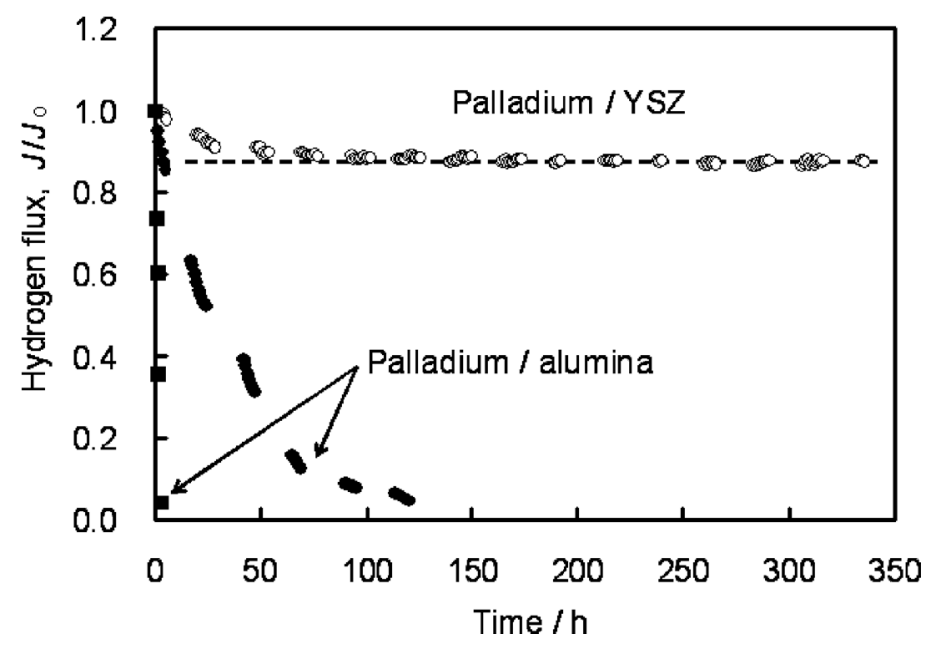

Figure 6. Hydrogen flux measured at $650{ }^{\circ} \mathrm{C}$ for $\mathrm{Pd}-\mathrm{YSZ}$ and $\mathrm{PdAl}_{2} \mathrm{O}_{3}$ membranes at $100 \mathrm{kPa}$ of pressure difference. Reprinted from [121] with permission from Royal Society of Chemistry.

As far as metal supports are concerned, most of the papers published in the last few years have used porous supports made of stainless steel, followed by nickel substrates for higher temperatures. Metallic supports employed in the most recent studies have been summarized in Table 7 including some characteristic parameters of the supports and techniques used for the deposition of the ceramic 
barriers. Stainless steel porous supports with different pore sizes from Mott Metallurgical Corporation are commonly used, where smaller pore size are preferred due to their smoother surface [54,122-125]. Commercially available PSS supports are made of stainless steel 316L with different pore size, also called media grade. Typical media grades used are $0.1 \mu \mathrm{m}$ and $0.2 \mu \mathrm{m}$, corresponding to an average pore size of $2-5 \mu \mathrm{m}$ and $10 \mu \mathrm{m}$, respectively (measured by mercury intrusion). Larger media grades, $0.5 \mu \mathrm{m}$, are less used due to their larger average pore size $(10-20 \mu \mathrm{m})$ which requires thicker Pd or interdiffusion barriers to reach complete surface coverage. Porous stainless steel substrates from Pall corporation were used with a pore size of $2 \mu \mathrm{m}$ [126], while YSZ modified PSS from Pall have also been used for membrane preparation [127-129]. Some research groups prepared in-house metallic porous supports. A PSS tubular support was prepared by Straczewski using powder from GKN Sinter Metals [130]. On the other hand, nickel porous support were prepared by sintering commercial nickel powder supplied by Vale Inco Pacific Ltd., Hong Kong (SAR), China [106,131]. For high temperature applications $\left(>550{ }^{\circ} \mathrm{C}\right)$, Hastelloy X (Ni-based) from Mott Corporation is another option [62,132]. Except for the $\mathrm{ZrO}_{2}$ modified PSS from Pall, all other metallic supports require an interdiffusion barrier, as discussed in the following section.

Table 7. Recently reported studies employing porous metal supports: materials and suppliers.

\begin{tabular}{ccccc}
\hline Material & Supplier & Media Grade $(\mu \mathrm{m}) *$ & Pore Size $(\mu \mathrm{m})$ & Reference \\
\hline & & 0.1 & $2-5$ & {$[54,125]$} \\
& Mott Metallurgical Corporation & 0.2 & 10 & {$[122,123]$} \\
Stainless steel & & 0.5 & 20 & {$[108]$} \\
& Pall Corporation & 0.1 & 2 & {$[126]$} \\
& Pall Corporation $(30 \mu \mathrm{m}$ YSZ) & - & - & {$[127-129]$} \\
GKN Sinter Metal ${ }^{* *}$ & - & - & {$[130]$} \\
\hline Nickel & Vale Inco Pacific Ltd. ${ }^{* *}$ & - & - & {$[106,131]$} \\
Hastelloy X & Mott Corporation & 0.2 & $-132]$ \\
\hline$*$ Particle retention size. 95\% rejection of particles with a size greater than the grade is guaranteed.
\end{tabular}

Mechanical failure of supported thin films due to the difference in thermal expansion coefficients between the selective layer and the porous supports can be avoided by deposition of an interdiffusion barrier with a similar expansion coefficient of the dense selective layer. Another possibility was reported by Zhao et al. [133], who prepared a membrane with a modified electroless plating bath mixing a solution containing $\mathrm{Pd}$ (II) with a $\gamma-\mathrm{Al}_{2} \mathrm{O}_{3}$ (boehmite) sol. The porous substrate was coated with this solution in the presence of small amounts of polyvinyl alcohol (PVA) and polyethyleneglycol (PEG). Before calcination at $600{ }^{\circ} \mathrm{C}$, the coated layer was dried during two days at low temperature $\left(5{ }^{\circ} \mathrm{C}\right)$ and $65 \%$ relative humidity. Before electroless plating, the membrane was exposed to hydrogen at $500{ }^{\circ} \mathrm{C}$ to reduce the palladium. Finally, a $1 \mu \mathrm{m}$ thick Pd layer was deposited by ELP as the support was activated. The permeated hydrogen flux of the supported membrane was $0.108 \mathrm{~mol} \cdot \mathrm{m}^{-2} \cdot \mathrm{s}^{-1}$ at $450{ }^{\circ} \mathrm{C}$, but the corresponding ideal $\mathrm{H}_{2} / \mathrm{N}_{2}$ selectivity was very low: 20 .

The development of a thin membrane with high permeation and selectivity is therefore not always possible due to the factors discussed before such as support pore size, roughness, etc. In many of the studies presented in this period either a high flux or a high selectivity was achieved. However, Bredesen and co-workers (SINTEF) reported the preparation of Pd-Ag membranes with both very high permeation and selectivity [126]. A $2.8 \mu \mathrm{m}$ thick $\mathrm{Pd}_{77} \mathrm{Ag}_{23}$ layer was deposited by magnetron sputtering onto a silicon wafer, which was removed and rolled onto a 316L stainless steel tubular porous support. The measured hydrogen flux at $400{ }^{\circ} \mathrm{C}$ and 26 bar of feed pressure was $8.64 \mathrm{~mol} \cdot \mathrm{m}^{-2} \cdot \mathrm{s}^{-1}$ with a $\mathrm{H}_{2} / \mathrm{N}_{2}$ selectivity of 1600 . These results were even improved after thermal treatment in air at $400{ }^{\circ} \mathrm{C}$ for three days. The hydrogen flux and selectivity measured under the same conditions reported before thermal treatment in air were $18.43 \mathrm{~mol} \cdot \mathrm{m}^{-2} \cdot \mathrm{s}^{-1}$ and 2900 , respectively. The initial hydrogen permeance, $6.48 \times 10^{-3} \mathrm{~mol} \cdot \mathrm{m}^{-2} \cdot \mathrm{s}^{-1} \cdot \mathrm{Pa}^{-0.5}$, was enhanced one order of magnitude after thermal 
treatment in air with a measured permeance of $1.46 \times 10^{-2} \mathrm{~mol} \cdot \mathrm{m}^{-2} \cdot \mathrm{s}^{-1} \cdot \mathrm{Pa}-0.5$. A long-term test was performed at temperatures below $375{ }^{\circ} \mathrm{C}$ during 85 days in the presence of a $50 \% \mathrm{H}_{2} / 50 \% \mathrm{~N}_{2}$ feed gas revealing great stability for the first 40 days. However, the nitrogen flux increased from $4.46 \times 10^{-3}$ to $6.32 \times 10^{-3} \mathrm{~mol} \cdot \mathrm{m}^{-2} \cdot \mathrm{s}^{-1}$ at 10 bar feed pressure, while the hydrogen flux was maintained at around $8.78 \mathrm{~mol} \cdot \mathrm{m}^{-2} \cdot \mathrm{s}^{-1}$. The corresponding $\mathrm{H}_{2} / \mathrm{N}_{2}$ ideal selectivity was 1400 . Pinholes of about $0.1-0.3 \mu \mathrm{m}$ in diameter were observed by SEM on the membrane surface exposed to hydrogen after long-term experiments. The membranes prepared by SINTEF were tested under WGS environment at $400{ }^{\circ} \mathrm{C}$ and 26 bar feed pressure [134]. In the presence of a gas mixture containing $57.5 \% \mathrm{H}_{2}, 18.7 \% \mathrm{CO}_{2}, 18.7 \%$ $\mathrm{H}_{2} \mathrm{O}, 3.8 \% \mathrm{CO}$ and $1 \% \mathrm{CH}_{4}$, the measured hydrogen permeance was $1.1 \times 10^{-3} \mathrm{~mol} \cdot \mathrm{m}^{-2} \cdot \mathrm{s}^{-1} \cdot \mathrm{Pa}^{-0.5}$. These membranes exhibited at least one year stability under WGS conditions and mixtures of $\mathrm{H}_{2}-\mathrm{N}_{2}$ at feed pressure of 10 bar.

A short air treatment allows activation (or perhaps cleaning) of the membrane and increases the flux of $\mathrm{H}_{2}$. It was suggested by Roa and Way [135] that exposure to air resulted in surface cleaning and enhancement in the surface area for "as prepared" (not totally clean) membranes. This effect depends on the exposition time and temperature. However, this effect is not representative for all Pd-alloyed membranes as Zhang et al. [136] reported in their study where $\mathrm{Pd}_{75} \mathrm{Ag}_{25}$ and $\mathrm{Pd}_{90} \mathrm{Au}_{10}$ membranes were "activated" under air treatment at $300{ }^{\circ} \mathrm{C}$. The measured hydrogen flux before and after air treatment for the PdAu layer were practically the same, while the authors observed an increase in the flux for the PdAg membrane ranging between $\sim 80 \%$ at a transmembrane pressure difference of $55 \mathrm{~Pa}^{0.5}$, and $\sim 50 \%$ at a pressure difference of $180 \mathrm{~Pa}^{0.5}$.

\subsubsection{Selection of Interdiffusion Layer}

The undesired diffusion of components from the porous stainless steel support such as $\mathrm{Fe}, \mathrm{Cr}$ and Ni to the Pd selective layer at high temperatures is a well-known phenomenon. After diffusion, an alloy with $\mathrm{Pd}$ is formed that decreases the hydrogen permeance of the membrane due to the reduction of the solubility and diffusivity of hydrogen into the Pd-alloy lattice; Pd and Fe from the support start forming a solid solution at $500{ }^{\circ} \mathrm{C}$ in the presence of hydrogen after $20 \mathrm{~h}$ [137]. The amount of iron in the Pd layer interface increases from $2 \mathrm{wt}$. \% to $59 \mathrm{wt}$. \% upon a thermal treatment with a temperature increase from $500{ }^{\circ} \mathrm{C}$ to $800{ }^{\circ} \mathrm{C}$. In contrast, silver does not form a solid solution with iron at these temperatures.

In order to avoid the diffusion of elements between the metallic support and the dense selective layer during operation at high temperatures, the deposition of a ceramic barrier is performed on top of the metallic porous support. Moreover, metallic supports having an adequate pore size and roughness for thin Pd membranes are difficult to fabricate. Therefore, the deposition of the ceramic layer also improves the surface quality of the original support allowing the deposition of thinner selective layers.

The selection of the ceramic material for the interdiffusion barrier layer is a critical point to take into account, since an asymmetric membrane composed of materials with different thermal expansion coefficients could result in a total failure of the membrane during operation especially at high temperatures. Ceramics used as inter-diffusion barrier need to have as similar thermal expansion coefficient as the selective metallic layer and support. The most common barrier material, alumina [123,138-140], has a low thermal expansion coefficient compared with $\mathrm{ZrO}_{2}[108,120,141-144]$ or YSZ (yttria stabilized zirconia) [120,125,128,130,145], which both have larger thermal expansion coefficients and closer to Pd and its alloys (see Table 4). Other ceramic layers used as barrier are $\mathrm{TiO}_{2}[120,130]$ or $\mathrm{CeO}_{2}[106,146]$ which both possess a large thermal expansion coefficient and close to the thermal expansion coefficient of $\mathrm{Pd}$. Oxidation of porous stainless steel supports provide a chromium oxide $\left(\mathrm{Cr}_{2} \mathrm{O}_{3}\right)$ layer, which can act as an interdiffusion barrier. The thickness of the $\mathrm{Cr}_{2} \mathrm{O}_{3}$ layer is controlled by the oxidation temperature and time [145,147] or by the electrodeposition of $\mathrm{Cr}$ followed by oxidation treatment in air [147]. Nickel porous supports are generally modified by the deposition of thin ceramic layers of $\mathrm{Al}_{2} \mathrm{O}_{3}, \mathrm{ZrO}_{2}$ and $\mathrm{CeO}_{2}$. By physical vapour deposition, 
$0.2 \mu \mathrm{m}$ thick alumina and zirconia layers were deposited [131], while $\mathrm{CeO}_{2}(0.5 \mu \mathrm{m})$ was obtained by dip-coating after modification of the Ni-support by wetness impregnation with alumina [106].

The composite membranes based on metallic porous supports modified with interdiffusion barriers have been summarized in Table 8 .

The large pore size of commercial PSS supports can be reduced before deposition of ceramic layers by a pre-treatment based on polishing and then etching with an acid solution $\left(\mathrm{HNO}_{3}\right.$ and $\mathrm{HCl}$ ) as Li et al. suggested [139]. The initial roughness of PSS supports with media grade of $0.2 \mu \mathrm{m}$ was reduced from $20 \mu \mathrm{m}$ to $5 \mu \mathrm{m}$ by polishing. However, most of the pores were completely closed, decreasing more than $99 \%$ the initial $\mathrm{H}_{2}$ permeation rate. Acid etching of the polished surface removed more than $15 \mu \mathrm{m}$ of material, opening pores and, as a result, the permeance of the support was enhanced $15 \%$ more than with the initial support without polishing. The remaining roughness was reduced by deposition of a $2 \mu \mathrm{m}$ thick alumina layer using particles of around $2.5 \mu \mathrm{m}$. The surface roughness was decreased from $5 \mu \mathrm{m}$ to $2 \mu \mathrm{m}$ after deposition of the first layer, which did not cover the metallic substrate completely and the permeation rate was reduced by $40 \%$. Subsequently, the metallic support was completely covered by deposition of a second layer $(\sim 1 \mu \mathrm{m})$ with a particle size of $0.3 \mu \mathrm{m}$. The measured separation factor $\mathrm{H}_{2} / \mathrm{N}_{2}$ was less than 3.74 (Knudsen diffusion), suggesting still a contribution of viscous flow. A defect-free Pd layer $(5 \mu \mathrm{m})$ was deposited by ELP [139] exhibiting a permeance of $3.39 \times 10^{-3} \mathrm{~mol} \cdot \mathrm{m}^{-2} \cdot \mathrm{s}^{-2} \cdot \mathrm{Pa}^{-0.5}$ at $550{ }^{\circ} \mathrm{C}$ and a pressure difference of $340 \mathrm{kPa}$.

A similar method for the deposition of alumina was reported by Chi et al. [140] without pre-treatment for supports with the same characteristics as used by Li et al. [139]. The particle sizes of the deposited layers were about $10 \mu \mathrm{m}$ and $1 \mu \mathrm{m}$. The authors did not report the thickness of the layers, but suggested that the first layer blocked the large pores of the metallic support, while the second layer covered the surface completely [140]. The measured helium flux was reduced $7.36 \%$ and $21.3 \%$ after deposition of the two layers, respectively. The deposited dense Pd-layer by ELP onto the original support and the modified support with two layers was reduced from $31.5 \mu \mathrm{m}$ to $4.4 \mu \mathrm{m}$. The permeance of the thinner membrane at $500{ }^{\circ} \mathrm{C}$ and a pressure difference of $800 \mathrm{kPa}$ was $2.94 \times 10^{-3} \mathrm{~mol} \cdot \mathrm{m}^{-2} \cdot \mathrm{s}^{-1} \cdot \mathrm{Pa}^{-0.5}$, with an ideal selectivity $\mathrm{H}_{2} / \mathrm{He}$ of 1124 . Additionally, the hydrogen flux through unmodified PSS with a $31.5 \mu \mathrm{m}$ thick Pd layer was decreasing during the experiment due to diffusion of metal elements from the support to the Pd layer. 
Table 8. Pd-based layers deposited onto modified metallic supports with different interdiffusion barriers.

\begin{tabular}{|c|c|c|c|c|c|c|c|c|c|c|c|}
\hline \multicolumn{2}{|r|}{ Interdiffusion Barrier } & \multicolumn{4}{|c|}{ Selective Layer } & \multicolumn{5}{|c|}{ Membrane Performance } & \multirow[b]{2}{*}{ Reference } \\
\hline Material & Deposition Method & $\begin{array}{c}\text { Thickness } \\
(\mu \mathrm{m})\end{array}$ & Material & Method & $\begin{array}{c}\text { Thickness } \\
(\mu \mathrm{m})\end{array}$ & $\mathrm{T}\left({ }^{\circ} \mathrm{C}\right)$ & $\begin{array}{c}\text { Pressure } \\
\text { Difference (kPa) }\end{array}$ & $\mathbf{n}$ & $\begin{array}{c}\mathrm{H}_{2} \text { Permeance } \\
\left(\mathrm{mol} \cdot \mathrm{m}^{-2} \cdot \mathrm{s}^{-1} \cdot \mathrm{Pa}^{-\mathrm{n}}\right)\end{array}$ & $\begin{array}{c}\mathrm{H}_{2} / \mathrm{N}_{2} \\
\text { Selectivity }\end{array}$ & \\
\hline \multicolumn{12}{|c|}{ Barriers deposited onto porous stainless steel supports } \\
\hline$\gamma-\mathrm{Al}_{2} \mathrm{O}_{3}$ & Dip coating Sol-gel & $3-4$ & $\mathrm{Pd}$ & ELP & 11 & - & - & - & - & - & [138] \\
\hline $\mathrm{Al}_{2} \mathrm{O}_{3}$ & 2 step Dip coating & $\sim 3$ & $\mathrm{Pd}$ & ELP & 5 & 550 & 340 & 0.5 & $3.39 \times 10^{-3}$ & - & [139] \\
\hline $\mathrm{Al}_{2} \mathrm{O}_{3}$ & 2 step Dip coating & - & $\mathrm{Pd}$ & ELP & 4.4 & 500 & 800 & 0.5 & $2.94 \times 10^{-3}$ & $1124^{*}$ & [140] \\
\hline $\mathrm{Al}_{2} \mathrm{O}_{3}$ & Vacuum assisted Dip-coating & $<1$ & $\mathrm{Pd}_{92} \mathrm{Au}_{8}$ & ELP & 24 & & & & & & [123] \\
\hline $\mathrm{ZrO}_{2}$ & PVD-MS & 2.0 & Pd & ELP & 14 & 500 & 50 & 0.5 & $8.93 \times 10^{-4}$ & $\sim 180$ & [120] \\
\hline $\mathrm{ZrO}_{2}$ & PVD-MS ** & 0.5 & & & & & & & & & [142] \\
\hline $\mathrm{ZrO}_{2}$ & Vacuum assisted dip-coating & $<<1$ & $\mathrm{Pd}_{92} \mathrm{Au}_{8}$ & ELP & 12 & 450 & 100 & 0.5 & $1.26 \times 10^{-3}$ & $>10,000$ & [123] \\
\hline $\mathrm{ZrO}_{2}$ & Vacuum assisted dip-coating & $\sim 5$ & $\mathrm{Pd}$ & ELP & 7.5 & 600 & 500 & 0.5 & $2.53 \times 10^{-3}$ & 685 & [108] \\
\hline $\mathrm{ZrO}_{2}$ & Vacuum assisted dip-coating & - & $\mathrm{Pd}_{78} \mathrm{Ag}_{9} \mathrm{Au}_{13}$ & ELP & $\sim 14$ & 450 & 50 & 0.5 & $1.15 \times 10^{-3}$ & - & [124] \\
\hline $\mathrm{ZrO}_{2}$ & Vacuum assisted dip-coating & - & $\mathrm{Pd}_{90} \mathrm{Ag}_{10}$ & ELP & $\sim 14$ & 450 & 50 & 0.5 & $1.46 \times 10^{-3}$ & - & [124] \\
\hline $\mathrm{ZrO}_{2}$ & Coating by sucking & - & $\mathrm{Pd}$ & ELP & 10 & 550 & 100 & 0.5 & $6.86 \times 10^{-4}$ & - & [143] \\
\hline $\mathrm{Pd}-\mathrm{ZrO}_{2}$ & Dip coating & - & $\mathrm{Pd}_{84} \mathrm{Cu}_{16}$ & ELP & 5 & 480 & 250 & 0.5 & $2.19 \times 10^{-3}$ & - & [144] \\
\hline YSZ & - & $\sim 30$ & $\mathrm{Pd}_{77} \mathrm{Au}_{23}$ & ELP & 5.7 & 400 & $\sim 590$ & 0.5 & $2.19 \times 10^{-3}$ & 690 & [127] \\
\hline YSZ & - & $\sim 30$ & $\mathrm{Pd}_{67} \mathrm{Ag}_{13} \mathrm{Au}_{20}$ & ELP & 9.3 & 400 & $\sim 590$ & 0.5 & $1.44 \times 10^{-3}$ & 2200 & [127] \\
\hline YSZ & - & $\sim 50$ & $\mathrm{Pd}_{95} \mathrm{Au}_{5}$ & ELP & 2.3 & 400 & 138 (Feed) & 0.6 & $2.72 \times 10^{-3}$ & 82,000 & [128] \\
\hline YSZ & - & $\sim 30$ & Pd & ELP & 4.9 & 550 & 50 & 0.5 & $2.39 \times 10^{-3}$ & 1750 & [129] \\
\hline YSZ & - & $\sim 30$ & $\mathrm{Pd}_{73} \mathrm{Pt}_{27}$ & ELP & 4.4 & 550 & 50 & 0.5 & $8.82 \times 10^{-4}$ & 626 & [129] \\
\hline YSZ & - & $\sim 30$ & $\mathrm{Pd}_{99.7} \mathrm{Ru}_{0.3}$ & ELP & 6 & 550 & 50 & 0.5 & $2.1 \times 10^{-3}$ & 1860 & [129] \\
\hline YSZ & APS & $\sim 100$ & $\mathrm{Pd}$ & ELP & 13.6 & 400 & 250 & 0.5 & $2.88 \times 10^{-4}$ & $\infty$ & [125] \\
\hline YSZ & APS & $80-100$ & $\mathrm{Pd}$ & ELP & 25.3 & 600 & 200 & 0.5 & $5.7 \times 10^{-4}$ & $\sim 225$ & [130] \\
\hline YSZ & APS & $10-70$ & $\mathrm{Pd}$ & ELP & 23 & 500 & 50 & 0.5 & $8.43 \times 10^{-4}$ & $\sim 200$ & [120] \\
\hline YSZ & Dip coating & $2.5-3$ & $\mathrm{Pd}$ & ELP & 11 & 650 & $\sim 220$ & 0.5 & $1.05 \times 10^{-3}$ & - & [145] \\
\hline $\mathrm{Cr}_{2} \mathrm{O}_{3}$ & Oxidation in air at $800^{\circ} \mathrm{C}, 12 \mathrm{~h}$ & - & $\mathrm{Pd}_{90.2} \mathrm{Ag}_{3.6} \mathrm{Cu}_{6.2}$ & ELP & 40 & 280 & 90 & 0.5 & $4.32 \times 10^{-4}$ & 700 & [122] \\
\hline $\mathrm{Cr}_{2} \mathrm{O}_{3}$ & Oxidation at $650^{\circ} \mathrm{C}, 12 \mathrm{~h}$ & - & $\mathrm{Pd}$ & ELP & 10.2 & 400 & 250 & 0.5 & $3.3 \times 10^{-4}$ & $\infty$ & [54] \\
\hline $\mathrm{Cr}_{2} \mathrm{O}_{3}$ & Oxidation at $800^{\circ} \mathrm{C}$ & - & $\mathrm{Pd}$ & ELP & 25 & 600 & $\sim 220$ & 0.5 & $1 \times 10^{-4}$ & - & [145] \\
\hline $\mathrm{Cr}_{2} \mathrm{O}_{3}$ & $\begin{array}{l}\text { Oxidation at } 700^{\circ} \mathrm{C}, 6 \mathrm{~h} \text { and } \\
\text { electrodeposition }\end{array}$ & $2-10$ & $\mathrm{Pd}$ & ELP & 32 & 500 & 100 & 0.5 & $5.84 \times 10^{-5}$ & - & [147] \\
\hline $\mathrm{TiO}_{2}$ & WPS & $<15$ & $\mathrm{Pd}$ & ELP & 14.4 & 600 & 200 & 0.5 & $2.6 \times 10^{-3}$ & $\sim 160$ & [130] \\
\hline $\mathrm{TiO}_{2}$ & WPS & $40-60$ & $\mathrm{Pd}$ & ELP & 9 & 500 & 50 & 0.5 & $1.91 \times 10^{-3}$ & $\sim 800$ & [120] \\
\hline $\mathrm{CeO}_{2}$ & Suction of $\mathrm{Ce}(\mathrm{OH})_{4}$ sol & - & $\mathrm{Pd}$ & ELP & 10 & 500 & 100 & 0.5 & $1.36 \times 10^{-3}$ & 108 ** & [146] \\
\hline $\mathrm{CeO}_{2}$ & Suction of $\mathrm{Ce}(\mathrm{OH})_{4}$ sol & - & $\mathrm{Pd}$ & $\mathrm{ELP}+\mathrm{CVD}$ & 6.4 & 500 & 100 & 0.5 & $1.79 \times 10^{-3}$ & $565^{* *}$ & [146] \\
\hline \multicolumn{12}{|c|}{ Barriers deposited onto porous nickel supports } \\
\hline $\mathrm{Al}_{2} \mathrm{O}_{3}$ & Sputtering & $\sim 0.2$ & $\mathrm{Pd}_{97} \mathrm{Au}_{3}$ & PVD & - & & - & - & - & - & [131] \\
\hline $\mathrm{ZrO}_{2}$ & Sputtering & $\sim 0.2$ & $\mathrm{Pd}_{97} \mathrm{Au}_{3}$ & PVD & 3.05 & 450 & 2000 & 0.83 & $1.52 \times 10^{-6}$ & 2000 & [131] \\
\hline $\mathrm{CeO}_{2}$ & Dip-coating & $\sim 0.5$ & $\mathrm{Pd}_{93} \mathrm{Cu}_{7}$ & PVD & 7 & 500 & 400 & 0.5 & $7 \times 10^{-4}$ & 50,000 & [106] \\
\hline $\mathrm{Al}_{2} \mathrm{O}_{3}-\mathrm{YSZ}$ & Dip-coating & 1 & PdAg & ELP & $4-5$ & 400 & 100 & 0.5 & $7.69 \times 10^{-4}$ & 200,000 & [132] \\
\hline
\end{tabular}

${ }^{*} \mathrm{H}_{2} /$ He selectivity; ${ }^{* *} \mathrm{H}_{2} /$ Ar selectivity. 
Broglia et al. [138] reduced the original roughness of PSS with a nominal pore size of $0.1 \mu \mathrm{m}$ with $\gamma-\mathrm{Al}_{2} \mathrm{O}_{3}$ by dip coating followed by the deposition of a second layer obtained by hydrolysis of metal-organic alumina. They found that the mesoporous alumina $(3-4 \mu \mathrm{m})$ layer covered the support completely. However, part of this ceramic layer was dissolved by the Pd-activation solution due to the acidity of the solution. A pinhole-free $11 \mu \mathrm{m}$ thick Pd layer was deposited by ELP with total coverage of the modified support. Unfortunately, the authors did not report permeation experiments.

Tong et al. introduced a cerium hydroxide solution into a Mott PSS tubular support (particle retention size of $0.2 \mu \mathrm{m}$ ) applying vacuum in the inner side of tube [146]. Two layers of $6 \mu \mathrm{m}$ and $10 \mu \mathrm{m}$ of Pd were deposited by ELP, resulting in a $\mathrm{H}_{2} / \mathrm{Ar}$ selectivity of 108 for the thicker layer, while the separation factor of the $6 \mu \mathrm{m}$ layer was lower (only 14). The defects of this last membrane were repaired by chemical vapor deposition sublimating Pd (II) hexafluoroacetylacetonate. After 3 CVD treatments the overall thickness of $\mathrm{Pd}$ was around $6.4 \mu \mathrm{m}$ and the selectivity was improved to 565 with a hydrogen permeation flux of $0.235 \mathrm{~mol} \cdot \mathrm{m}^{-2} \cdot \mathrm{s}^{-1}$ at $500{ }^{\circ} \mathrm{C}$ and a pressure difference of $100 \mathrm{kPa}$.

Straczewski deposited YSZ and $\mathrm{TiO}_{2}$ onto an in-house PSS substrate produced using powder from GKN Sinter Metals [130]. A smoother surface was obtained before deposition of the interdiffusion layer by wet powder spraying of fine particles, followed by deposition of $<100 \mu \mathrm{m}$ thick YSZ layer by atmospheric plasma spraying (APS) or thinner $\left(<15 \mu \mathrm{m}\right.$ thick) $\mathrm{TiO}_{2}$ by wet powder spraying (WPS). The thinner $\mathrm{TiO}_{2}$ layers presented a larger surface quality (small pore size, large porosity and smooth surface) than the YSZ layers. Furthermore, the measured nitrogen permeance for the $\mathrm{TiO}_{2}$ layers was $\sim 1.8 \times 10^{-5} \mathrm{~mol} \cdot \mathrm{m}^{-2} \cdot \mathrm{s}^{-1} \cdot \mathrm{Pa}^{-1}$, one order of magnitude higher than for the thicker YSZ layer, $\sim 3.2 \times 10^{-6} \mathrm{~mol} \cdot \mathrm{m}^{-2} \cdot \mathrm{s}^{-1} \cdot \mathrm{Pa}^{-1}$. No significant changes were observed on the permeated $\mathrm{N}_{2}$ flux through the YSZ layer after nine thermal-cycling tests at $700{ }^{\circ} \mathrm{C}$ with different heating rates. On the other hand, the $\mathrm{N}_{2}$ flux was reduced every cycle for $\mathrm{TiO}_{2}$ till $10 \%$ of the initial $\mathrm{N}_{2}$ flux. Thicker Pd layers were required and were deposited onto YSZ $(24.8-30 \mu \mathrm{m})$ than on $\mathrm{TiO}_{2}(8.3-14.9 \mu \mathrm{m})$ due to the better surface quality of last one. A slight increase in the $\mathrm{N}_{2}$ flux was measured for the Pd-YSZ-PSS composite after a thermal treatment at $700{ }^{\circ} \mathrm{C}$. Meanwhile, the $\mathrm{N}_{2}$ flux decreased for the $\mathrm{Pd}^{-\mathrm{TiO}_{2}}$ system when the heating rate was increased, suggesting sintering of the particles of the intermediate layer. The properties of the intermediate and selective layers are reflected in the hydrogen permeation flux. The thicker $\operatorname{Pd}(25.3 \mu \mathrm{m})$-YSZ-PSS membranes permeated $0.14 \mathrm{~mol} \cdot \mathrm{m}^{-2} \cdot \mathrm{s}^{-1} \mathrm{of}_{2}$ at $600{ }^{\circ} \mathrm{C}$ and a transmembrane pressure of $2 \mathrm{bar}$, in terms of permeance $\left(5.7 \times 10^{-4} \mathrm{~mol} \cdot \mathrm{m}^{-2} \cdot \mathrm{s}^{-1} \cdot \mathrm{Pa}^{-0.5}\right)$ one order of magnitude smaller than for the $\mathrm{Pd}(14.3 \mu \mathrm{m})-\mathrm{TiO}_{2}-\mathrm{PSS}$ composite $\left(2.6 \times 10^{-3} \mathrm{~mol} \cdot \mathrm{m}^{-2} \cdot \mathrm{s}^{-1} \cdot \mathrm{Pa}^{-0.5}\right)$. The calculated ideal $\mathrm{H}_{2} / \mathrm{N}_{2}$ selectivity was similar and close to 200 for both membranes [130].

Huang et al. [120] compared three different ceramic barriers $\left(\mathrm{ZrO}_{2}, \mathrm{YSZ}\right.$ and $\left.\mathrm{TiO}_{2}\right)$ deposited onto 310L porous supports by different deposition techniques. Very thin $(2 \mu \mathrm{m}) \mathrm{ZrO}_{2}$ layers were obtained by magnetron sputtering resulting in incomplete coverage of the porous support, which resulted in intermetallic diffusion at points where the Pd-layer was in contact with stainless steel. Thicker $(10-70 \mu \mathrm{m})$ and rougher YSZ layers were obtained by APS, where the largest pore size $(1.9 \mu \mathrm{m})$ of the original support was reduced to $0.78 \mu \mathrm{m}$. However, the nitrogen flux was reduced to $15 \%$ of the flux through the original support. In contrast, the nitrogen flux of the deposited $\mathrm{TiO}_{2}$ by WPS with a large thickness $(40-60 \mu \mathrm{m})$ was still $77 \%$ of the initial value having a smaller pore diameter $(0.22 \mu \mathrm{m})$. Nevertheless, adherence of the $\mathrm{TiO}_{2}$ layer was compromised at higher temperatures. The required thicknesses of Pd to obtain complete coverage via ELP were $9 \mu \mathrm{m}, 14 \mu \mathrm{m}$ and $23 \mu \mathrm{m}$ for $\mathrm{TiO}_{2}, \mathrm{ZrO}_{2}$ and YSZ, respectively. Permeance values of the composite membranes at $500{ }^{\circ} \mathrm{C}$ and a pressure difference of 0.5 bar are reported in Table 8, where the best results were obtained for a $\mathrm{Pd} / \mathrm{TiO}_{2} / \mathrm{PSS}$ with $1.91 \times 10^{-3} \mathrm{~mol} \cdot \mathrm{m}^{-2} \cdot \mathrm{s}^{-1} \cdot \mathrm{Pa}^{-0.5}$ with an ideal $\mathrm{H}_{2} / \mathrm{N}_{2}$ selectivity of $\sim 800$. Other composites showed a lower permeance related to the thicker Pd layers, however, the selectivity of both was around $\sim 200$ Tardini et al. [123] compared the effect of $\mathrm{ZrO}_{2}$ and $\mathrm{Al}_{2} \mathrm{O}_{3}$ as an interdiffusion barrier layer on top of PSS, requiring at least a $10 \mu \mathrm{m}$ thick selective layer $\left(\mathrm{Pd}_{92} \mathrm{Au}_{8}\right)$ for $\mathrm{ZrO}_{2}$ modified porous stainless steel support, while a double thickness was required to deposit a defect-free membrane on top of an $\mathrm{Al}_{2} \mathrm{O}_{3}$ 
modified porous support. Moreover, $4 \%-5 \%$ Fe was detected in the PdAu layer deposited on top of an $\mathrm{Al}_{2} \mathrm{O}_{3}$ modified composite due to interdiffusion of elements from the metallic support, because the ceramic layer was too thin and did not cover the metallic support adequately. In terms of permeation rates, the Korea Institute of Energy Research (KIER) reported that $\mathrm{ZrO}_{2}$ deposited by sputtering was preferred as interdiffusion barrier layer on top of porous nickel supports (PNS), since the measured nitrogen flux was 1.5 times higher when compared with $\mathrm{Al}_{2} \mathrm{O}_{3}$ interdiffusion barrier layers. Larger pore sizes were observed by SEM on the $\mathrm{ZrO}_{2}$ supported surface [131]. Chotirach and co-workers [142] reported that a $0.5 \mu \mathrm{m}$ thick $\mathrm{ZrO}_{2}$ (used as a barrier) deposited by DC magnetron sputtering and oxidized in air, reduced the diffusion of elements from the support to the selective layer. The same authors also deposited $\mathrm{ZrN}$, however larger hydrogen permeation rates were obtained with $\mathrm{ZrO}_{2}$.

Wang et al. [143] used a colloidal zirconium oxide (colloid size around 3 media grade at a pH 7.6) solution into PSS with media grade of $0.2 \mu \mathrm{m}$. The deposition was repeated five times until a constant separation factor between $\mathrm{He} / \mathrm{Ar}$ was obtained. A pinhole-free Pd layer of $10 \mu \mathrm{m}$ was deposited by ELP exhibiting $6.86 \times 10^{-4} \mathrm{~mol} \cdot \mathrm{m}^{-2} \cdot \mathrm{s}^{-1} \cdot \mathrm{Pa}^{-0.5}$ as permeance at $550{ }^{\circ} \mathrm{C}$ and a pressure difference of $100 \mathrm{kPa}$. Argon was detected during the heating process indicating the formation of defects.

Gao and co-workers [144] deposited Pd-doped zirconia sol by dip coating onto PSS substrates ( $0.2 \mu \mathrm{m}$ media grade) followed by co-deposition of pinhole-free $\mathrm{Pd}_{84} \mathrm{Cu}_{15}$ layers of $5 \mu \mathrm{m}$ by electroless plating. The thicknesses of the $\mathrm{ZrO} 2$ layers were not reported. Homogeneity of the selective layer was confirmed by XPS analysis after a thermal treatment at $480{ }^{\circ} \mathrm{C}$ in $\mathrm{H}_{2}$ for $5 \mathrm{~h}$. The measured hydrogen flux at $480{ }^{\circ} \mathrm{C}$ and a pressure difference between the retentate and permeated side of $250 \mathrm{kPa}$ was $0.6 \mathrm{~mol} \cdot \mathrm{m}^{-2} \cdot \mathrm{s}^{-1}$ corresponding to a permeance of $2.19 \times 10^{-3} \mathrm{~mol} \cdot \mathrm{m}^{-2} \cdot \mathrm{s}^{-1} \cdot \mathrm{Pa}^{-0.5}$.

To select the powder that provides smaller surface roughness, the research group from Universidad Rey Juan Carlos (URJC) [125] studied and reported the porosity and roughness of the intermediate layer of different commercial YSZ particles obtained by atmospheric plasma spraying (APS) on top of PSS with media grade of $0.1 \mu \mathrm{m}$.

The initial porosity of the support $(20 \%)$ was reduced to $2 \%$ by the intermediate YSZ layer made by Nanox s4007 and AMDRY 6600. The selected YSZ powder was Nanox s4007 since the deposited $100 \mu \mathrm{m}$ thick layer presented the smallest average roughness ( $\mathrm{Ra}=2.89 \mu \mathrm{m})$ compared to the value measured with AMDRY $6600(\mathrm{Ra}=4.73 \mu \mathrm{m})$ and original supports $(\mathrm{Ra}=5.87 \mu \mathrm{m})$. The differences in surface quality of the original porous support and YSZ-modified with Nanox s4007 are shown in Figure 7. It is clear from the pictures that the layer completely covered the support and at the same time a reduction in pore size was achieved. A $13.6 \mu \mathrm{m}$ thick Pd-membrane was deposited by ELP onto YSZ/PSS. No nitrogen leaks were detected during single gas tests of the Pd-composite membrane, where the best hydrogen flux measured at $400{ }^{\circ} \mathrm{C}$ and a trans-membrane pressure of 2.5 bar was $0.062 \mathrm{~mol} \cdot \mathrm{m}^{-2} \cdot \mathrm{s}^{-1}$. This flux dramatically decreased in the presence of $\mathrm{CO}$ and $\mathrm{CO}_{2}$ during gas mixture tests with $70 \mathrm{~mol} \% \mathrm{H}_{2}$. The initial $\mathrm{H}_{2}$ flux was, however, recovered after removing all gas mixtures, thus the reduction is to be attributed to the very well-known $\mathrm{CO}$ poisoning of the membrane surface [82].
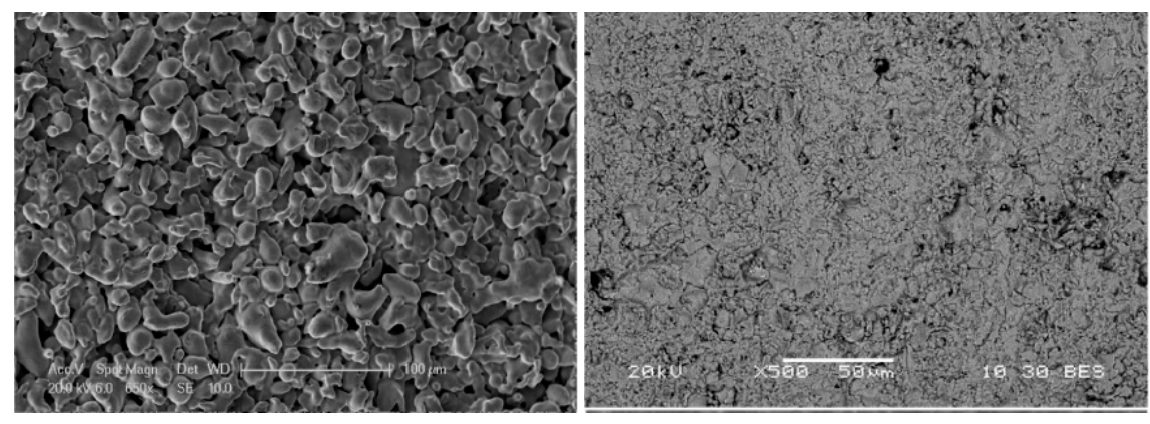

Figure 7. SEM images of original PSS support surface (left) and YSZ intermediate layer obtained with Nanox s4007 (right). Reprinted from [125] with permission from Elsevier. 
Zhang et al. [145] pre-treated PSS (316L) disks with large media grade $(0.5 \mu \mathrm{m})$ by polishing with \#3000 carborundum sandpaper followed by oxidation at $800{ }^{\circ} \mathrm{C}$ during $8 \mathrm{~h}$. The measured nitrogen permeance at room temperature was $3.13 \times 10^{-6} \mathrm{~mol} \cdot \mathrm{m}^{-2} \cdot \mathrm{s}^{-1} \cdot \mathrm{Pa}^{-1}$, which was two orders of magnitude smaller than for the original support. A larger $\mathrm{N}_{2}$ permeance was obtained $\left(1.21 \times 10^{-5} \mathrm{~mol} \cdot \mathrm{m}^{-2} \cdot \mathrm{s}^{-1} \cdot \mathrm{Pa}^{-1}\right)$ with thick YSZ layers of $2.5-3 \mu \mathrm{m}$ deposited directly onto the supports by dip-coating. Diffusion of components from the porous support was suppressed only with YSZ at $700{ }^{\circ} \mathrm{C}$. An $11 \mu \mathrm{m}$ thick Pd layer was deposited onto an YSZ/PSS substrate by ELP technique. The hydrogen permeance of the composite was $1.05 \times 10^{-3} \mathrm{~mol} \cdot \mathrm{m}^{-2} \cdot \mathrm{s}^{-1} \cdot \mathrm{Pa}^{-0.5}$ at $650^{\circ} \mathrm{C}$ and a pressure difference of $\sim 220 \mathrm{kPa}$. The ideal $\mathrm{H}_{2} / \mathrm{N}_{2}$ selectivity was not reported, however $\mathrm{N}_{2}$ was observed at room temperature and $100 \mathrm{kPa}$ of pressure difference $\left(10^{-1} \mathrm{~mol} \cdot \mathrm{m}^{-2} \cdot \mathrm{s}^{-1} \cdot \mathrm{Pa}^{-1}\right)$. On the other hand, a thicker Pd layer $(25 \mu \mathrm{m})$ was deposited onto oxidized PSS, which suffered from intermetallic diffusion at $650{ }^{\circ} \mathrm{C}$, since the hydrogen flux started decreasing after a few $\mathrm{h}$. The authors suggested high atomic vibrations of elements from stainless steel and palladium, since they were exposed to temperatures above their Tamman temperature $\left(316 \mathrm{~L}, 560^{\circ} \mathrm{C} ; \mathrm{Pd}, 640{ }^{\circ} \mathrm{C}\right)$. The hydrogen permeance was measured at $600{ }^{\circ} \mathrm{C}$ and the same pressure difference as for the thinner membrane resulting in one order of magnitude smaller permeance $\left(1 \times 10^{-4} \mathrm{~mol} \cdot \mathrm{m}^{-2} \cdot \mathrm{s}^{-1} \cdot \mathrm{Pa}^{-0.5}\right)$ at the same temperature.

Interdiffusion barriers of mixed $\mathrm{Al}_{2} \mathrm{O}_{3}$-YSZ were deposited on top of Hastelloy $\mathrm{X}(0.2 \mu \mathrm{m}$ media grade) by APS and powder suspension deposition (dip-coating) [132]. The roughnesses for layers deposited by APS were found to be larger than by dip-coating. A 4-5 $\mu \mathrm{m}$ thick PdAg layer was deposited by ELP on top of a modified support with a ceramic interdiffusion layer deposited by dip-coating, and the measured hydrogen permeance was $7.69 \times 10^{-4} \mathrm{~mol} \cdot \mathrm{m}^{-2} \cdot \mathrm{s}^{-1} \cdot \mathrm{Pa}^{-0.5}$ at $400^{\circ} \mathrm{C}$ and $100 \mathrm{kPa}$ pressure difference. The measured $\mathrm{H}_{2} / \mathrm{N}_{2}$ perm-selectivity was over 200,000. A long-term test with this membrane was performed by Medrano et al. [62] during $800 \mathrm{~h}$ in the temperature range of $500-600{ }^{\circ} \mathrm{C}$. The ideal perm-selectivity was maintained over 200,000 during $795 \mathrm{~h}$. Nonetheless, defects started being formed at high operating temperatures $\left(600^{\circ} \mathrm{C}\right)$ and the ideal perm-selectivity dropped to 2650 .

Oxidation of metallic supports allows growth of an Fe-Cr oxide $\left(\mathrm{Cr}_{2} \mathrm{O}_{3}\right)$ layer in order to prevent diffusion of support elements to the selective layer. Ghabiri et al. [122] oxidized a porous stainless steel $316 \mathrm{~L}$ disk (nominal particle retention size of $0.2 \mu \mathrm{m}$ ) in air at $800^{\circ} \mathrm{C}$ for $12 \mathrm{~h}$ before the depositing a $\mathrm{Pd}_{90.2} \mathrm{Ag}_{3.6} \mathrm{Cu}_{6.2}$ layer by electroless plating. A very thick selective layer, $40 \mu \mathrm{m}$, was required to avoid the presence of defects. The thickness and pore size of the grown oxide was not reported. However, it can be expected to be of the order of nanometers with a small reduction of the initial pore size of the supports.

Deposition of a 4 times thinner Pd layer $(10.2 \mu \mathrm{m})$ by electroless plating was achieved by Sanz et al. [54] as the retention size of the used PSS was $0.1 \mu \mathrm{m}$. Since the initial pore size of supports is small, the required thickness for the creation of a defect-free dense layer is decreased. Fe-Cr oxide was obtained at lower temperatures $\left(650^{\circ} \mathrm{C}\right)$ also for $12 \mathrm{~h}$. Again the thickness of the $\mathrm{Fe}-\mathrm{Cr}$ oxide was not reported. The membrane was first tested with pure hydrogen before being used with syngas in a packed-bed membrane reactor. The best permeation results were obtained in pure hydrogen at $400{ }^{\circ} \mathrm{C}$ and a pressure difference between retentate and permeate sides of $2.5 \mathrm{bar}$, obtaining a hydrogen flux of $0.054 \mathrm{~mol} \cdot \mathrm{m}^{-2} \cdot \mathrm{s}^{-1}$ with an infinite ideal perm-selectivity $\left(\mathrm{H}_{2} / \mathrm{N}_{2}\right)$, which indicates that the membrane was completely dense and defect-free.

However, it has also been reported that the generated oxide layer by oxidation in air on top of PSS substrates could not completely suppress intermetallic diffusion, as Samingprai and co-workers found [147]. The authors compared oxidized PSS in air at $450{ }^{\circ} \mathrm{C}$ for $6 \mathrm{~h}$ with $\mathrm{Cr}_{2} \mathrm{O}_{3}$ layers of different thickness obtained by electrodeposition of $\mathrm{Cr}$ followed by oxidation at $700{ }^{\circ} \mathrm{C}$ for $6 \mathrm{~h}$ in air. Intermetallic diffusion was suppressed for a $2 \mu \mathrm{m}$ thick $\mathrm{Cr}_{2} \mathrm{O}_{3}$ layer on top of substrates with an average pore size of $0.1 \mu \mathrm{m}$. The authors deposited Pd onto the modified supports by ELP until a dense film was achieved. 
A defect-free layer was obtained with a $32 \mu \mathrm{m}$ thick layer which exhibited a low permeance due to the large thickness, $5.84 \times 10^{-5} \mathrm{~mol} \cdot \mathrm{m}^{-2} \cdot \mathrm{s}^{-1} \cdot \mathrm{Pa}^{-0.5}$ at $500{ }^{\circ} \mathrm{C}$ and a pressure difference of $100 \mathrm{kPa}$.

Summarizing, smooth surfaces are required in order to deposit a very thin selective layer without compromising the permeation rate. Also, it is well established that the mechanical stability of thin films is improved as they are supported. Chemical compatibility (avoiding interdiffusion of elements from metallic supports) and closer thermal expansion coefficients between the materials is necessary for long-term stability of the membranes.

\subsection{Embrittlement and Sulfur Resistant Membranes}

Hydrogen selective membranes are often made of Pd-alloys. The metals used to alloy the palladium help in decreasing the challenges that can be detrimental for the hydrogen flux and hydrogen purity. The first challenge affecting Pd membranes is the hydrogen embrittlement occurring below $298{ }^{\circ} \mathrm{C}$ and $2 \mathrm{MPa}$ of pressure. Below these critical conditions, the so called $\alpha-\beta$ transition occurs. The $\alpha$-phase appears at low concentrations of hydrogen (solid solution), and the $\beta$-phase is formed at high concentrations of hydrogen (metal hydride). Transformation to the $\beta$-phase results in crystal expansion with an increased lattice parameter, and may cause membrane failure. Characteristic lattice parameters and $\mathrm{Pd} / \mathrm{H}$ ratio of both phases and pure palladium are shown in Table $9[148,149]$.

Table 9. Characteristics of $\mathrm{Pd} / \mathrm{H}$ phases and pure $\mathrm{Pd}[147,148]$.

\begin{tabular}{ccc}
\hline Phase & $\mathbf{P d} / \mathbf{H}$ & Lattice Parameter $(\AA)$ \\
\hline$\alpha$ & $\leq 1 / 0.015$ & $3.889-3.894$ \\
$\beta$ & $\geq 1 / 0.6$ & $\geq 4.025$ \\
Pd-metal & - & 3.889 \\
\hline
\end{tabular}

This problem can be diminished by alloying Pd with elements such as silver. For instance, it has been proven that the durability of $\mathrm{Pd}$ membranes alloyed with $20 \%$ of silver is improved and $\mathrm{H}_{2}$ embrittlement was not observed after cycling hydrogenation/dehydrogenation even at temperatures as low as $100{ }^{\circ} \mathrm{C}$ [150]. Additionally, it has been proven that the hydrogen permeance is improved by $70 \%$ when the silver content reaches $23 \%$ in comparison with pure palladium [151]. McCool et al. [110] investigated the effect of the silver content on membrane embrittlement. Membranes with a lower content of silver $\left(4 \mathrm{wt}\right.$. \%) delaminated at $200{ }^{\circ} \mathrm{C}$ in the presence of hydrogen, whereas membranes with a larger amount of silver (7.8 wt. \%-12.3 wt. \%) delaminated at lower temperatures $\left(150{ }^{\circ} \mathrm{C}\right)$. The same authors did not observe peel-off of the membranes at $150{ }^{\circ} \mathrm{C}$ when using higher contents of silver.

Furthermore, alloying palladium with other noble and non-noble metals could enhance the permeation rate, reduce the temperature of phase transition and improve the sulfur resistance [152]. The largest permeance improvement has been reported when alloying Pd with yttrium in a weight content from $6.6 \%$ to $10 \%$, exhibiting a hydrogen flux $350 \%-375 \%$ larger than for pure palladium [151].

When integrating the membranes in membrane reactors for steam reforming of different feedstocks $\left(\mathrm{CH}_{4}, \mathrm{CH}_{3} \mathrm{OH}, \mathrm{C}_{2} \mathrm{H}_{5} \mathrm{OH}\right)$, the membrane surface may be exposed surface to gases like $\mathrm{H}_{2} \mathrm{~S}$ and $\mathrm{CO}$ which react with palladium and/or other metals, poisoning the membrane and decreasing the permeation rate.

As far as the $\mathrm{CO}$ poisoning is concerned, it has been demonstrated that $\mathrm{CO}$ adsorbs on the palladium surface occupying the same sites where hydrogen adsorbs before splitting [82]. The poisoning of the membrane occurs at very low concentrations of $\mathrm{CO}$, and when the surface coverage reaches a certain value, the additional $\mathrm{CO}$ in the mixture only contributes to the dilution of the hydrogen. The effect of $\mathrm{CO}$ is well studied, and it is evident that this poisoning decreases with temperature (as the adsorption is decreased at higher temperatures). Moreover, the membrane can be completely regenerated by removing the $\mathrm{CO}$, and the $\mathrm{CO}$ poisoning effect can be easily taken 
into account in models by modifying Sieverts' equation with a Langmuir type sorption term [153]. On the other hand, poisoning with $\mathrm{H}_{2} \mathrm{~S}$ is a more serious problem for Pd-based membranes. First of all, the poisoning with $\mathrm{H}_{2} \mathrm{~S}$ occurs at much lower concentrations (at ppm levels). Secondly, the poisoning occurs via a reaction and a palladium sulfide layer is produced at the membrane surface that in many cases cannot be removed, so that the poisoning is not completely reversible. Alloying Pd with other metals can also help in decreasing the poisoning effects of the contaminant. Pd membranes alloyed with Ag have been shown to be more resistant to hydrogen inhibition by CO [154,155]. Resistance to $\mathrm{H}_{2} \mathrm{~S}$ poisoning is improved by alloying palladium with noble metals. The most common alloys which present poisoning resistance are $\mathrm{Pd}-\mathrm{Cu}$ [156] and $\mathrm{Pd}-\mathrm{Au}$ [127] alloys.

Presence of gold reduces embrittlement problems associated with the hydride phase transformation and improves resistance to sulfur poisoning due to the large heat of formation of $\mathrm{Au}_{2} \mathrm{~S}\left(+230.5 \mathrm{~kJ} \cdot \mathrm{mol}^{-1}\right)$ compared with other elements of the periodic table, which possess a negative value of heat formation [152].

Gade et al. [157] prepared PdAu membranes with different gold contents (0-20 wt. \%), where Au was sequentially deposited on top of Pd layers by EDTA-free electroless plating, followed by an annealing treatment at $750{ }^{\circ} \mathrm{C}$ for $20 \mathrm{~h}$ in order to create an homogeneous alloy. However, heterogeneous layers were obtained by this sequential deposition of Pd and $\mathrm{Au}$ [157]. Deposition of gold happens indeed on top of palladium and not on gold surfaces. When the desired amount of gold is larger than the maximum deposited by electroless plating, extra metal was electrodeposited using a commercial electroplating bath from Caswell Incorporation. Different layers were deposited with an increasing content of gold. The best hydrogen permeance was measured for a $5.4 \mu \mathrm{m}$ thick membrane with $4.1 \%$ of $\mathrm{Au}, 2.05 \mathrm{wt}$. \%) $10^{-3} \mathrm{~mol} \cdot \mathrm{m}^{-2} \cdot \mathrm{s}^{-1} \cdot \mathrm{Pa}^{-0.5}$ before thermal treatment in air with an ideal selectivity $\mathrm{H}_{2} / \mathrm{N}_{2}$ of 2500 . However, the permeability of the obtained $\mathrm{PdAu}$ layers was lower than the ones obtained by other techniques such as physical vapor deposition or cold-work. This is most probably due to the poor interdiffusion of Pd and gold during annealing in a nitrogen atmosphere, especially when the amount of gold is increased [157]. To better understand this, different annealing processes were tested for a Pd-Au foil with $7.8 \mathrm{wt}$. \% gold under a nitrogen stream for $20 \mathrm{~h}$. XRD diffractograms revealed that after thermal treatment at $400{ }^{\circ} \mathrm{C}$ the $\mathrm{Pd}$ and Au were not perfectly alloyed. However, a completely alloyed layer was obtained when the temperature was increased to $750{ }^{\circ} \mathrm{C}$. Okazaki et al. [158] tested a $24 \mathrm{~h}$ of annealing treatment in hydrogen at $750{ }^{\circ} \mathrm{C}$ and obtained full homogenization of a $\mathrm{Pd}_{92} \mathrm{Au}_{8}$ alloy deposited sequentially onto an $\mathrm{Al}_{2} \mathrm{O}_{3}$ porous substrate with an average pore size of $150 \mathrm{~nm}$. Meléndez et al. [159] reported a $\operatorname{Pd}_{79} \mathrm{Ag}_{16} \mathrm{Au}_{5}$ homogeneous membrane after an annealing treatment at $550{ }^{\circ} \mathrm{C}$ for at least $8 \mathrm{~h}$. The authors co-deposited a $\sim 4 \mu \mathrm{m}$ PdAg layer on top of an $\alpha-\mathrm{Al}_{2} \mathrm{O}_{3}$ support followed by annealing at $550{ }^{\circ} \mathrm{C}$ for $2 \mathrm{~h}$. Finally, gold was added to this membrane at $98{ }^{\circ} \mathrm{C}$ and annealed at $550{ }^{\circ} \mathrm{C}$ to create the alloy. Different tests were performed with different annealing times. The XRD patterns of the samples annealed for 3 and $6 \mathrm{~h}$, showed the peaks corresponding to $\mathrm{Pd}_{79} \mathrm{Ag}_{16} \mathrm{Au}_{5}$ alloys, while the peak (111) related to $\mathrm{Au}$ disappeared. A homogeneous ternary alloy was observed after 8 and $24 \mathrm{~h}$ of annealing and this was confirmed by ICP analysis. The measured hydrogen permeance at $300{ }^{\circ} \mathrm{C}$ and 1 bar of pressure difference was $1.12 \times 10^{-6} \mathrm{~mol} \cdot \mathrm{m}^{-2} \cdot \mathrm{s}^{-1} \cdot \mathrm{Pa}^{-0.5}$ with a $\mathrm{H}_{2} / \mathrm{N}_{2}$ ideal separation factor of $\sim 8800$.

Hatlevik and co-workers [128] developed a defect-free $2.3 \mu \mathrm{m}$ thick $\mathrm{Pd}_{95} \mathrm{Au}_{5}$ membrane which possesses a high hydrogen flux $\left(1.01 \mathrm{~mol} \cdot \mathrm{m}^{-2} \cdot \mathrm{s}^{-1}\right)$ and ultra-high $\mathrm{H}_{2} / \mathrm{N}_{2}$ ideal perm-selectivity $(82,000)$ at $400{ }^{\circ} \mathrm{C}$ and 1.38 bar pressure difference. The $\mathrm{Pd}_{95} \mathrm{Au}_{5}$ thin layer was deposited by sequential electroless plating followed by annealing to produce a homogeneous alloy on top of a commercial porous stainless steel support with an interdifussion barrier of $50 \mu \mathrm{m}$ thick YSZ deposited by Pall Corporation.

Tardini et al. developed defect-free PdAu membranes by sequential electroless plating on top of $\mathrm{Al}_{2} \mathrm{O}_{3}$ or $\mathrm{ZrO}_{2}$ modified porous stainless steel [123]. A $12 \mu \mathrm{m}$ thick $\mathrm{Pd}_{92} \mathrm{Au}_{8}$ selective layer (annealed at $500{ }^{\circ} \mathrm{C}$ for $120 \mathrm{~h}$ in hydrogen) showed its highest hydrogen flux of $0.16 \mathrm{~mol} \cdot \mathrm{m}^{-2} \cdot \mathrm{s}^{-1}$ at $450{ }^{\circ} \mathrm{C}$ and a pressure difference of $100 \mathrm{kPa}$, with a calculated ideal $\mathrm{H}_{2} / \mathrm{N}_{2}$ perm-selectivity above 10,000 . 
The asymmetric membrane was tested for $250 \mathrm{~h}$ in hydrogen $(120 \mathrm{~h}$ at $10 \mathrm{kPa}$ and the last $130 \mathrm{~h}$ at $100 \mathrm{kPa}$ ) showing a good stability of the membrane at temperatures between 400 and $500{ }^{\circ} \mathrm{C}$. No experiments in the presence of $\mathrm{H}_{2} \mathrm{~S}$ were reported by the authors.

$\mathrm{A} \mathrm{Pd}_{97} \mathrm{Au}_{3}$ thin membrane deposited by sputtering using radiofrequency (RF) and direct current (DC) for $\mathrm{Au}$ and $\mathrm{Pd}$ deposition respectively, was reported by KIER (Korea Institute of Energy Research) [131]. A $200 \mathrm{~nm}$ interdiffusion barrier $\left(\mathrm{ZrO}_{2}\right.$ or $\left.\mathrm{Al}_{2} \mathrm{O}_{3}\right)$ was sputtered on top of an in-house Ni disk-shaped porous support. The Ni-support modified with $\mathrm{ZrO}_{2}$ was selected due to the larger nitrogen permeation flux. A $3 \mu \mathrm{m} \mathrm{Pd} / 0.05 \mu \mathrm{m}$ Au layer was deposited followed by a thermal treatment to alloy the two metals. The best results were obtained at $450{ }^{\circ} \mathrm{C}$ and $2000 \mathrm{kPa}$ pressure difference, where the measured hydrogen flux and selectivity were $4.07 \mathrm{~mol} \cdot \mathrm{m}^{-2} \cdot \mathrm{s}^{-1}$ and 2000 , respectively. For lower hydrogen pressure differences, a higher selectivity was achieved, up to 5000 at $100 \mathrm{kPa}$. The XRD pattern after hydrogen measurement revealed PdAu alloy peaks which were not presented on the diffractogram of the fresh membrane. However, SEM-EDX on the membrane cross section showed higher concentrations of gold close to the interdiffusion barrier, which proved that homogeneity of the selective layer is not completely obtained.

$\mathrm{H}_{2} \mathrm{~S}$ poisoning of $\mathrm{Pd}$ is also reduced by the introduction of $\mathrm{Cu}$ into the $\mathrm{Pd}$ lattice. Depending on the amount of copper in the alloys, the FCC structure is modified to BCC, which is less resistant to sulfur compounds [160]. Ryi and coworkers prepared a sulfur resistant $7 \mu \mathrm{m}$ thick $\mathrm{Pd}_{93} \mathrm{Cu}_{7}$ layer by magnetron sputtering deposited on top of $\mathrm{CeO}_{2} / \mathrm{PNS}$ (porous nickel support) [106]. First, the PNS surface was modified with alumina particles $(300 \mathrm{~nm})$ by wet impregnation of an aluminum nitrate solution followed by calcination at $500{ }^{\circ} \mathrm{C}$ for $10 \mathrm{~h}$. An even smoother layer made of alumina and ceria was deposited on top of the alumina-modified PNS, employing nanoparticles ceria sol $(<25 \mathrm{~nm})$, using a dip-coating approach followed by calcination at $700{ }^{\circ} \mathrm{C}$ in the presence of hydrogen for $2 \mathrm{~h}$. Knudsen diffusion was suggested for the modified support since the measured ideal perm-selectivity of $\mathrm{H}_{2} / \mathrm{N}_{2}$ was 3.4, which is close to value when Knudsen diffusion is dominating (3.74). The observed $\mathrm{H}_{2}$ / He selectivity for a dense (defect-free) layer was above 50,000 and the measured hydrogen flux at $500{ }^{\circ} \mathrm{C}$ and a pressure difference of $400 \mathrm{kPa}$ was $0.28 \mathrm{~mol} \cdot \mathrm{m}^{-2} \cdot \mathrm{s}^{-1}$.

Gharibi et al. [122] prepared novel $\mathrm{Pd}_{90.2} \mathrm{Ag}_{3.6} \mathrm{Cu}_{6.2}$ membranes by sequential ELP, which kept the hydrogen flux constant even after exposing them to $5 \mathrm{ppm} \mathrm{H}_{2} \mathrm{~S}$ in a hydrogen stream. On the other hand, the authors demonstrated that binary PdAg membranes suffered a $15 \%$ reduction in the initial hydrogen flux due to sulfur poisoning. A Pd-Ag-Pd layer sequentially deposited was annealed at $500{ }^{\circ} \mathrm{C}$ and followed by the deposition of a PdCu bilayer and finally annealed at $480{ }^{\circ} \mathrm{C}$ in order to form the desired ternary alloy. The membrane thickness was $40 \mu \mathrm{m}$ where only $0.5 \mu \mathrm{m}$ was $\mathrm{Cu}$. SEM-EDX of the cross-section revealed a lower content in silver in the first $7 \mu \mathrm{m}$ of the selective layer (where the PdCu bilayer was deposited). Copper was not detected at a depth larger than $7 \mu \mathrm{m}$, so there was not a complete alloy formed between the three elements. The highest hydrogen flux was measured at $280{ }^{\circ} \mathrm{C}$ and $90 \mathrm{kPa}$ of difference pressure (using pure hydrogen as feed) and was $0.054 \mathrm{~mol} \cdot \mathrm{m}^{-2} \cdot \mathrm{s}^{-1}$ and the obtained $\mathrm{H}_{2} / \mathrm{N}_{2}$ ideal perm-selectivity was around 700 .

Zhao et al. [161] observed that total hydrogen flux recovery is possible for $\mathrm{Pd}_{81} \mathrm{Cu}_{19}$ at $500{ }^{\circ} \mathrm{C}$ after being exposed to 7 and 35 ppm of $\mathrm{H}_{2} \mathrm{~S}$. During inhibition with $\mathrm{H}_{2} \mathrm{~S}$, reduction of defects was found (i.e., largest $\mathrm{H}_{2} / \mathrm{N}_{2}$ perm-selectivity). This effect might be related to sulfur segregation at the grain boundaries [162]. However, during regeneration, nitrogen leaks doubled and the selectivity halved (from 2369 to 1194) compared with the initial values before poisoning with hydrogen sulfide [161]. The same authors reported [163] that addition of silver (5, 10 and $19 \mathrm{wt}$. \%) to the PdCu alloy increased the inhibition of the hydrogen flux through the membrane, when it is exposed to $\mathrm{H}_{2} \mathrm{~S}$. As a conclusion, sulfide formation is enhanced as the concentration of silver is increased in the ternary alloy. Membranes with $10 \mathrm{wt}$. \% of silver showed in a XRD pattern the formation of $\mathrm{Pd}_{4} S$ and $\mathrm{Ag}_{5} \mathrm{Pd}_{10} \mathrm{~S}$ in the presence of $100 \mathrm{ppm} \mathrm{H}_{2} \mathrm{~S}$ at $500{ }^{\circ} \mathrm{C}$. 
In 2015, Nayebossadri et al. [164] reported that the introduction of zirconium traces into PdCu alloys provides structural stability at high temperatures. After exposure to $1000 \mathrm{ppm} \mathrm{H}_{2} \mathrm{~S}$ at $450{ }^{\circ} \mathrm{C}$ for $14 \mathrm{~h}$, the hydrogen flux of $\mathrm{Pd}_{65.1} \mathrm{Cu}_{34.9}$ and $\mathrm{Pd}_{61} \mathrm{Cu}_{37.2} \mathrm{Zr}_{1.8}$ were reduced by $80 \%$ and $60 \%$, respectively.

In a study performed by Braun and co-workers [124], Au was introduced into different PdAg alloys by electroless plating with a similar deposition strategy as was explained for the PdAgCu membranes. An oxidized stainless steel 316L disk was modified with $\mathrm{ZrO}_{2}$ deposited by dip-coating assisted by vacuum. After deposition of binary and ternary alloys, a long annealing process (72-120 h) was carried out at $500-600{ }^{\circ} \mathrm{C}$, resulting in a highly homogeneous alloy along the membrane cross-section, as concluded from SEM-EDS after all experiments. The permeability at a differential pressure of $50 \mathrm{kPa}$ for every alloy $\left(\sim 14 \mu \mathrm{m}\right.$ thickness) were compared at $400{ }^{\circ} \mathrm{C}$ in presence of pure

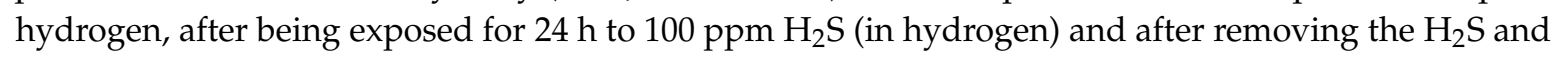
feeding pure hydrogen (see Figure 8).

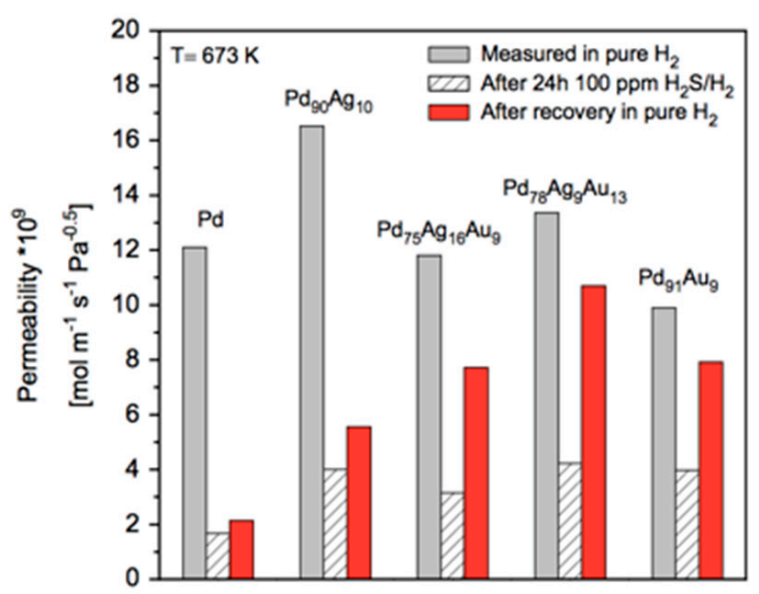

Figure 8. Hydrogen permeability at $400{ }^{\circ} \mathrm{C}(673 \mathrm{~K})$ measured in pure hydrogen (grey bars), after exposure for $24 \mathrm{~h}$ to $100 \mathrm{ppm}$ of $\mathrm{H}_{2} \mathrm{~S}$ (cross lined bars) and after removing $\mathrm{H}_{2} \mathrm{~S}$ and flux recovery (red bars). Reprinted from [124] with permission from Elsevier.

As was expected, in presence of pure hydrogen the highest permeability was measured for $\mathrm{Pd}_{90} \mathrm{Ag}_{10}$ alloy followed by $\mathrm{Pd}_{75} \mathrm{Ag}_{16} \mathrm{Au}_{9}>\mathrm{Pd}_{78} \mathrm{Ag}_{9} \mathrm{Au}_{13}>\mathrm{Pd}_{91} \mathrm{Au}_{9}>\mathrm{Pd}$. In all cases the hydrogen permeability was reduced when introducing $\mathrm{H}_{2} \mathrm{~S}$, however, the most poisoned materials were pure palladium and $\mathrm{Pd}_{90} \mathrm{Ag}_{10}$ alloys, while a lower decrease was observed for layers alloyed only with gold. The larger hydrogen permeability recovery after $\mathrm{H}_{2} \mathrm{~S}$ removal was for the ternary layer with $13 \%$ $\mathrm{Au}$, recovering $80 \%$ of the permeability before exposure to $\mathrm{H}_{2} \mathrm{~S}$ during $24 \mathrm{~h}$ [124]. Lewis et al. [127] prepared a $\mathrm{Pd}_{77} \mathrm{Au}_{23}(5.7 \mu \mathrm{m})$ membrane, deposited by sequential electroless deposition followed by annealing at $500{ }^{\circ} \mathrm{C}$ for five days, which showed good permeation results even in the presence of $20 \mathrm{ppm} \mathrm{H}_{2} \mathrm{~S}$ in hydrogen, where the hydrogen flux decreased only $29 \%$ at $500{ }^{\circ} \mathrm{C}$ and the initial flux was totally recovered after removing $\mathrm{H}_{2} \mathrm{~S}$. A larger reduction, $52 \%$, in the hydrogen permeance was observed for $\mathrm{Pd}_{67} \mathrm{Au}_{20} \mathrm{Ag}_{13}(9.3 \mu \mathrm{m})$ at the same temperature and $\mathrm{H}_{2} \mathrm{~S}$ concentration. When the operating temperature decreased to $400{ }^{\circ} \mathrm{C}$, the reduction in the hydrogen flux was $75 \%$. Both alloys were tested under WGS conditions $\left(49 \% \mathrm{~N}_{2}, 36 \% \mathrm{H}_{2}, 11 \% \mathrm{CO}_{2}, 3 \% \mathrm{H}_{2} \mathrm{O}\right.$ and $\left.1 \% \mathrm{CO}\right)$ in the presence of $20 \mathrm{ppm} \mathrm{H}_{2} \mathrm{~S}$ during $96 \mathrm{~h}$ resulting in similar behaviour. Before the introduction of $\mathrm{H}_{2} \mathrm{~S}$, the $\mathrm{PdAuAg}$ hydrogen permeance at $400{ }^{\circ} \mathrm{C}$ and feed pressure of $1.1 \mathrm{MPa}$ was $\sim 1 \times 10^{-3} \mathrm{~mol} \cdot \mathrm{m}^{-2} \cdot \mathrm{s}^{-1} \cdot \mathrm{Pa}^{-0.5}$, which is slightly larger than for the PdAu layer $\left(\sim 8 \times 10^{-4} \mathrm{~mol} \cdot \mathrm{m}^{-2} \cdot \mathrm{s}^{-1} \cdot \mathrm{Pa}^{-0.5}\right)$. After being exposed for $48 \mathrm{~h}$ to syngas, $\mathrm{H}_{2} \mathrm{~S}(20 \mathrm{ppm})$ was introduced resulting in a reduction of the hydrogen permeance of both membranes. When removing $\mathrm{H}_{2} \mathrm{~S}$, the permeance started recovering and after $24 \mathrm{~h}$, in the presence of syngas, the initial hydrogen flux was reached. 
An interesting study was reported by Lee et al. [165], where a PdAu (1.4 wt. \% Au) membrane was covered with $179 \mathrm{~nm}$ thick $\mathrm{Pt}-\mathrm{ZrO}_{2}$ layer. The PdAu layer was deposited by magnetron sputtering on top of a modified porous nickel support. The authors studied the influence of the deposition of a protective layer onto the selective layer. After been exposed to short periods with $100 \mathrm{ppm}$ of $\mathrm{H}_{2} \mathrm{~S}$, the hydrogen flux of the covered membrane decreased to $92 \%$ of the initial value at $400{ }^{\circ} \mathrm{C}$, while the uncovered membrane decreased till $80 \%$. The perm-selectivity (1650) of the uncovered membrane declined to zero due to formation of big holes. However, no bulk sulfidation was observed. On the other hand, the selectivity of the covered membrane remained almost unchanged (at 2500) after exposure to $\mathrm{H}_{2} \mathrm{~S}$.

Peters et al. [166] reported the influence of exposure of a PdAg layer $(10 \mu \mathrm{m}$ thick foil on top of a microchannel support) to different compositions of $\mathrm{H}_{2} \mathrm{~S}$ in a temperature range of $350-450{ }^{\circ} \mathrm{C}$. The authors observed that inhibition is more influenced by the $\mathrm{H}_{2} \mathrm{~S}$ level and temperature than the exposure time. Up to $30 \%$ and $80 \%$ reduction in $\mathrm{H}_{2}$ flux was observed when the membrane was exposed to $2 \mathrm{ppm}$ and $20 \mathrm{ppm} \mathrm{H}_{2} \mathrm{~S}$, respectively. However, the hydrogen flux was almost completely

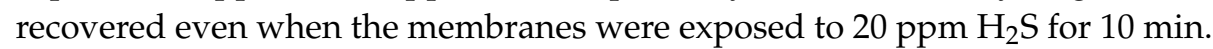

Sulfur resistance of PdAu alloys could be improved by alloying with $\mathrm{Pt}$, as Coulter and co-workers [167] reported in their work. Platinum improves the sulfur tolerance at the expense of the $\mathrm{H}_{2}$ permeability, which is reduced. The authors showed that the hydrogen permeance of self-supported $33.2 \mu \mathrm{m}$ thick $\mathrm{Pd}_{77} \mathrm{Au}_{12} \mathrm{Pt}_{11}$, obtained by magnetron sputtering, was constant during $90 \mathrm{~h}$ in the presence of $20 \mathrm{ppm} \mathrm{H}_{2} \mathrm{~S}$. The recovered hydrogen purity was enhanced from $99.7 \%$ to $100 \%$ when $\mathrm{H}_{2} \mathrm{~S}$ was removed. The measured hydrogen flux after exposure to $\mathrm{H}_{2} \mathrm{~S}$ at $400{ }^{\circ} \mathrm{C}$ and feed pressure of $1.27 \mathrm{MPa}$ was around $0.2 \mathrm{~mol} \cdot \mathrm{m}^{-2} \cdot \mathrm{s}^{-1}$ in the presence of $50 \mathrm{vol} . \% \mathrm{H}_{2}, 30 \mathrm{vol} . \% \mathrm{CO}_{2}$, 19 vol. $\% \mathrm{H}_{2} \mathrm{O}$ and 1 vol. $\% \mathrm{CO}$.

\subsection{Thermal Stability at High Temperature}

For Pd-based membranes, one can distinguish "low" (below $450{ }^{\circ} \mathrm{C}$ ) and "high" (above $450{ }^{\circ} \mathrm{C}$ ) temperature applications. Many industrially relevant applications fall in the "low" temperature class, including high-temperature water-gas-shift. Other applications, such as methane steam reforming, it would be convenient from an efficiency point of view, to work at higher temperatures (in the range of $600{ }^{\circ} \mathrm{C}$ ). At these temperatures a good balance between membrane flux, reaction kinetics and thermodynamic constrains can be found. For these "high" temperature applications, the main issue for the membrane is their thermal stability and sealing.

For Pd thin films it was observed that the high-temperature resistance is somewhat limited due to pinholes/defects formation. As temperature increases, not only the hydrogen diffusion through the membrane lattice is improved, but also Pd diffusion itself is increased, which could result in the formation of micro-holes, which are responsible for the loss of selectivity. Strategies to increase the thermal stability are based on employment of: (i) different synthesis techniques; (ii) alloying the metal with different dopants; and (iii) thermal treatments. It was recently observed by Abu El Hawa and coworkers [129] that alloying Pd with Pt or Ru improves the stability of thin films deposited by ELP. This phenomenon is related to the higher melting points of both alloying elements reducing the diffusivity of each atom along the thin film for membranes with a thickness lower than $5 \mu \mathrm{m}$. Experiments performed at $500-600{ }^{\circ} \mathrm{C}$ showed that the $\mathrm{N}_{2}$ leaks increased faster for $\mathrm{Pd}$ than for alloys with $27 \mathrm{wt}$. \% Pt or $0.3 \mathrm{wt}$. \% Ru. An increase in the nitrogen leakage was measured at $600{ }^{\circ} \mathrm{C}$ for every membrane, but the increase in the $\mathrm{N}_{2}$ leakage was one order of magnitude larger for the pure $\mathrm{Pd}$ membrane. In terms of hydrogen flux and selectivity, the PdPt alloy represented the best choice, since the hydrogen flux was extremely stable after $850 \mathrm{~h}$, while pinhole formation was very low.

In a recent study of the same authors [60], the stability of a $5 \mu \mathrm{m}$ thick Pd-Ru membrane (0.3 wt. \%) was investigated at $580{ }^{\circ} \mathrm{C}$ in a membrane reactor for MSR for $1000 \mathrm{~h}$ (described in Section 2.1). After the experiments, the membrane was cooled down to room temperature to check for leakages at the membrane by submerging the membrane in water and pressurizing the membrane from the lumen 
side with nitrogen to 1 barg. Small bubbles were observed emerging from the membrane surface suggesting the formation of defects during the long term test. The addition of $\mathrm{Ru}$ decreased the $\mathrm{Pd}$ grain growth, so that the grain size did not reach the selective layer thickness. Addition of ruthenium in small quantities ( $<1 \mathrm{wt}$. \%) did not only improve the mechanical properties of the alloy, but also the permeability increased [168]. However, due to their immiscibility, alloys of Pd and Ru with higher amounts than $1 \mathrm{wt}$. \% cannot be obtained at temperatures below $600{ }^{\circ} \mathrm{C}$ [169]. It was recently reported by Didenko and coworkers [170] that the properties of a Pd-In-Ru alloy $(93.5 ; 6 ; 0.5 \mathrm{wt}$. \%) showed an almost three times larger hydrogen flux than $\mathrm{Pd}_{77} \mathrm{Ag}_{23}$.

Applications of membranes for high-temperature processes such as methane steam reforming, which are often also operated at elevated pressures, need supports with higher mechanical stability. While metallic membranes are mechanically more stable than ceramic supported membranes, high-temperature applications require metals that are more stable than stainless steel. This is why often Inconel and Hastelloy supports are being investigated. Porous nickel supports (PNS) represents another possibility, however, all metallic supports still require surface modification to avoid interdiffusion [106].

\subsection{Non-Palladium Membranes}

Palladium and its alloys are not the only materials proposed for the preparation of hydrogen perm-selective membranes. BCC metals with a high hydrogen diffusion rate and lower thermal expansion (closer to alumina, $7.6 \times 10^{-6}{ }^{\circ} \mathrm{C}^{-1}$ ) for hydrogen separation and purification have been studied and fully characterized already more than 20 years ago. Elements from group $\mathrm{V}$ such as $\mathrm{Nb}$, $\mathrm{V}$ and Ta possess higher permeation rates than FCC metals and alloys [171] and their permeation rate increases as the temperature decreases, as shown in Figure 9 [172].

This phenomenon is based on the number and size of octahedral and tetrahedral interstices. The number of tetrahedral interstices per atom in FCC and BCC structures is 2 and 6 respectively, which have a relative size to metallic atom radius of 0.225 and 0.291 , respectively. In case of octahedral sites, the FCC structure gives three times more sites than the BCC structure with larger size, but the tetrahedral sites represent the main path for transport of hydrogen through the crystal structure. Despite the higher permeation rates, the main disadvantage of these metals is the low resistance to embrittlement, which leads to membrane failure after only few $h$ of operation [173].

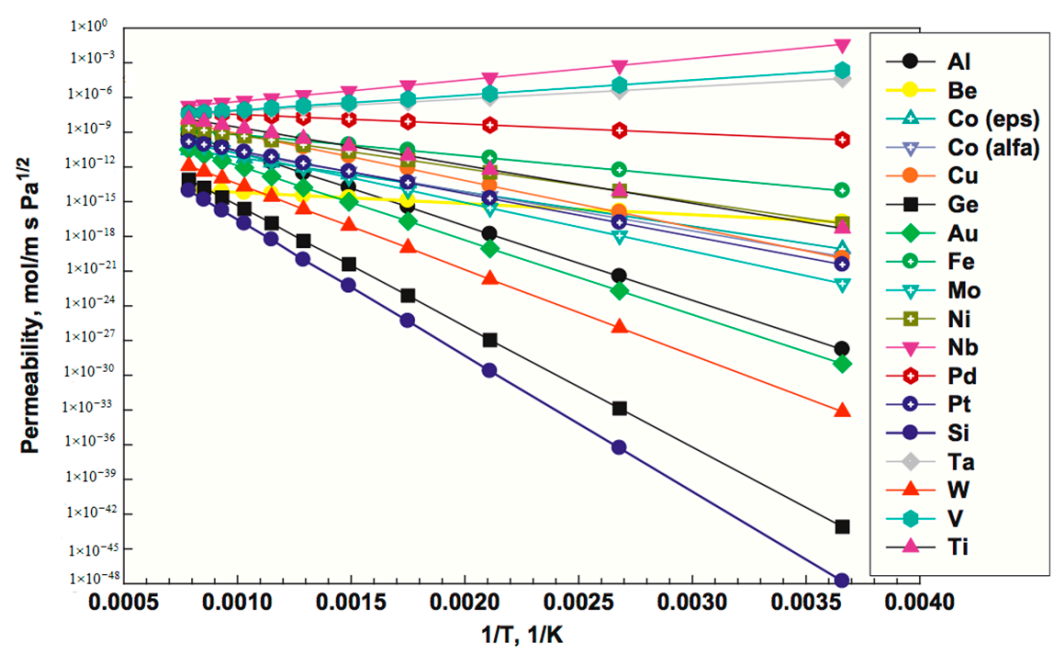

Figure 9. Hydrogen permeability as a function of temperature for different interesting metals. Reprinted from [172] with permission from Elsevier.

Moreover, their surface activation is much larger than for palladium and the surface is easily oxidized in the presence of low oxygen content, even at very low temperatures $\left(\sim 100{ }^{\circ} \mathrm{C}\right)$ [8]. Their susceptibility to oxidation and their low catalytic activity for hydrogen 
dissociation/recombination can be solved by covering their surface with other materials which acts as oxygen barrier and as catalysts for hydrogen. Often the membranes based on these metals were prepared by depositing a very thin layer of palladium on both sides of the membrane [174]. However, the embrittlement problem is not solved and remains a key issue for these membranes. Resistance against embrittlement is enhanced by alloying with metals which can reduce the hydrogen solubility. As suggested by Kim et al. [175], addition of Fe to vanadium decreases the hydrogen solubility and the ductility of the alloy. Additionally, the introduction of aluminium to V-Fe alloys increases the embrittlement resistance, but the hydrogen solubility is dramatically decreased. A V-Fe-Al ternary alloy was prepared by arc melting and $400 \mu \mathrm{m}$ thick disc cut by electrical discharge. In order to promote hydrogen dissociation, palladium was sputtered in both sides (150 $\mathrm{nm})$. The best result was obtained with a ternary alloy $\mathrm{V}_{0.9} \mathrm{Fe}_{0.05} \mathrm{Al}_{0.05}$ at $500{ }^{\circ} \mathrm{C}$ with a permeance of $3 \times 10^{-4} \mathrm{~mol} \cdot \mathrm{m}^{-2} \cdot \mathrm{s}^{-1} \cdot \mathrm{Pa}^{-0.5}$, while the embrittlement resistance was enhanced since (under cooling tests) the membrane only failed when operated close to $175{ }^{\circ} \mathrm{C}$. Better results were obtained by Alimov and co-workers [174] with a $\operatorname{Pd}(2 \mu \mathrm{m})-\mathrm{V}(100 \mu \mathrm{m})-\operatorname{Pd}(2 \mu \mathrm{m})$ composite membrane obtained by depositing palladium by electroless plating onto a vanadium disc. At $400{ }^{\circ} \mathrm{C}$ the hydrogen permeance was $1.8 \times 10^{-3} \mathrm{~mol} \cdot \mathrm{m}^{-2} \cdot \mathrm{s}^{-1} \cdot \mathrm{Pa}^{-0.5}$. In order to minimize the cost of the membrane, Viano et al. [176] replaced the Pd layer at the permeate side with nickel. The flux of the asymmetric membrane composed by $\mathrm{Pd}(500 \mathrm{~nm})-\mathrm{V}(200 \mu \mathrm{m})-\mathrm{Ni}(150 \mathrm{~nm})$ was $65 \%$ of that of a Pd-V-Pd symmetric membrane. On the other hand, $\mathrm{Oh}$ et al. [177] showed that addition of yttrium ( 0.2 at. \%) to a $\mathrm{V}_{85} \mathrm{Ni}_{15} 500 \mu \mathrm{m}$ thick layer enhanced the stability of the membrane at $480{ }^{\circ} \mathrm{C}$. The permeability of the $\mathrm{V}_{85} \mathrm{Ni}_{15}$ layer decreased from $2.4 \times 10^{-7}$ to $1.4 \times 10^{-7} \mathrm{~mol} \cdot \mathrm{m}^{-1} \cdot \mathrm{s}^{-1} \cdot \mathrm{Pa}^{-0.5}$ after $290 \mathrm{~h}$, while the doped layer with yttrium showed a smaller decline, from $2.0 \times 10^{-7}$ to $1.65 \times 10^{-7} \mathrm{~mol} \cdot \mathrm{m}^{-1 \cdot} \mathrm{s}^{-1} \cdot \mathrm{Pa}^{-0.5}$.

Watanabe and co-workers improved the embrittlement resistance as well as the hydrogen permeation flux of niobium by alloying it with $5 \mathrm{~mol} \%$ of $\mathrm{W}$ or $\mathrm{Ru}$ [178]. Paglieri et al. prepared a ternary (Ni-Nb-Zr) and quaternary (Ni-Nb-Zr-Ta) alloy membranes by planar flow casting, which were coated with $500 \mathrm{~nm}$ of palladium by PVD [179]. The thickness of the disk-shaped membranes was around 50-90 $\mu \mathrm{m}$. Those membranes were tested employing porous stainless steel with $0.5 \mu \mathrm{m}$ grade as mechanical support. The authors found that increasing the amount of zirconium enhanced the hydrogen permeation flux, while the embrittlement resistance was reduced as well as the thermal stability. When tantalum is added, the thermal stability was improved at the expense of a decrease in permeability. The higher permeability $\left(1.4 \times 10^{-8} \mathrm{~mol} \cdot \mathrm{m}^{-1} \cdot \mathrm{s}^{-1} \cdot \mathrm{Pa}^{-0.5}\right)$ was obtained for $\left(\mathrm{Ni}_{0.6} \mathrm{Nb}_{0.4}\right)_{0.7} \mathrm{Zr}_{0.3}$ alloy at $450{ }^{\circ} \mathrm{C}$.

\subsection{Atrittion Resistance Membrane}

The durability of the membranes in membrane reactors could be compromised by their contact with catalyst particles. This could even be more stringent when the membranes are integrated in a fluidized bed membrane reactor, as the surface of the selective layer is directly exposed to particles in continuous movement. While very long-term tests should be carried out to assure the stability of the membranes under such conditions, a possible solution to circumvent or decrease erosion problems is to reduce the exposed surface of the membrane. An option for minimization of the membrane area exposed to the fluidized suspension is the use of Cermet membranes, since the exposed area is about $50 \%$ of conventional thin-film membranes. Another possibility to protect the surface from contact with catalyst particles is by covering it with a nanoporous ceramic layer, such as in the pore-filled type membranes prepared by Pacheco Tanaka et al. [111]. A comparison of the permeation characteristics of conventional, Cermet and pore-filled membranes is reported in Table 10.

\subsubsection{Dual-Phase Ceramic-Metallic Membraners (Cermet)}

Ceramic-metallic composite membranes or more commonly called Cermet membranes for hydrogen separation are increasingly attracting the interest of researchers. In 1994 Iwhara et al. [180] reported proton conductivity of $\mathrm{BaCeO}_{3-\delta}$ layers and suggested the possibility to be used as hydrogen 
selective membranes, since these layers exhibit the highest reported proton conductivity reported so far [181]. However, their electronic conductivity is insufficient for achieving high hydrogen permeation rates without applying voltage, as reported by Balachandran et al. [182], because the measured electronic conductivity of $\mathrm{BaCe}_{0.95} \mathrm{Y}_{0.05} \mathrm{O}_{3-\delta}(\mathrm{BCY})$ at $700{ }^{\circ} \mathrm{C}$ was $2.1 \times 10^{-3} \Omega^{-1} \cdot \mathrm{m}^{-1}$, which is 3 times smaller than the protonic conductivity. The same authors found that $\mathrm{SrCeO}_{3-\delta}$ has a lower conductivity than the $\mathrm{BaCeO}_{3-\delta}$ material [183]. Although the conductivity was improved by doping it with larger contents of yttrium, they found that the electronic conductivity was too low for real applications as a hydrogen separation system. Some years later, they increased the electronic conductivity of $\mathrm{BaCe}_{0.8} \mathrm{Y}_{0.2} \mathrm{O}_{3-\delta}(\mathrm{BCY})$ by dispersing a metallic powder in a ceramic matrix, creating a novel metallic-ceramic matrix [184]. The authors suggested that the dispersion of metal helps the hydrogen permeability by creating an additional transport path for hydrogen. When $40 \%$ of the hydrogen transport metal was dispersed in the ceramic (BCY) matrix, the hydrogen permeation flux was enhanced. However, higher permeation rates were obtained when the perovskite structure was replaced with $\mathrm{Al}_{2} \mathrm{O}_{3}$ or $\mathrm{ZrO}_{2}$. A $40 \mu \mathrm{m}$ thick membrane consisting of a mechanically stable ceramic mixed with a hydrogen transport metal (the authors did not specify the employed materials), exhibited a hydrogen flux of $0.108 \mathrm{~mol} \cdot \mathrm{m}^{-2} \cdot \mathrm{s}^{-1}$ at $900{ }^{\circ} \mathrm{C}$ [185]. The same permeation rate was obtained with a $22 \mu \mathrm{m}$ thick $\mathrm{Pd}(50 \mathrm{vol} . \%)-\mathrm{YSZ}$ at $900{ }^{\circ} \mathrm{C}$ in the presence of pure hydrogen at atmospheric pressure [186]. The interconnected ceramic/metal networks (see Figure 10) were prepared by pressing powders into a disc-shape membrane with different thicknesses $(22-200 \mu \mathrm{m})$. The authors observed an inverse linearity of the hydrogen flux with the membrane thickness, which suggests that bulk diffusion was the limiting step for the membrane permeation. The stability of these materials under synthetic syngas $\left(61.3 \% \mathrm{H}_{2}, 8.2 \% \mathrm{CH}_{4}, 11.5 \% \mathrm{CO}, 9 \% \mathrm{CO}_{2}, 0 \% \mathrm{He}\right)$ and $\mathrm{H}_{2} \mathrm{~S}$ was confirmed at $900{ }^{\circ} \mathrm{C}$ after $90 \mathrm{~h}$, presenting an initial decrease in the hydrogen flux which was almost completely recovered after exposure for a couple of $h$ to the synthetic gas with $100 \mathrm{ppm}$ of $\mathrm{H}_{2} \mathrm{~S}$. 
Table 10. Permeation data of some conventional supported membranes, cermet membranes and pore-filled membranes.

\begin{tabular}{|c|c|c|c|c|c|c|c|c|c|c|}
\hline \multicolumn{2}{|r|}{ Membrane Materials } & \multirow[b]{2}{*}{ Preparation Method } & \multirow{2}{*}{$\begin{array}{l}\text { Selective Layer } \\
\text { Thickness }(\mu \mathrm{m})\end{array}$} & \multirow[b]{2}{*}{$\mathrm{T}\left({ }^{\circ} \mathrm{C}\right)$} & \multirow{2}{*}{$\underset{\left(\mathrm{mol} \cdot \mathrm{m}^{-2} \cdot \mathrm{s}^{-1}\right)}{\mathrm{H}_{2} \text { Flux }}$} & \multirow{2}{*}{$\begin{array}{c}\text { Pressure } \\
\text { Difference } \\
\text { (kPa) }\end{array}$} & \multirow[b]{2}{*}{$\mathrm{n}$} & \multirow{2}{*}{$\begin{array}{c}\text { Permeance } \mathrm{H}_{2} \\
\left(\mathrm{~mol} \cdot \mathrm{m}^{-2} \cdot \mathrm{s}^{-1} \cdot \mathrm{Pa}^{-\mathrm{n}}\right)\end{array}$} & \multirow{2}{*}{$\begin{array}{c}\mathrm{H}_{2} / \mathrm{N}_{2} \\
\text { Selectivity }\end{array}$} & \multirow[b]{2}{*}{ Reference } \\
\hline $\begin{array}{c}\text { Porous Support/ } \\
\text { Inter-Diffusion Layer }\end{array}$ & Selective Layer & & & & & & & & & \\
\hline PSS & $\mathrm{Pd}_{77} \mathrm{Ag}_{23}$ (+TT air) & PVD-MS & 2.8 & 400 & 18.43 & 2500 & 0.5 & $1.46 \times 10^{-2}$ & 2900 & [126] \\
\hline$\alpha-\mathrm{Al}_{2} \mathrm{O}_{3}$ & $\mathrm{Pd}_{(90-96)} \mathrm{Au}_{(4-10)}$ & ELP & $\sim 4.5$ & 600 & $\sim 0.8$ & 400 & 0.5 & $\sim 2.0 \times 10^{-3}$ & 1000 & [150] \\
\hline$\alpha-\mathrm{Al}_{2} \mathrm{O}_{3}$ & $\mathrm{Pd}_{79} \mathrm{Ag}_{16} \mathrm{Au}_{5}$ & ELP & $\sim 4$ & 300 & $\sim 0.17$ & 100 & 0.5 & $1.12 \times 10^{-6}$ & $\sim 8800$ & [159] \\
\hline Self-supported & $\mathrm{V}_{0.9} \mathrm{Fe}_{0.05} \mathrm{Al}_{0.05}$ & Arc melting & $400^{\mathrm{a}}$ & 400 & 0.170 & 700 & 0.5 & $3 \times 10^{-4}$ & - & [175] \\
\hline Self-supported & Pd-V-Pd & ELP & $2-100-2$ & 400 & 1.12 & 600 & 0.5 & $1.8 \times 10^{-3}$ & $\infty$ & [174] \\
\hline PSS & $\left(\mathrm{Ni}_{0.6} \mathrm{Nb}_{0.4}\right)_{0.7} \mathrm{Zr}_{0.3}$ & Flow casting & $50-90^{\mathrm{b}}$ & 450 & 0.155 & 627 & 0.5 & $1.4 \times 10^{-8}$ & - & [178] \\
\hline Self-supported & 60 vol. \%. Ta-YSZ & Uniaxial Pressed & 500 & 500 & $8.93 \times 10^{-3}$ & $<200$ & - & - & - & [187] \\
\hline Self-supported & 50 vol. \% Pd-GDC & Isostatically pressed & 282 & 900 & 0.041 & $<100$ & 0.5 & $1.74 \times 10^{-4}$ & - & [188] \\
\hline Self-supported & 50 vol. \% Pd-CZY & Pressed & 500 & 900 & 0.017 & $<100$ & 0.5 & $6.2 \times 10^{-5}$ & - & [189] \\
\hline Self-supported & 50 vol. \% Pd-YSZ & Isostatically pressed & 218 & 900 & 0.024 & $<100$ & - & - & - & [190] \\
\hline Self-supported & 40 vol. $\%$ Ni-BZCY $\left(\mathrm{Ba}\left(\mathrm{Zr}_{0.1} \mathrm{Ce}_{0.7} \mathrm{Y}_{0.2}\right) \mathrm{O}_{3-\delta}\right)$ & Uniaxially pressed & 1000 & 900 & $4.2 \times 10^{-4}$ & - & - & & - & [191] \\
\hline Self-supported & 40 vol. $\% \mathrm{Ni}-\mathrm{BZCY}\left(\mathrm{Ba}\left(\mathrm{Zr}_{0.1} \mathrm{Ce}_{0.7} \mathrm{Y}_{0.2}\right) \mathrm{O}_{3-\delta}\right)$ & Uniaxially pressed & 266 & 900 & $6 \times 10^{-3}$ & $<100$ & 0.5 & $2.17 \times 10^{-5}$ & - & [192] \\
\hline BZCY & 40 vol. \% Ni-BZCY $\left(\mathrm{Ba}\left(\mathrm{Zr}_{0.1} \mathrm{Ce}_{0.7} \mathrm{Y}_{0.2}\right) \mathrm{O}_{3-\delta}\right)$ & Co-pressed & 30 & 900 & $2.4 \times 10^{-3}$ & - & - & - & - & [193] \\
\hline Self-supported & 40 vol. \% Ni-BCY $\left(\mathrm{Ba}\left(\mathrm{Ce}_{0.9} \mathrm{Y}_{0.1}\right) \mathrm{O}_{3-\delta}\right)$ & Cold isostatic pressing & 230 & 800 & $5.88 \times 10^{-3}$ & - & - & - & - & [194] \\
\hline 40 vol. \% Ni-BZCYYb & 40 vol. \% Ni-BZCYYb $\left(\mathrm{Ba}\left(\mathrm{Zr}_{0.1} \mathrm{Ce}_{0.7} \mathrm{Y}_{0.1} \mathrm{Yb}_{0.1}\right) \mathrm{O}_{3-\delta}\right)$ & Particle suspension coating & 44 & 900 & $8.33 \times 10^{-3}$ & - & - & - & - & [195] \\
\hline 40 vol. \% Ni-BCTb & 40 vol. $\% \mathrm{Ni}-\mathrm{BCTb}\left(\mathrm{BaCe}_{0.95} \mathrm{~Tb}_{0.05} \mathrm{O}_{3-\delta}\right)$ & Uniaxial pressing & 90 & 850 & 0.068 & - & - & - & - & [196] \\
\hline$\alpha-\mathrm{Al}_{2} \mathrm{O}_{3}$ & 60 vol. \% Pd-YSZ & Paste-painting ${ }^{\circ}$ & 18 & 900 & 0.387 & $<100$ & - & - & - & [197] \\
\hline$\alpha-\mathrm{Al}_{2} \mathrm{O}_{3}$ & $\mathrm{Pd} / \gamma-\mathrm{Al}_{2} \mathrm{O}_{3}$ & Pore-filled & $4-5$ & 300 & 0.55 & 400 & - & - & 1000 & [111] \\
\hline$\alpha-\mathrm{Al}_{2} \mathrm{O}_{3}$ & $\mathrm{Pd} / \mathrm{YSZ}-\gamma-\mathrm{Al}_{2} \mathrm{O}_{3}$ & Pore-filled & 3.23 & 500 & 0.616 & 500 & - & - & 350 & [117] \\
\hline$\alpha-\mathrm{Al}_{2} \mathrm{O}_{3}$ & $\mathrm{Pd} / \gamma-\mathrm{Al}_{2} \mathrm{O}_{3}$ & CVD & 10 & 300 & $\sim 0.265$ & 200 & 0.5 & $1.3 \times 10^{-3}$ & $883^{\mathrm{a}}$ & [198] \\
\hline$\alpha-\mathrm{Al}_{2} \mathrm{O}_{3}$ & $\mathrm{Pd} / \gamma-\mathrm{Al}_{2} \mathrm{O}_{3}$ & Pore-filled & 10 & 300 & $\sim 0.095$ & 200 & 0.5 & $4.05 \times 10^{-4}$ & $176^{\mathrm{b}}$ & [198] \\
\hline$\alpha-\mathrm{Al}_{2} \mathrm{O}_{3}(\mathrm{HF})$ & Pd-encapsulated (M-E) & Pore-filled & 1.1 & 370 & 0.26 & 300 & - & - & 3800 & [199] \\
\hline$\alpha-\mathrm{Al}_{2} \mathrm{O}_{3}(\mathrm{HF})$ & Pd-encapsulated nanopore (M-EN) & Pore-filled & 1.6 & 370 & 0.25 & 300 & - & - & 8750 & [199] \\
\hline$\alpha-\mathrm{Al}_{2} \mathrm{O}_{3}(\mathrm{HF})$ & Pd-nanopore $(\mathrm{M}-\mathrm{N})$ & Pore-filled + thin layer & 2.6 & 370 & 0.13 & 300 & - & - & 550 & [199] \\
\hline$\alpha-\mathrm{Al}_{2} \mathrm{O}_{3}(\mathrm{HF})$ & Pd-nanopore & Pore-filled + thin layer & 4 & 400 & 0.56 & 50 & - & - & 6600 & [200] \\
\hline$\alpha-\mathrm{Al}_{2} \mathrm{O}_{3}$ & $\mathrm{Pd} / \mathrm{YSZ}-\gamma-\mathrm{Al}_{2} \mathrm{O}_{3}$ & Pore-filled & $\sim 2$ & 550 & $9.04 \times 10^{-3}$ & 50 & - & - & 50 & [201] \\
\hline$\alpha-\mathrm{Al}_{2} \mathrm{O}_{3}$ & $70 \% \mathrm{Pd}-30 \% \mathrm{ZrO}_{2}$ & Pore-filled & $\sim 0.215$ & 320 & 0.25 & 200 & - & - & & [202] \\
\hline$\alpha-\mathrm{Al}_{2} \mathrm{O}_{3}$ & $\mathrm{Pd} / \gamma-\mathrm{Al}_{2} \mathrm{O}_{3}$ & Pore-filled & $(8-10)$ & 500 & & 50 & 1 & $1.20 \times 10^{-6}$ & 10,000 & [203] \\
\hline
\end{tabular}

Pore-filled

320
500

$1.20 \times 10^{-6}$

10,000 Then hydrogen permeance is $1.32 \times 10^{-6} \mathrm{~mol} \cdot \mathrm{m}^{-2} \cdot \mathrm{s}^{-1} \cdot \mathrm{Pa}^{-1}$; ${ }^{\mathrm{b}}$ Recalculated value. $\mathrm{N}_{2}$ permeance: $2.7 \times 10^{-9} \mathrm{~mol} \cdot \mathrm{m}^{-2} \cdot \mathrm{s}^{-1} \cdot \mathrm{Pa}^{-1}$ (Table 1 of reference). Hydrogen flux at $200 \mathrm{kPa}$ of pressure difference: $\sim 0.095 \mathrm{~mol} \cdot \mathrm{m}^{-2} \cdot \mathrm{s}^{-1}$. Then hydrogen permeance is $4.75 \times 10^{-7} \mathrm{~mol} \cdot \mathrm{m}^{-2} \cdot \mathrm{s}^{-1} \cdot \mathrm{Pa}^{-1}$ 


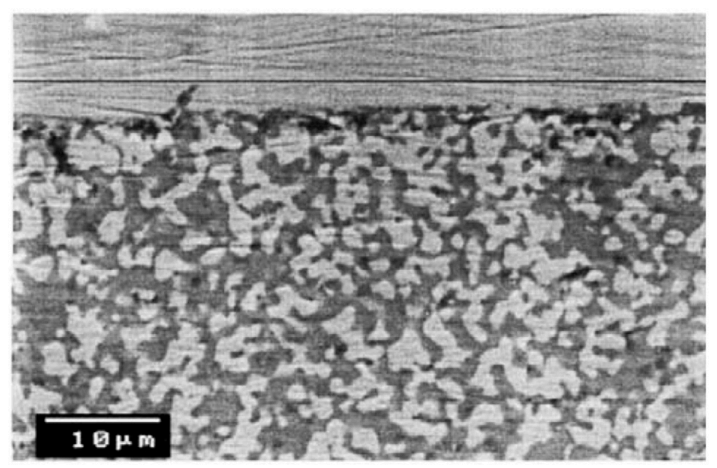

Figure 10. Cross section SEM image of Pd-YSZ membrane after exposure to $\mathrm{H}_{2} \mathrm{~S}$ at $600{ }^{\circ} \mathrm{C}$. Reprinted from [186] with permission from Elsevier.

In 2011 Park et al. [187] employed Ta (60 vol. \%) as metallic phase dispersed in YSZ since tantalum is cheaper than noble metals like $\mathrm{Ag}, \mathrm{Au}, \mathrm{Pd}$ or $\mathrm{Pt}$ and exhibit higher permeation rates. However, a critical point of this metal is its instability under oxygen and hydrogen containing atmospheres, which react at low temperatures with the membrane decreasing its permeation properties. Tantalum hydride was formed during permeation tests resulting in membrane failure. Before failure, the measured hydrogen flux was $8.93 \times 10^{-3} \mathrm{~mol} \cdot \mathrm{m}^{-2} \cdot \mathrm{s}^{-1}$ at $500{ }^{\circ} \mathrm{C}$ in the presence of pure hydrogen (feed pressure 2 bar) for a membrane with a thickness of $500 \mu \mathrm{m}$.

In 2011 other research groups reported the preparation of cermet membranes dispersing $\mathrm{Pd}$ in fluorite type GDC [188] and perovskite type $\mathrm{CaZr}_{0.9} \mathrm{Y}_{0.1} \mathrm{O}_{3-\delta}$ (CZY) [189]. Proton conducting CZY was chosen, since it is thermodynamically stable in $\mathrm{CO}_{2}$-containing atmospheres and mixed with electron and hydrogen conducting palladium powder. The highest hydrogen flux, $0.017 \mathrm{~mol} \cdot \mathrm{m}^{-2} \cdot \mathrm{s}^{-1}$, was obtained for a $500 \mu \mathrm{m}$ thick 50 vol. \% Pd-50 vol. \% CZY membrane at $900{ }^{\circ} \mathrm{C}$ using a feed gas with $80 \%$ hydrogen. This value is higher than cermet membranes based on $\mathrm{Al}_{2} \mathrm{O}_{3}$ and $\mathrm{YSZ}$ as these showed lower hydrogen fluxes at the same operating conditions. The hydrogen flux for $\mathrm{Pd} / \mathrm{Al}_{2} \mathrm{O}_{3}$ and $\mathrm{Pd} / \mathrm{YSZ}$ membranes were $1.41 \times 10^{-2}$ and $8.18 \times 10^{-3} \mathrm{~mol} \cdot \mathrm{m}^{-2} \cdot \mathrm{s}^{-1}$, respectively. In 2013 the same authors prepared a thinner $(218 \mu \mathrm{m}) \mathrm{Pd} / \mathrm{YSZ}$ membranes for water splitting [190], showing a higher hydrogen flux $\left(0.024 \mathrm{~mol} \cdot \mathrm{m}^{-2} \cdot \mathrm{s}^{-1}\right)$ from $\mathrm{H}_{2}-\mathrm{H}_{2} \mathrm{O}$ mixture with a steam partial pressure below $1 \mathrm{~atm}$. Although the thermal stability is enhanced and the YSZ does not form the corresponding oxysulfide in $\mathrm{H}_{2} \mathrm{~S}$ environment, the Pd metal reacts easily in the presence of $300 \mathrm{ppm}_{2} \mathrm{~S}$ forming $\mathrm{Pd}_{4} \mathrm{~S}$ and decreasing the hydrogen permeation flux. Luckily, when introducing steam (even as sweep gas), it reacts with $\mathrm{Pd}_{4} \mathrm{~S}$ producing $\mathrm{SO}_{2}$, which "regenerates" the Pd so that the permeation flux can be recovered.

Results obtained with Pd/CZY membranes [189] where improved when the perovskite phase was replaced by GDC $\left(\mathrm{Ce}_{0.8} \mathrm{Gd}_{0.2} \mathrm{O}_{2-\delta}\right)$ [188]. GCD is also known as Gd-doped ceria or GCO (gadolinium cerium oxide). $\mathrm{Pd} / \mathrm{GDC}$ operating under the same conditions as Pd/CZY presented a hydrogen flux of $0.041 \mathrm{~mol} \cdot \mathrm{m}^{-2} \cdot \mathrm{s}^{-1}$.

As was explained before, the proton conductivity of $\mathrm{BCY}$ is one of the highest reported. Nevertheless, degradation of this material occurs in the presence of $\mathrm{CO}_{2}$ and $\mathrm{H}_{2} \mathrm{O}$ forming cerium oxide and barium carbonate [204], as well as $\mathrm{BaCeO}_{3}$ peroskite [205]. The chemical stability of yttrium-doped barium zirconate is larger than $\mathrm{BCY}$, but their electron conductivity is lower due to the presence of zirconium [206]. An increase in the electron conduction rate is achieved by dispersing 40 vol. \% nickel in the BZCY $\left(\mathrm{Ba}\left(\mathrm{Zr}_{0.1} \mathrm{Ce}_{0.7} \mathrm{Y}_{0.2}\right) \mathrm{O}_{3-\delta}\right)$ phase [191,192]. A low hydrogen permeation $\left(4.2 \times 10^{-4} \mathrm{~mol} \cdot \mathrm{m}^{-2} \cdot \mathrm{s}^{-1}\right)$ was achieved at $900{ }^{\circ} \mathrm{C}$ for a $1 \mathrm{~mm}$ thick Ni-BZCY membrane [191]. For a thinner membrane $(266 \mu \mathrm{m})$ the hydrogen flux was increased up to $6.0 \times 10^{-3} \mathrm{~mol} \cdot \mathrm{m}^{-2} \cdot \mathrm{s}^{-1}$ at $900{ }^{\circ} \mathrm{C}$ when $100 \% \mathrm{H}_{2}$ was fed [192]. The hydrogen flux decreases in the presence of $\mathrm{CO}_{2}$. In particular, when using mixtures containing $10 \%-30 \%$ of $\mathrm{CO}_{2}$ and $40 \%$ of hydrogen, an initial decrease in the hydrogen flux was observed followed by a constant flux for the remaining $80 \mathrm{~h}$. However, once the $\mathrm{CO}_{2}$ is removed from the feed gas, the initial hydrogen flux is recovered for Ni-BCZY. In contrast, 
unstable Ni-BCY presented a continuous decrease in the flux in the presence of $20 \%-30 \% \mathrm{CO}_{2}$ [207]. The advantage of doping Ni-BCZ with rare earth metals such as erbium and samarium was reported in 2015 [208]. The chemical stability against $\mathrm{CO}_{2}$ was improved when erbium was used as a dopant. The chemical stability in the presence of a pure $\mathrm{CO}_{2}$ atmosphere of several perosvkites based on $\mathrm{BaCeO}_{3}$ is shown in Figure 11. The decomposition of $\mathrm{BaCeO}_{3}$ is promoted at higher temperatures, while substitution of $\mathrm{Ce}$ with samarium and erbium enhances the chemical stability. On the other hand, introduction of zirconium to $\mathrm{BaCeO}_{3}, \mathrm{BaCe}_{0.8} \mathrm{Er}_{0.2} \mathrm{O}_{3-\delta}$ and $\mathrm{BaCe}_{0.8} \mathrm{Sm}_{0.2} \mathrm{O}_{3-\delta}$, increases the stability for all cases, since the temperature at which barium carbonate started to be formed was increased to $550{ }^{\circ} \mathrm{C}$. As shown in Figure 11, the chemical stability of $\mathrm{Ni}-\mathrm{BaCe}_{0.5} \mathrm{Zr}_{0.3} \mathrm{M}_{0.2} \mathrm{O}_{3-\delta}(\mathrm{M}=\mathrm{Sm}$, Er) in the range of $550-670{ }^{\circ} \mathrm{C}$ is better than $\mathrm{Ni}-\mathrm{BCZ}$, and these cermets can be applied for hydrogen separation from methane steam reforming.

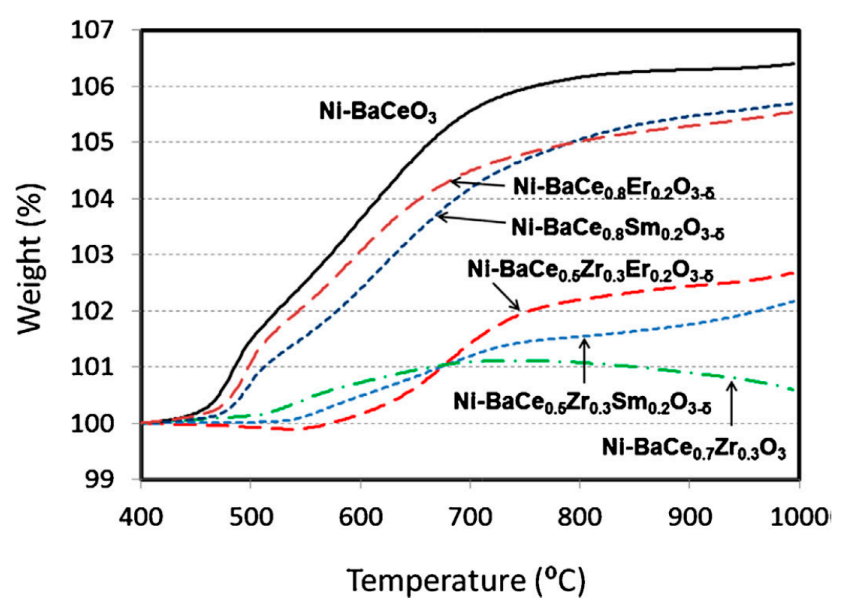

Figure 11. Weight change of reduced $\mathrm{Ni}-\mathrm{BaCeO}_{3}, \mathrm{Ni}-\mathrm{BaCe}_{0.7} \mathrm{Zr}_{0.3} \mathrm{O}_{3}, \mathrm{Ni}-\mathrm{BaCe}_{0.8} \mathrm{M}_{0.2} \mathrm{O}_{3-\delta}$ and $\mathrm{Ni}-\mathrm{BaCe}_{0.5} \mathrm{Zr}_{0.3} \mathrm{M}_{0.2} \mathrm{O}_{3-\delta}\left(\mathrm{M}=\mathrm{Sm}\right.$, Er) cermet powders with increasing temperature in pure $\mathrm{CO}_{2}$ atmosphere. Reprinted from [208] with permission from Elsevier.

As the hydrogen flux is increased by preparing thin membranes on asymmetric supports, Zhu et al. [193] prepared a $30 \mu \mathrm{m}$ Ni-BZCY on top of a porous support made of $\mathrm{BZCY}\left(\mathrm{Ba}\left(\mathrm{Zr}_{0.1} \mathrm{Ce}_{0.7} \mathrm{Y}_{0.2}\right) \mathrm{O}_{3-\delta}\right)$. However, the obtained result was not as good as expected. At $900{ }^{\circ} \mathrm{C}$ with $80 \%$ of hydrogen in the feed gas, the permeation flux was only $2.5 \times 10^{-3} \mathrm{~mol} \cdot \mathrm{s}^{-1} \cdot \mathrm{m}^{-2}$, which is one order of magnitude smaller than for Pd/GDC reported by Jeon et al. [188]. Suggested reasons for the observed low flux are: (i) surface exchange becomes the rate limiting step as the thickness of the membrane decreases and (ii) too low porosity of the porous substrate. Self-supported cermet with a similar composition (50 wt. \% Ni-50 wt. \% BaCe $\mathrm{B}_{0.9} \mathrm{Y}_{0.1} \mathrm{O}_{3-\delta}$ ) was studied by Kim et al. [194], who found for a thicker membrane $(230 \mu \mathrm{m})$ a higher hydrogen permeation flux $\left(5.88 \times 10^{-3} \mathrm{~mol} \cdot \mathrm{s}^{-1} \cdot \mathrm{m}^{-2}\right)$ than supported Ni-BZCY even at a lower temperature $\left(800{ }^{\circ} \mathrm{C}\right)$ when feeding pure hydrogen. In 2013, a supported Ni-BZCYYb $\left(\mathrm{BaZr}_{0.1} \mathrm{Ce}_{0.7} \mathrm{Y}_{0.1} \mathrm{Yb}_{0.1} \mathrm{O}_{3-\delta}\right)$ was developed by Mingfei Liu et al. [195]. Incorporation of $\mathrm{Yb}$ enhances the ionic conductivity while maintaining the thermal and chemical stability. The highest hydrogen permeation flux, $8.33 \times 10^{-3} \mathrm{~mol} \cdot \mathrm{m}^{-1} \cdot \mathrm{s}^{-1}$, was measured at $900{ }^{\circ} \mathrm{C}$ when pure hydrogen and nitrogen were used on the feed and permeate side, respectively. During 2014 and 2015, many research groups investigated other types of cermets such as Ni-BZPY [209], Ni-BCTZ [210] and Ni-LCD [211], which showed stability in the presence of $\mathrm{CO}_{2}$ and $\mathrm{H}_{2} \mathrm{O}$, while the hydrogen fluxes were below $2 \times 10^{-3} \mathrm{~mol} \cdot \mathrm{m}^{-1} \cdot \mathrm{s}^{-1}$ at $800{ }^{\circ} \mathrm{C}$.

In 2014, a supported $18 \mu \mathrm{m}$ thick 60 vol. \% Pd/YSZ cermet membrane supported on an alumina porous substrate was reported by Balachandran et al. [197]. The dense cermet layer was supported on a porous disk made by the paste-painting method (see Figure 12). The permeated hydrogen flux increased from $0.193 \mathrm{~mol} \cdot \mathrm{m}^{-1} \cdot \mathrm{s}^{-1}$ at $400{ }^{\circ} \mathrm{C}$ to $0.387 \mathrm{~mol} \cdot \mathrm{m}^{-1} \cdot \mathrm{s}^{-1}$ at $900{ }^{\circ} \mathrm{C}$ for a feed gas containing 
$90 \% \mathrm{H}_{2}$ (in helium) at ambient pressure and nitrogen as sweep gas. Bulk diffusion is the rate limiting step for this thin dense membrane. A long-term test was carried out for four months for a thicker membrane $(25 \mu \mathrm{m})$ in the temperature range of $500-600{ }^{\circ} \mathrm{C}$. The hydrogen flux was stable as the same hydrogen flux was measured at $500{ }^{\circ} \mathrm{C}$ initially and at the end of test $\left(0.07 \mathrm{~mol} \cdot \mathrm{m}^{-1 \cdot} \cdot \mathrm{s}^{-1}\right)$. Moreover, the Pd/YSZ cermet membrane was chemically stable in the presence of syngas at high pressure. The resistance to $\mathrm{H}_{2} \mathrm{~S}$ was also determined for an even thicker membrane $(200 \mu \mathrm{m})$ at $900{ }^{\circ} \mathrm{C}$ in the presence of $400 \mathrm{ppm} \mathrm{H}_{2} \mathrm{~S}$ and $79.8 \% \mathrm{H}_{2}$. In the first h a decrease in the hydrogen flux was observed, however, the permeated flux reached a plateau that was maintained for more than $120 \mathrm{~h}$. This underlines that the Pd/YSZ cermet membrane is an interesting membrane for hydrogen production systems.

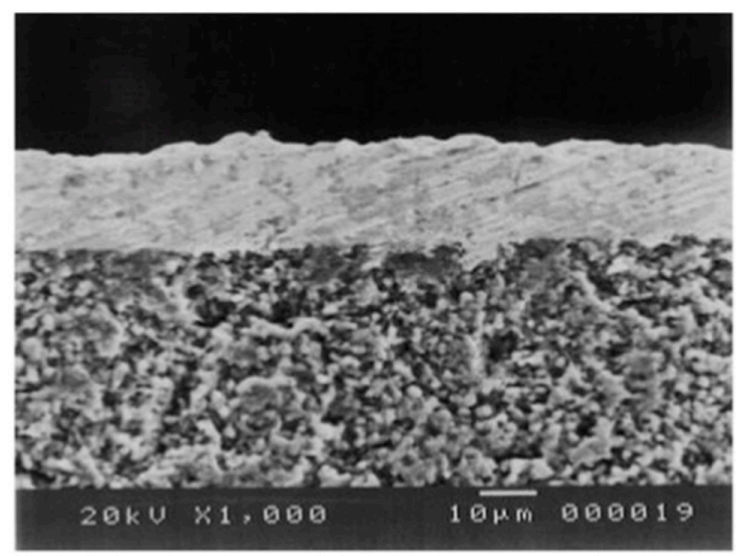

Figure 12. Cross section SEM image of a cermet membrane (top part) on a porous alumina support (bottom part). Reprinted from [197] with permission from Elsevier.

Lee et al. [212] reported a novel cermet membrane composed of $\mathrm{Ti}_{4} \mathrm{Cr}_{3} \mathrm{Nb}_{3} \mathrm{O}_{2}$ with 50 wt. \% of PdAg. Niobium oxide was added due to the catalytic properties for ionization of hydrogen molecules. The measured permeability of this mixture was $1 \times 10^{-4} \mathrm{~mol} \cdot \mathrm{m}^{-1} \cdot \mathrm{s}^{-1 \cdot} \mathrm{Pa}^{-0.5}$ at $400{ }^{\circ} \mathrm{C}$ and $300 \mathrm{kPa}$ of pressure difference using a planar membrane of $1.2 \mathrm{~mm}$ thick.

Cermet membranes are not only applied for the separation of hydrogen from gas mixtures such as syngas, but they can also be applied in membrane reactors for other applications such as water splitting, as reported in the literature [213].

\subsubsection{Pore-Filled Type Membraners}

The principle of hydrogen permeation in pore-filled membranes is similar to that of cermet membranes: a mixed ceramic/metal membrane is produced and used for the separation. In cermet membranes powders of both materials are mixed and pressed before sintering. However, as the name implies, in pore-fill membranes the pores of a ceramic phase are filled with the metallic phase. The employed amount of metallic phase is only a fraction in comparison with cermet membranes and much less than conventional in thin film membranes. Moreover, the deposition of a porous ceramic layer on top of a filled mesoporous layer avoids exposure of the selective material to the external environment, such as in fluidized-bed membrane reactors.

The first reported pore-filled type membrane was for oxygen perm-selective separation, as discussed by Kim et al. [214]. Before the deposition of palladium, an YSZ layer was obtained with a dip-coating method on top of an $\alpha-\mathrm{Al}_{2} \mathrm{O}_{3}$ porous support, having $5 \mu \mathrm{m}$ thick layer after being dried at $40{ }^{\circ} \mathrm{C}$ and relative humidity of $40 \%-50 \%$ followed by calcination at $1000{ }^{\circ} \mathrm{C}$ for $3 \mathrm{~h}$. Palladium was introduced into the $100 \mathrm{~nm}$ pore-sized YSZ layer by a reservoir method. Palladium acetate was dissolved in a $\mathrm{HCl}$-acetone mixture followed by one day drying and subsequent calcination at $500{ }^{\circ} \mathrm{C}$ for $2 \mathrm{~h}$ under hydrogen, in order to reduce $\mathrm{Pd}^{2+}$ into $\mathrm{Pd}^{0}$. The remaining pores were filled with YSZ by 
CVD employing $\mathrm{ZrCl}_{4}$ and $\mathrm{YCl}_{3}$ as metal precursors. The deposition was performed in the presence of oxygen in order to form the desired metal oxide $\left(\mathrm{Y}_{2} \mathrm{O}_{3}-\mathrm{ZrO}_{2}\right)$ at $1000{ }^{\circ} \mathrm{C}$. The prepared membrane was used for oxygen separation, but the presence of palladium suggested the possibility to use the same membrane as a hydrogen separation membrane.

Pacheco Tanaka and co-workers from AIST (National Institute of Advanced Industrial Science and Technology, Tsukuba, Japan) [111] prepared pore-filled membranes for hydrogen separation introducing palladium in a thin nanoporous $\gamma-\mathrm{Al}_{2} \mathrm{O}_{3}$ layer deposited on top of a tubular porous $\alpha$-alumina support by vacuum-assisted dip-coating of a boehmite sol containing PVA and PEG. The calcination was performed at $600{ }^{\circ} \mathrm{C}$ for $3 \mathrm{~h}$. Palladium seeds were introduced in the $5 \mu \mathrm{m}$ thick $\gamma-\mathrm{Al}_{2} \mathrm{O}_{3}$ layer by dipping into a palladium acetate dissolved in chloroform followed by reduction $\left(\mathrm{Pd}^{2+} \rightarrow \mathrm{Pd}^{\circ}\right)$ in hydrazine. Afterward, a ceramic protective layer $\left(\gamma-\mathrm{Al}_{2} \mathrm{O}_{3}\right)$ was deposited on top of the previous Pd-activated ceramic layer using the same approach. During the cool-down step after calcination, a hydrogen stream was introduced to reduce possible oxidized palladium. Finally, the activated Pd seeds were grown by vacuum-assisted ELP. A schematic representation of this membrane configuration is represented in Figure 13. Reduction of palladium grains to $\mathrm{nm}$ size suppresses $\alpha-\beta$ transition and the membrane can work at lower temperatures [213,214]. Indeed, these membranes were tested in the temperature range from 50 to $300{ }^{\circ} \mathrm{C}$ without failure of the membrane and the best results were obtained at $300{ }^{\circ} \mathrm{C}$ and a pressure difference of $400 \mathrm{kPa}$, yielding a hydrogen flux of $\sim 0.55 \mathrm{~mol} \cdot \mathrm{m}^{-2} \cdot \mathrm{s}^{-1}$ and a $\mathrm{H}_{2} / \mathrm{N}_{2}$ perm-selectivity of 1000 [111]. Due to the difference in thermal expansion coefficient between alumina and $\mathrm{Pd}$ (Table 4) the permeation test at temperatures above $400{ }^{\circ} \mathrm{C}$ resulted in membrane failure. To avoid this problem, the mesoporous $\gamma-\mathrm{Al}_{2} \mathrm{O}_{3}$ layer was replaced by an $\mathrm{YSZ} / \gamma-\mathrm{Al}_{2} \mathrm{O}_{3}$ layer in order to minimize the difference in thermal expansion with the metal [117]. The effect of the amount of YSZ was studied and it was observed that the nitrogen flux was increased when the amount of YSZ was increased. The measured hydrogen flux at $500{ }^{\circ} \mathrm{C}$ and a pressure difference of $400 \mathrm{kPa}$ was $\sim 0.616 \mathrm{~mol} \cdot \mathrm{m}^{-2} \cdot \mathrm{s}^{-1}$, which was half of the flux achieved for a conventional supported thin film with the same membrane thickness $(3.23 \mu \mathrm{m})$. The ideal $\mathrm{H}_{2} / \mathrm{N}_{2}$ perm-selectivity was 350. Since the amount of palladium is only a fraction of that employed for films and $\mathrm{YSZ}-\mathrm{Al}_{2} \mathrm{O}_{3}$ does not transport hydrogen, the obtained results are as expected. Long-term tests were performed for $200 \mathrm{~h}$ in the temperature range of 500-600 ${ }^{\circ} \mathrm{C}$. A gradual loss in the hydrogen flux was observed during the first $100 \mathrm{~h}$ at $500{ }^{\circ} \mathrm{C}$, then the temperature was increased to $600{ }^{\circ} \mathrm{C}$, showing an initial hydrogen flux increases related to the temperature effect. Again, the hydrogen flux decreased during the first $20 \mathrm{~h}$ at $600{ }^{\circ} \mathrm{C}$. Afterward a stable permeated hydrogen flux was maintained for longer times. The preparation of this type of membranes was patented in 2006 [215].

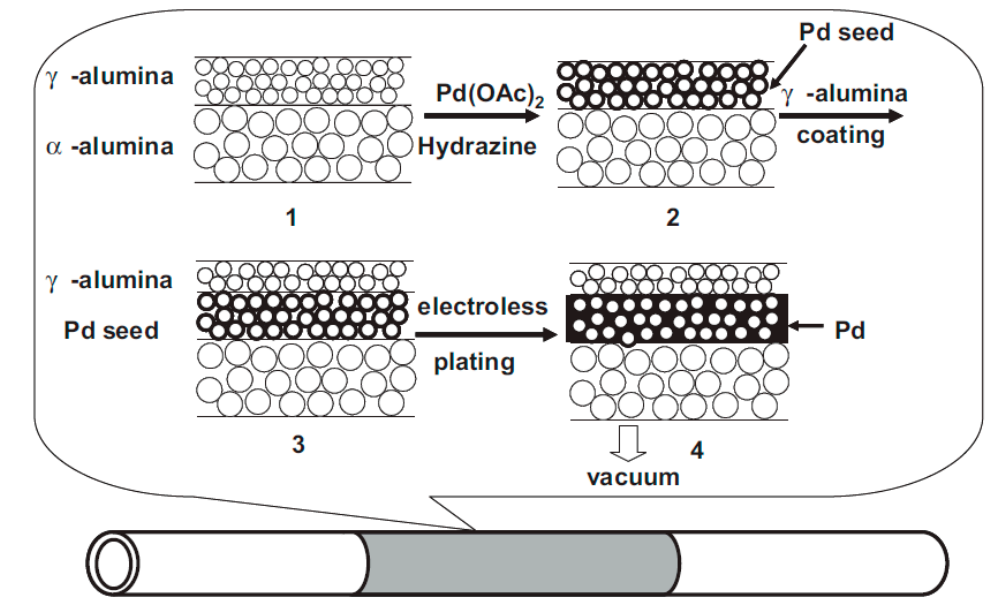

Figure 13. Schematic representation of pore-filled type membranes performed by Pacheco Tanaka et al. Reprinted from [111] with permission from Wiley VCH. 
A pore-filled type membrane was integrated in a membrane reactor for hydrogen production by dehydrogenation of methylcyclohexane producing toluene and hydrogen [213]. Platinum supported onto alumina particles was used as catalyst, mixed with sand and introduced into the inner part of the tube, where the palladium was located (see Figure 14). The reaction was performed in the temperature range below the critical temperature for $\alpha-\beta$ phase transition, $150-325^{\circ} \mathrm{C}$ without formation of coke onto the catalyst bed. The introduction of the membrane into the reactor improved the conversion of the reaction to $60 \%-80 \%$ in a temperature range of $150-225^{\circ} \mathrm{C}$, while at higher temperatures complete conversion in both systems was achieved, where the effect of the membrane was only visible in the recovery of the hydrogen, which increased as the temperature increased. The stability of membrane was proven for $600 \mathrm{~h}$ confirming constant membrane efficiency (i.e., flux and selectivity).

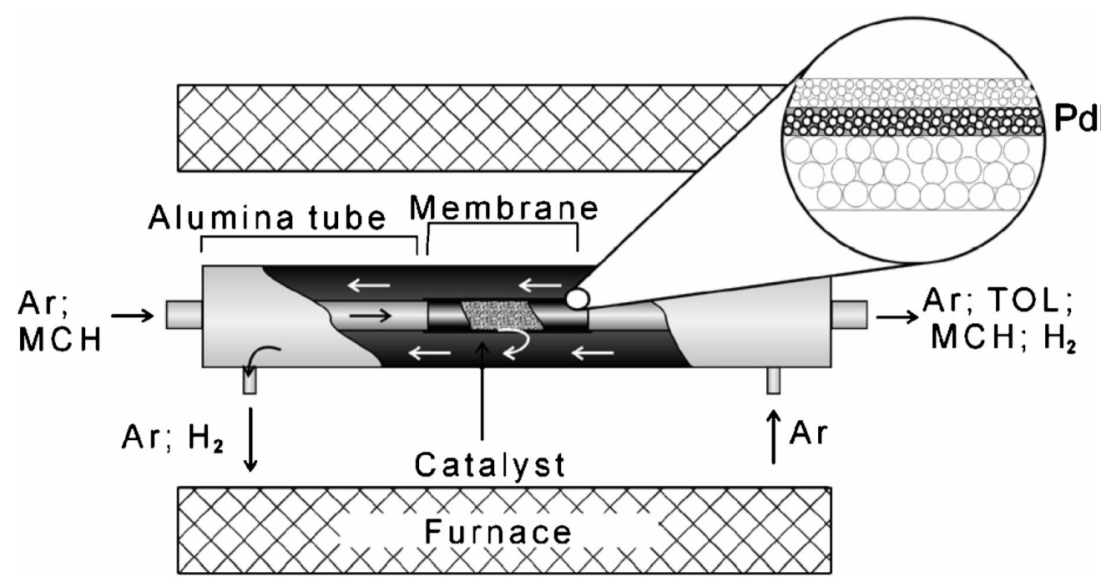

Figure 14. Schematic representation of a pore-filled type membrane integrated in a packed-bed membrane reactor for the dehydrogenation of methylcyclohexane into toluene and hydrogen. Reprinted from [213] with permission from The Chemical Society of Japan.

The use of YSZ guarantees better thermal properties than palladium membranes as was reported for a pore-fill-type membrane prepared with an YSZ porous support and coated with a mesoporous layer of the same material [214]. The hydrogen selectivity was improved by adding a surfactant (Triton ${ }^{\circledR} \mathrm{X}-100$ ) to the plating solution in order to decrease the surface tension. The hydrogen flux at $600{ }^{\circ} \mathrm{C}$ and $50 \mathrm{kPa}$ of pressure difference increased from $0.956 \mathrm{~mol} \cdot \mathrm{m}^{-2} \cdot \mathrm{s}^{-1}$ (without addition of the surfactant) to $1.368 \mathrm{~mol} \cdot \mathrm{m}^{-2} \cdot \mathrm{s}^{-1}$ when the concentration of the surfactant in the resulting plating solution was $0.05 \mathrm{wt}$. \%. The $\mathrm{H}_{2} / \mathrm{N}_{2}$ ideal perm-selectivity for a membrane prepared without addition of the surfactant was 1200 , while for the membrane with $0.05 \mathrm{wt}$. \% of surfactant in the plating solution the resulting ideal perm-selectivity was 20,000.

Some years later (2012) the AIST research group reported a study where hydrogen permeation of thin-film and pore-filled type membranes were compared in the presence of steam and $\mathrm{CO}_{2}$ [198]. A thin palladium membrane was deposited by chemical vapor deposition onto an $\alpha-\mathrm{Al}_{2} \mathrm{O}_{3}$ porous support, while pore-filled type membranes were produced in a similar way as reported earlier [111]. The thickness of the deposited film by CVD was around 1-2 $\mu \mathrm{m}$, while the embedded $\mathrm{Pd}$ on $\gamma-\mathrm{Al}_{2} \mathrm{O}_{3}$ layer was close to $10 \mu \mathrm{m}$ thick. The filled pores presented a distribution in pore size of about $1-9 \mathrm{~nm}$ and a surface area of $213 \mathrm{~m}^{2} \cdot \mathrm{g}^{-1}$ after calcination at $600{ }^{\circ} \mathrm{C}$, which means that the Pd particle size was in the nano-range. In the presence of pure hydrogen, the permeance of the conventional thin-film membrane was a factor three larger than the pore-filled type membrane, $1.3 \times 10^{-3} \mathrm{~mol} \cdot \mathrm{m}^{-2} \cdot \mathrm{s}^{-1} \cdot \mathrm{Pa}^{-0.5}$ for the thin film and $4.1 \times 10^{-4} \mathrm{~mol} \cdot \mathrm{m}^{-2} \cdot \mathrm{s}^{-1} \cdot \mathrm{Pa}^{-0.5}$ for the pore-filled membrane at $300{ }^{\circ} \mathrm{C}$ and a pressure difference of $200 \mathrm{kPa}$. The hydrogen permeation rates decreased for both membranes when $\mathrm{CO}_{2}$ was introduced into the gas stream at $300^{\circ} \mathrm{C}$. However, the $\mathrm{CO}_{2}$ poisoning was more pronounced for the conventional thin-film membrane than for pore-filled membrane. Moreover, the hydrogen flux was completely recovered when $\mathrm{CO}_{2}$ was removed for the pore-filled membrane, whereas only $80 \%$ of the 
initial hydrogen flux was recovered for the CVD membrane. The introduction of steam decreases the initial hydrogen flux for both membrane types, but the flux was successfully recovered after exposure to steam for both membranes. Concerning the perm-selectivity, for the conventional membrane the initial $\mathrm{H}_{2} / \mathrm{N}_{2}$ separation factor was $\sim 883$ (re-calculated values explained at Table 10), which was decreased to $\sim 447$ and $\sim 409$ after exposure to $\mathrm{CO}_{2}$ and steam, respectively. For the pore-filled membrane, the hydrogen flux before and after exposure to $\mathrm{CO}_{2}$ and $\mathrm{H}_{2} \mathrm{O}$ remain the same, $\sim 0.095 \mathrm{~mol} \cdot \mathrm{m}^{-2} \cdot \mathrm{s}^{-1}$ at $200 \mathrm{kPa}\left(4.75 \times 10^{-7} \mathrm{~mol} \cdot \mathrm{m}^{-2} \cdot \mathrm{s}^{-1} \cdot \mathrm{Pa}^{-1}\right)$ and an initial selectivity of $\sim 176$. No changes were reported by the authors for the pore-filled membrane. However, re-calculated selectivities after exposure to $\mathrm{CO}_{2}$ and steam were 206 and $\sim 12$, respectively.

A similar concept was reported by Nair et al. [199] for a hollow fiber configuration. Three types of configurations were reported, the so-called "encapsulated Pd (M-E)", "Pd encapsulated nanopore $(\mathrm{M}-\mathrm{EN})$ " and "Pd nanopore (M-N)" membranes. All these types of membranes were supported on an $\alpha-\mathrm{Al}_{2} \mathrm{O}_{3}$ hollow fiber followed by boehmite slip casting. For the Pd encapsulated case, the $\gamma$-alumina surface was activated with Pd followed by growth of a thin Pd layer by ELP. Subsequently, the surface was coated with another $\gamma$-alumina layer (Figure 15a). The second type of membrane, "Pd encapsulated nanopore", can be easily prepared by filling the resulted pores of the "encapsulated Pd membrane" with palladium using ELP, connected with the first deposited Pd layer as shown in Figure 15b. The equivalent palladium thickness was $1.6 \mu \mathrm{m}$, but the amount of deposited palladium was relatively low in comparison with convectional supported membranes.

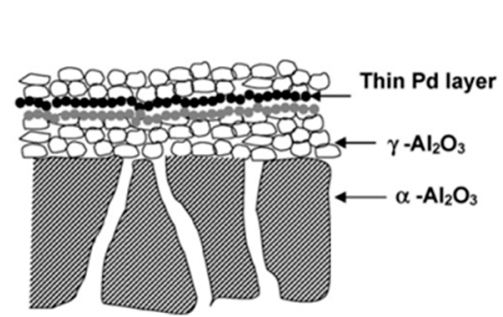

(a)

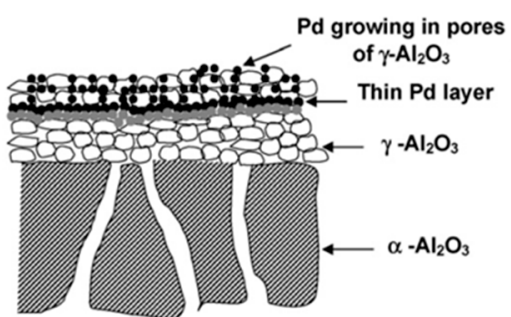

(b)

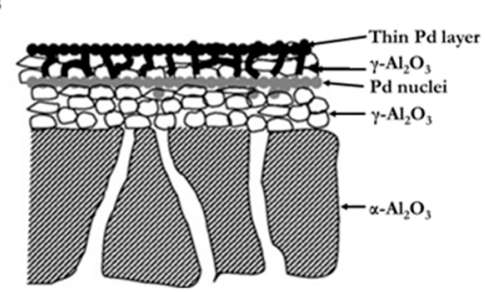

(c)

Figure 15. Schematic representation of encapsulated Pd (a), Pd encapsulated nanopore (b) and Pd nanopore (c). Reprinted from [199] with permission from Elsevier.

The other membrane configuration, "Pd nanopore" (Figure 15c), differs from the other two configurations in that not only pores are filled, but also a $2 \mu \mathrm{m}$ thick Pd layer is grown on top of the alumina layer. Permeation tests were performed at $370^{\circ} \mathrm{C}$ and a feed side pressure of $300 \mathrm{kPa}$, observing a higher hydrogen flux and perm-selectivity for the encapsulated nanopore membranes. Indeed, the measured hydrogen flux (and selectivity) for Pd-encapsulated nanopore, Pd encapsulate and Pd-nanopore membranes were $\sim 0.25 \mathrm{~mol} \cdot \mathrm{m}^{-2} \cdot \mathrm{s}^{-1}\left(\mathrm{H}_{2} / \mathrm{N}_{2}=8750\right), \sim 0.26 \mathrm{~mol} \cdot \mathrm{m}^{-2} \cdot \mathrm{s}^{-1}\left(\mathrm{H}_{2} / \mathrm{N}_{2}=3800\right)$, and $\sim 0.13 \mathrm{~mol} \cdot \mathrm{m}^{-2} \cdot \mathrm{s}^{-1}\left(\mathrm{H}_{2} / \mathrm{N}_{2}=550\right)$, respectively. Thermal stability was confirmed at the same temperature $\left(370{ }^{\circ} \mathrm{C}\right)$ for $150-200 \mathrm{~h}$, resulting in an increase of the hydrogen flux at lower pressures for the encapsulated nanopore membrane, $0.67 \mathrm{~mol} \cdot \mathrm{m}^{-2} \cdot \mathrm{s}^{-1}$, while the perm-selectivity decreased to 160 . The selectivity of the nanopore membrane was reduced to half of the calculated value before thermal aging, while the hydrogen flux remained close to $0.1 \mathrm{~mol} \cdot \mathrm{m}^{-2} \cdot \mathrm{s}^{-1}$. The largest decrease in terms of selectivity was for the encapsulated membrane, 10 times lower (380) with a hydrogen flux increase from 0.26 to $0.5 \mathrm{~mol} \cdot \mathrm{m}^{-2} \cdot \mathrm{s}^{-1}$. The low selectivity of these membranes was associated to thermal stress caused by the discontinuities between alumina and palladium due to differences in thermal expansion, as for the pore-filled membranes prepared by Pacheco Tanaka and coworkers [111]. The same group also showed similar results for a nanopore type membrane [200], where the hydrogen flux and ideal perm-selectivity at $500{ }^{\circ} \mathrm{C}$ and a pressure difference of 4 bar were $0.56 \mathrm{~mol} \cdot \mathrm{m}^{-2} \cdot \mathrm{s}^{-1}$ and 6600 , respectively. On the other hand, Arratibel et al. [201] recently reported a pore-filled membrane with a high stability at $500{ }^{\circ} \mathrm{C}$ and $550{ }^{\circ} \mathrm{C}$ after $900 \mathrm{~h}$ at $50 \mathrm{kPa}$ of pressure difference. Palladium 
seeds were deposited into the nanoporous layer of $\mathrm{YSZ} / \gamma-\mathrm{Al}_{2} \mathrm{O}_{3}$. However, the hydrogen flux $\left(9.04 \times 10^{-3} \mathrm{~mol} \cdot \mathrm{m}^{-2} \cdot \mathrm{s}^{-1}\right)$ and perm-selectivity $(\sim 50)$ were too low at the end of the experiment at $550{ }^{\circ} \mathrm{C}$.

Another way to prepare pore-filled type membranes was patented in 2009 by Wakuy et al. [215]. The authors first deposited a thin mesoporous ceramic layer followed by activation of the surface by filling the pores with Pd particles. Afterward, the deposited ceramic layer with palladium seeds was removed leaving a portion of the deposited Pd into the original porous surface. Again, a ceramic layer was deposited as a protective layer followed by electroless plating to grow palladium and completely fill the pores.

Ohio State University patented in 2010 a pore-filled type membrane employing $\mathrm{ZrO}_{2}$ as an intermediate layer between the support and palladium layer [202]. They suggested deposition of $\mathrm{ZrO}_{2} / \mathrm{Pd}$ nano-composite on top of a macroporous support, consisting of $\mathrm{Al}_{2} \mathrm{O}_{3}$ or $\mathrm{ZrO}_{2}$, followed by deposition of a thin $\mathrm{Pd}$ (or Pd alloy) layer by ELP with a thickness ranging from $10 \mathrm{~nm}$ to $1 \mu \mathrm{m}$. The $\mathrm{ZrO}_{2} / \mathrm{Pd}(30 / 70$ vol. \%) and the macroporous layers were also deposited on top of the Pd or $\mathrm{Pd}$-alloy layer to protect the hydrogen selective metals. There is no chemical adhesion between $\mathrm{Pd}$ and $\mathrm{ZrO}$, but the adherence of $\mathrm{ZrO}_{2}$ with the macroporous layer is easier due to their chemical affinity. A membrane supported on top of $\gamma$-alumina with a $120 \mathrm{~nm} \mathrm{Pd} / \mathrm{ZrO}_{2}$ composite layer was covered with $215 \mathrm{~nm} \mathrm{Pd}$ and tested in the presence of pure hydrogen at 200,260 and $320^{\circ} \mathrm{C}$. The measured fluxes were $0.04,0.1$ and $0.25 \mathrm{~mol} \cdot \mathrm{m}^{-2} \cdot \mathrm{s}^{-1}$ respectively, with a pressure difference of 2 bar across the feed and permeate sides.

The most recent reported study on pore-filled type membranes was performed by Yogo and co-workers [203]. They deposited directly $\mathrm{Pd}$ into $\alpha-\mathrm{Al}_{2} \mathrm{O}_{3}$ porous tubes by dip-coating with an average pore size of $100 \mathrm{~nm}$ using a Pd-gel containing $\mathrm{PdCl}_{2}$ as palladium carrier in $\mathrm{HCl}$ and agarose $\mathrm{L}$ polymer as binder. An ice bath was used to cool the Pd-gel onto the porous support followed by reduction in the presence of hydrazine. After cleaning, 10 min of electroless plating was performed in order to grow the Pd seeds. Before carrying out a loner ELP, the Pd-gel was removed by calcination of the sample at $850{ }^{\circ} \mathrm{C}$. The palladium layer obtained inside the porous support was around $8-10 \mu \mathrm{m}$ at $10 \mu \mathrm{m}$ depth. The amount of palladium used for the pore-filled membranes was $34 \%$ of that required for a supported thin-film membrane with the same thickness. The hydrogen permeance at $500{ }^{\circ} \mathrm{C}$ and $150 \mathrm{kPa}$ of pressure difference was $1.2 \times 10^{-6} \mathrm{~mol} \cdot \mathrm{m}^{-2} \cdot \mathrm{s}^{-1} \cdot \mathrm{Pa}^{-1}$, and stable for $150 \mathrm{~h}$ at different temperatures $\left(200-500{ }^{\circ} \mathrm{C}\right.$ ) in the presence of a gas mixture $\mathrm{H}_{2} / \mathrm{N}_{2}$. The ideal perm-selectivity of this membrane was above 10,000. In conclusion, pore-filled type membranes represent an interesting alternative when membranes are integrated in a fluidized bed membrane reactor to avoid abrasion problems of the membrane surface due to the scouring action of the fluidized catalyst particles.

\section{Conclusions}

In this review, an overview of the latest achievements with different types of membrane reactors with different types of integrated $\mathrm{H}_{2}$ perm-selective membranes for the production of $\mathrm{H}_{2}$ from different feedstocks has been given. Requirements that need to be fulfilled by $\mathrm{H}_{2}$ perm-selective membranes for its integration in packed or fluidized bed membrane reactors are discussed, as well as the selection of the materials for the support and interdiffusion layer. Depending on the operation conditions, stainless steel $\left(316 \mathrm{~L}\right.$ ) and $\mathrm{ZrO}_{2} / \mathrm{YSZ}$ as a support and diffusion barrier are preferred for applications at around $400-500{ }^{\circ} \mathrm{C}$. For applications at higher operating temperatures supports with higher stability are required, such as Hastelloy $\mathrm{X}$ and $\mathrm{Ni}$-based alloys (Inconel).

Concerning the material for the selective layer, Pd-based membranes represent the best choice in comparison with non-palladium alloys $(\mathrm{V}, \mathrm{Nb}, \mathrm{Ta})$, yielding higher permeabilities than pure $\mathrm{Pd}$. However, their tendency to embrittlement is also high. PdAg membranes exhibit a high flux, PdAu membranes a high sulfur resistance, whereas PdAgAu membranes combine both properties. However, for high-temperature applications such as methane steam reforming, alloys like $\mathrm{PdRu}$ and $\mathrm{PdPt}$ are requited for improved thermal stability at temperatures above $500{ }^{\circ} \mathrm{C}$. Combination of all these 
elements to create a membrane which could work under extreme conditions is an interesting option. Nevertheless, the possible techniques for their preparation is limited to PVD, due to the complexity to prepare these mixed membranes with ELP.

Integration of supported membranes in fluidized bed membrane reactors require membranes with improved abrasion resistance because of the scouring action of the catalyst particles which may deteriorate the membrane properties dramatically. Cermet membranes may represent an interesting option, since part of their surface do not suffer from erosion since they are much harder than the catalyst particles. However, the hydrogen selective material is not completely covered. For this reason, pore-filled membranes are suggested as the best alternative to avoid membrane abrasion. They have been investigated for their application in the dehydrogenation of methylcyclohexane at low temperatures with a high stability during $600 \mathrm{~h}$. However, their use in membrane reactors for hydrogen production via reforming of hydrocarbons (methane, methanol or ethanol) is very interesting, but has not been studied yet.

Acknowledgments: The presented work is funded within Reforcell (grant agreement No. 278997) and FERRET (grant agreement No. 621181) projects as part of European Union's Seventh Framework Programme (FP7/2007-2013) for the Fuel Cells and Hydrogen Joint Technology Initiative. Note: "The present publication reflects only the authors' views and the Union is not liable for any use that may be made of the information contained therein".

Conflicts of Interest: The authors declare no conflict of interest.

\section{References}

1. Samingprai, S.; Tantayanon, S.; Ma, Y.H. Chromium oxide intermetallic diffusion barrier for palladium membrane supported on porous stainless steel. J. Membr. Sci. 2010, 347, 8-16. [CrossRef]

2. Khatib, S.J.; Yun, S.; Oyama, S.T. Sulfur resistant Pd and Pd alloy membranes by phosphidation. J. Membr. Sci. 2014, 455, 283-293. [CrossRef]

3. Kuji, T.; Matsumura, Y.; Uchida, H.; Aizawa, T. Hydrogen absorption of nanocrystalline palladium. J. Alloys Compd. 2002, 330-332, 718-722. [CrossRef]

4. Pundt, A.; Sachs, C.; Winter, M.; Reetz, M.; Fritsch, D.; Kirchheim, R. Hydrogen sorption in elastically soft stabilized Pd-clusters. J. Alloys Compd. 1999, 293-295, 480-483. [CrossRef]

5. Helmi, A.; Gallucci, F.; Annaland, M.V. Resource scarcity in palladium membrane applications for carbon capture in integrated gasification combined cycle units. Int. J. Hydrog. Energy 2014, 39, 10498-10506. [CrossRef]

6. Energy Efficiency and Renewable Energy Report of the DOE Workshop on Hydrogen Separations and Purification; Department of Energy Office of Hydrogen, Fuel Cells \& Infrastructure Technologies: Arlington, VA, USA, 2004.

7. Yun, S.; Oyama, S.T. Correlations in palladium membranes for hydrogen separation: A review. J. Membr. Sci. 2011, 375, 28-45. [CrossRef]

8. Paglieri, S.N.; Way, J.D. Innovations in Palladium Membrane Research. Sep. Purif. Rev. 2002, 31, 1-169. [CrossRef]

9. Boeltken, T.; Belimov, M.; Pfeifer, P.; Peters, T.A.; Bredesen, R.; Dittmeyer, R. Fabrication and testing of a planar microstructured concept module with integrated palladium membranes. Chem. Eng. Process. Process Intensif. 2013, 67, 136-147. [CrossRef]

10. Marra, L.; Wolbers, P.F.; Gallucci, F.; Annaland, M.V.S. Development of a $\mathrm{RhZrO}_{2}$ catalyst for low temperature autothermal reforming of methane in membrane reactors. Catal. Today 2013, 236, 23-33. [CrossRef]

11. Lee, S.; Boeltken, T.; Mogalicherla, A.K.; Gerhards, U.; Pfeifer, P.; Dittmeyer, R. Inkjet printing of porous nanoparticle-based catalyst layers in microchannel reactors. Appl. Catal. A Gen. 2013, 467, 69-75. [CrossRef]

12. Dang, N.T.Y.; Gallucci, F.; van Sint Annaland, M. An experimental investigation on the onset from bubbling to turbulent fluidization regime in micro-structured fluidized beds. Chem. Eng. Sci. 2014, 108, 194-202. [CrossRef] 
13. Boeltken, T.; Wunsch, A.; Gietzelt, T.; Pfeifer, P.; Dittmeyer, R. Ultra-compact microstructured methane steam reformer with integrated Palladium membrane for on-site production of pure hydrogen: Experimental demonstration. Int. J. Hydrog. Energy 2014, 39, 18058-18068. [CrossRef]

14. Gallucci, F.; van Sintannaland, M.; Kuipers, J.A.M. Theoretical comparison of packed bed and fluidized bed membrane reactors for methane reforming. Int. J. Hydrog. Energy 2010, 35, 7142-7150. [CrossRef]

15. Mejdell, A.L.; Peters, T.A.; Stange, M.; Venvik, H.J.; Bredesen, R. Performance and application of thin Pd-alloy hydrogen separation membranes in different configurations. J. Taiwan Inst. Chem. Eng. 2009, 40, 253-259. [CrossRef]

16. Gallucci, F.; Fernandez, E.; Corengia, P.; Annaland, M.V. Recent advances on membranes and membrane reactors for hydrogen production. Chem. Eng. Sci. 2013, 92, 40-66. [CrossRef]

17. Fernandez, E.; Helmi, A.; Coenen, K.; Melendez, J.; Viviente, J.L.; Tanaka, D.A.P.; Annaland, M.V.; Gallucci, F. Development of thin Pd-Ag supported membranes for fluidized bed membrane reactors including WGS related gases. Int. J. Hydrog. Energy 2015, 40, 3506-3519. [CrossRef]

18. Barbieri, G.; Brunetti, A.; Tricoli, G.; Drioli, E. An innovative configuration of a Pd-based membrane reactor for the production of pure hydrogen. Experimental analysis of water gas shift. J. Power Source 2008, 182, 160-167. [CrossRef]

19. Ikuchi, E.K.; Awabe, S.K.; Atsukata, M.M. Steam Reforming of Methanol on $\mathrm{Ni} / \mathrm{Al}_{2} \mathrm{O}_{3}$ Catalyst in a Pd-membrane Reactor. J. Jpn. Pet. Inst. 2003, 46, 93-98. [CrossRef]

20. Gallucci, F.; Paturzo, L.; Basile, A. A simulation study of the steam reforming of methane in a dense tubular membrane reactor. Int. J. Hydrog. Energy 2004, 29, 611-617. [CrossRef]

21. Patil, C.S.; Annaland, M.V.; Kuipers, J.A.M. Fluidised bed membrane reactor for ultrapure hydrogen production via methane steam reforming: Experimental demonstration and model validation. Chem. Eng. Sci. 2007, 62, 2989-3007. [CrossRef]

22. Ghasemzadeh, K.; Liguori, S.; Morrone, P.; Iulianelli, A.; Piemonte, V.; Babaluo, A.A.; Basile, A. $\mathrm{H}_{2}$ production by low pressure methanol steam reforming in a dense Pd-Ag membrane reactor in co-current flow configuration: Experimental and modeling analysis. Int. J. Hydrog. Energy 2013, 38, 16685-16697. [CrossRef]

23. Brunetti, A.; Drioli, E.; Barbieri, G. Energy and mass intensities in hydrogen upgrading by a membrane reactor. Fuel Process. Technol. 2014, 118, 278-286. [CrossRef]

24. De Falco, M.; Piemonte, V.; di Paola, L.; Basile, A. Methane membrane steam reforming: Heat duty assessment. Int. J. Hydrog. Energy 2014, 39, 4761-4770. [CrossRef]

25. Abir, H.; Sheintuch, M. Modeling $\mathrm{H}_{2}$ transport through a $\mathrm{Pd}$ or $\mathrm{Pd} / \mathrm{Ag}$ membrane, and its inhibition by co-adsorbates, from first principles. J. Membr. Sci. 2014, 466, 58-69. [CrossRef]

26. Rahnama, H.; Farniaei, M.; Abbasi, M.; Rahimpour, M.R. Modeling of synthesis gas and hydrogen production in a thermally coupling of steam and tri-reforming of methane with membranes. J. Ind. Eng. Chem. 2014, 20, 1779-1792. [CrossRef]

27. Singh, A.; Singh, S.; Ganguly, S.; Patwardhan, A.V. Steam reforming of methane and methanol in simulated macro \& micro-scale membrane reactors: Selective separation of hydrogen for optimum conversion. J. Nat. Gas Sci. Eng. 2014, 18, 286-295.

28. Anderson, D.M.; Kottke, P.A.; Fedorov, A.G. Thermodynamic analysis of hydrogen production via sorption-enhanced steam methane reforming in a new class of variable volume batch-membrane reactor. Int. J. Hydrog. Energy 2014, 39, 17985-17997. [CrossRef]

29. Dang, N.T.Y.; Gallucci, F.; Annaland, M.V. Micro-structured fluidized bed membrane reactors: Solids circulation and densified zones distribution. Chem. Eng. J. 2014, 239, 42-52. [CrossRef]

30. Tan, L.; Roghair, I.; Annaland, M.V. Simulation study on the effect of gas permeation on the hydrodynamic characteristics of membrane-assisted micro fluidized beds. Appl. Math. Model. 2014, 38, 4291-4307. [CrossRef]

31. Rahimpour, M.R.; Bayat, M.; Rahmani, F. Enhancement of methanol production in a novel cascading fluidized-bed hydrogen permselective membrane methanol reactor. Chem. Eng. J. 2010, 157, 520-529. [CrossRef]

32. Deshmukh, S.A.R.K.; Annaland, M.V.; Kuipers, J.A.M. Gas back-mixing studies in membrane assisted bubbling fluidized beds. Chem. Eng. Sci. 2007, 62, 4095-4111. [CrossRef] 
33. Roses, L.; Gallucci, F.; Manzolini, G.; Campanari, S.; Annaland, M.V. Comparison between fixed bed and fluidized bed membrane reactor configurations for PEM based micro-cogeneration systems. Chem. Eng. J. 2011, 171, 1415-1427. [CrossRef]

34. Dang, N.T.Y.; Gallucci, F.; Annaland, M.V. Influence of reactor and particle scale on the hydrodynamics of microstructured fluidized bed membrane reactors. Ind. Eng. Chem. Res. 2013, 52, 18192-18205. [CrossRef]

35. Damle, A.S. Hydrogen production by reforming of liquid hydrocarbons in a membrane reactor for portable power generation-Model simulations. J. Power Source 2008, 180, 516-529. [CrossRef]

36. $\mathrm{Fu}, \mathrm{C}$; $\mathrm{Wu}, \mathrm{J}$. Mathematical simulation of hydrogen production via methanol steam reforming using double-jacketed membrane reactor. Int. J. Hydrog. Energy 2007, 32, 4830-4839. [CrossRef]

37. Tosti, S.; Borelli, R.; Santucci, A.; Scuppa, L. Pd-Ag membranes for auto-thermal ethanol reforming. Asia-Pac. J. Chem. Eng. 2010, 5, 207-212. [CrossRef]

38. Ayabe, S.; Omoto, H.; Utaka, T.; Kikuchi, R.; Sasaki, K.; Teraoka, Y.; Eguchi, K. Catalytic autothermal reforming of methane and propane over supported metal catalysts. Appl. Catal. A Gen. 2003, 241, $261-269$. [CrossRef]

39. Halabi, M.; Decroon, M.; Vanderschaaf, J.; Cobden, P.; Schouten, J. Modeling and analysis of autothermal reforming of methane to hydrogen in a fixed bed reformer. Chem. Eng. J. 2008, 137, 568-578. [CrossRef]

40. Mironova, E.Y.; Ermilova, M.M.; Orekhova, N.V.; Muraviev, D.N.; Yaroslavtsev, A.B. Production of high purity hydrogen by ethanol steam reforming in membrane reactor. Catal. Today 2014, 236, 64-69. [CrossRef]

41. Lee, S.; Applegate, D.; Ahmed, S.; Calderone, S.; Harvey, T. Hydrogen from natural gas: Part I-Autothermal reforming in an integrated fuel processor. Int. J. Hydrog. Energy 2005, 30, 829-842. [CrossRef]

42. Liming, D.; Jun, Z.; Liping, S. A compact fuel processor integrated with $75 \mathrm{kw}$ PEM Fuel Cells. In Proceedings of the 2011 International Conference on Electric Information and Control Engineering, Wuhan, China, 25-27 March 2011.

43. Rostrup-Nielsen, J.R. New aspects of syngas production and use. Catal. Today 2000, 63, 159-164. [CrossRef]

44. Jørgensen, S.L.; Nielsen, P.E.H.; Lehrmann, P. Steam reforming of methane in a membrane reactor. Catal. Today 1995, 25, 303-307. [CrossRef]

45. Mahecha-Botero, A.; Boyd, T.; Grace, J.R.; Lim, C.J.; Gulamhusein, A.; Wan, B.; Kurokawa, H.; Shirasaki, Y. In-situ $\mathrm{CO}_{2}$ capture in a pilot-scale fluidized-bed membrane reformer for ultra-pure hydrogen production. Int. J. Hydrog. Energy 2011, 36, 4038-4055.

46. Løvvik, O.M.; Peters, T.A.; Bredesen, R. First-principles calculations on sulfur interacting with ternary Pd-Ag-transition metal alloy membrane alloys. J. Membr. Sci. 2014, 453, 525-531. [CrossRef]

47. Mendes, D.; Sá, S.; Tosti, S.; Sousa, J.M.; Madeira, L.M.; Mendes, A. Experimental and modeling studies on the low-temperature water-gas shift reaction in a dense Pd-Ag packed-bed membrane reactor. Chem. Eng. Sci. 2011, 66, 2356-2367. [CrossRef]

48. Kniep, J.; Anderson, M.; Lin, Y.S. Autothermal Reforming of Methane in a Proton-Conducting Ceramic Membrane Reactor. Ind. Eng. Chem. Res. 2011, 50, 12426-12432. [CrossRef]

49. Laosiripojana, N.; Assabumrungrat, S. Catalytic steam reforming of methane, methanol, and ethanol over Ni/YSZ: The possible use of these fuels in internal reforming SOFC. J. Power Source 2007, 163, $943-951$. [CrossRef]

50. Kyriakides, A.-S.; Rodríguez-García, L.; Voutetakis, S.; Ipsakis, D.; Seferlis, P.; Papadopoulou, S. Enhancement of pure hydrogen production through the use of a membrane reactor. Int. J. Hydrog. Energy 2014, 39, 4749-4760. [CrossRef]

51. Patrascu, M.; Sheintuch, M. On-site pure hydrogen production by methane steam reforming in high flux membrane reactor: Experimental validation, model predictions and membrane inhibition. Chem. Eng. J. 2015, 262, 862-874. [CrossRef]

52. Matsuka, M.; Higashi, M.; Ishihara, T. Hydrogen production from methane using vanadium-based catalytic membrane reactors. Int. J. Hydrog. Energy 2013, 38, 6673-6680. [CrossRef]

53. Gil, A.G.; Wu, Z.; Chadwick, D.; Li, K. Ni/SBA-15 Catalysts for combined steam methane reforming and water gas shift-Prepared for use in catalytic membrane reactors. Appl. Catal. A Gen. 2015, 506, 188-196.

54. Sanz, R.; Calles, J.A.; Alique, D.; Furones, L. $\mathrm{H}_{2}$ production via water gas shift in a composite Pd membrane reactor prepared by the pore-plating method. Int. J. Hydrog. Energy 2014, 39, 4739-4748. [CrossRef]

55. Faroldi, B.; Bosko, M.L.; Múnera, J.; Lombardo, E.; Cornaglia, L. Comparison of $\mathrm{Ru} / \mathrm{La}_{2} \mathrm{O}_{2} \mathrm{CO}_{3}$ performance in two different membrane reactors for hydrogen production. Catal. Today 2013, 213, 135-144. [CrossRef] 
56. Silva, F.S.A.; Benachour, M.; Abreu, C.A.M. Evaluating Hydrogen Production in Biogas Reforming in a Membrane Reactor. Braz. J. Chem. Eng. 2015, 32, 201-210. [CrossRef]

57. Sánchez, J.M.; Barreiro, M.M.; Maroño, M. Bench-scale study of separation of hydrogen from gasification gases using a palladium-based membrane reactor. Fuel 2014, 116, 894-903.

58. Chen, Z.; Grace, J.; Jimlim, C.; Li, A. Experimental studies of pure hydrogen production in a commercialized fluidized-bed membrane reactor with SMR and ATR catalysts. Int. J. Hydrog. Energy 2007, 32, 2359-2366. [CrossRef]

59. Mahecha-Botero, A.; Boyd, T.; Gulamhusein, A.; Comyn, N.; Lim, C.J.; Grace, J.R.; Shirasaki, Y.; Yasuda, I. Pure hydrogen generation in a fluidized-bed membrane reactor: Experimental findings. Chem. Eng. Sci. 2008, 63, 2752-2762. [CrossRef]

60. El Hawa, H.W.A.; Paglieri, S.N.; Morris, C.C.; Harale, A.; Way, J.D. Application of a Pd-Ru composite membrane to hydrogen production in a high temperature membrane reactor. Sep. Purif. Technol. 2015, 147, 388-397. [CrossRef]

61. Roses, L.; Gallucci, F.; Manzolini, G.; Annaland, M.V. Experimental study of steam methane reforming in a Pd-based fluidized bed membrane reactor. Chem. Eng. J. 2013, 222, 307-320. [CrossRef]

62. Medrano, J.A.; Fernandez, E.; Melendez, J.; Parco, M.; Tanaka, D.A.P.; Annaland, M.V.; Gallucci, F. Pd-based metallic supported membranes: High-temperature stability and fluidized bed reactor testing. Int. J. Hydrog. Energy 2015, 41, 8706-8718. [CrossRef]

63. Fernandez, E.; Coenen, K.; Helmi, A.; Melendez, J.; Zuniga, J.; Tanaka, D.A.P.; Annaland, M.V.; Gallucci, F. Preparation and characterization of thin-film Pd-Ag supported membranes for high-temperature applications. Int. J. Hydrog. Energy 2015, 40, 13463-13478. [CrossRef]

64. Liguori, S.; Iulianelli, A.; Dalena, F.; Piemonte, V.; Huang, Y.; Basile, A. Methanol steam reforming in an $\mathrm{Al}_{2} \mathrm{O}_{3}$ supported thin Pd-layer membrane reactor over $\mathrm{Cu} / \mathrm{ZnO} / \mathrm{Al}_{2} \mathrm{O}_{3}$ catalyst. Int. J. Hydrog. Energy 2014, 39, 18702-18710. [CrossRef]

65. Mateos-Pedrero, C.; Silva, H.; Tanaka, D.A.P.; Liguori, S.; Iulianelli, A.; Basile, A.; Mendes, A. CuO/ZnO catalysts for methanol steam reforming: The role of the support polarity ratio and surface area. Appl. Catal. B Environ. 2015, 174-175, 67-76. [CrossRef]

66. García-García, F.R.; Tsang, S.C.; Li, K. Hollow fibre based reactors for an enhanced $\mathrm{H}_{2}$ production by methanol steam reforming. J. Membr. Sci. 2014, 455, 92-102. [CrossRef]

67. Islam, M.A.; Ilias, S. Steam Reforming of Methanol in a Pd-Composite Membrane Reactor. Sep. Sci. Technol. 2012, 47, 2177-2185.

68. Da Silva, A.M.; Mattos, L.V.; Múnera, J.; Lombardo, E.; Noronha, F.B.; Cornaglia, L. Study of the performance of $\mathrm{Rh} / \mathrm{La}_{2} \mathrm{O}_{3}-\mathrm{SiO}_{2}$ and $\mathrm{Rh} / \mathrm{CeO}_{2}$ catalysts for SR of ethanol in a conventional fixed-bed reactor and a membrane reactor. Int. J. Hydrog. Energy 2015, 40, 4154-4166. [CrossRef]

69. Domínguez, M.; Taboada, E.; Molins, E.; Llorca, J. Ethanol steam reforming at very low temperature over cobalt talc in a membrane reactor. Catal. Today 2012, 193, 101-106. [CrossRef]

70. Iulianelli, A.; Basile, A. An experimental study on bio-ethanol steam reforming in a catalytic membrane reactor. Part I: Temperature and sweep-gas flow configuration effects. Int. J. Hydrog. Energy 2010, 35, 3170-3177. [CrossRef]

71. Iulianelli, A.; Liguori, S.; Longo, T.; Tosti, S.; Pinacci, P.; Basile, A. An experimental study on bio-ethanol steam reforming in a catalytic membrane reactor. Part II: Reaction pressure, sweep factor and WHSV effects. Int. J. Hydrog. Energy 2010, 35, 3159-3164. [CrossRef]

72. Espinal, R.; Anzola, A.; Adrover, E.; Roig, M.; Chimentao, R.; Medina, F.; López, E.; Borio, D.; Llorca, J. Durable ethanol steam reforming in a catalytic membrane reactor at moderate temperature over cobalt hydrotalcite. Int. J. Hydrog. Energy 2014, 39, 10902-10910. [CrossRef]

73. Seelam, P.K.; Liguori, S.; Iulianelli, A.; Pinacci, P.; Calabrò, V.; Huuhtanen, M.; Keiski, R.; Piemonte, V.; Tosti, S.; de Falco, M.; et al. Hydrogen production from bio-ethanol steam reforming reaction in a Pd/PSS membrane reactor. Catal. Today 2012, 193, 42-48. [CrossRef]

74. Murmura, M.A.; Patrascu, M.; Annesini, M.C.; Palma, V.; Ruocco, C.; Sheintuch, M. Directing selectivity of ethanol steam reforming in membrane reactors. Int. J. Hydrog. Energy 2015, 40, 5837-5848. [CrossRef]

75. Iulianelli, A.; Liguori, S.; Vita, A.; Italiano, C.; Fabiano, C.; Huang, Y.; Basile, A. The oncoming energy vector: Hydrogen produced in $\mathrm{Pd}$-composite membrane reactor via bioethanol reforming over $\mathrm{Ni} / \mathrm{CeO}_{2}$ catalyst. Catal. Today 2014, 259, 368-375. [CrossRef] 
76. Santucci, A.; Annesini, M.C.; Borgognoni, F.; Marrelli, L.; Rega, M.; Tosti, S. Oxidative steam reforming of ethanol over a Pt $/ \mathrm{Al}_{2} \mathrm{O}_{3}$ catalyst in a Pd-based membrane reactor. Int. J. Hydrog. Energy 2011, 36, 1503-1511. [CrossRef]

77. Lim, H.; Gu, Y.; Oyama, S.T. Studies of the effect of pressure and hydrogen permeance on the ethanol steam reforming reaction with palladium- and silica-based membranes. J. Membr. Sci. 2012, 396, 119-127. [CrossRef]

78. Yun, S.; Lim, H.; Oyama, S.T. Experimental and kinetic studies of the ethanol steam reforming reaction equipped with ultrathin $\mathrm{Pd}$ and $\mathrm{Pd}-\mathrm{Cu}$ membranes for improved conversion and hydrogen yield. J. Membr. Sci. 2012, 409-410, 222-231. [CrossRef]

79. Rahman, M.A.; García-García, F.R.; Li, K. Development of a catalytic hollow fibre membrane microreactor as a microreformer unit for automotive application. J. Membr. Sci. 2012, 390-391, 68-75. [CrossRef]

80. López, E.; Divins, N.J.; Llorca, J. Hydrogen production from ethanol over Pd-Rh/CeO2 with a metallic membrane reactor. Catal. Today 2012, 193, 145-150. [CrossRef]

81. Hedayati, A.; le Corre, O.; Lacarrière, B.; Llorca, J. Experimental and exergy evaluation of ethanol catalytic steam reforming in a membrane reactor. Catal. Today 2016, 268, 68-69. [CrossRef]

82. Gallucci, F.; Chiaravalloti, F.; Tosti, S.; Drioli, E.; Basile, A. The effect of mixture gas on hydrogen permeation through a palladium membrane: Experimental study and theoretical approach. Int. J. Hydrog. Energy 2007, 32, 1837-1845. [CrossRef]

83. Caravella, A.; Scura, F.; Barbieri, G.; Drioli, E. Inhibition by CO and polarization in pd-based membranes: A novel permeation reduction coefficient. J. Phys. Chem. B 2010, 114, 12264-12276. [CrossRef] [PubMed]

84. Goldbach, A.; Bao, F.; Qi, C.; Bao, C.; Zhao, L.; Hao, C.; Jiang, C.; Xu, H. Evaluation of Pd composite membrane for pre-combustion CO2 capture. Int. J. Greenh. Gas Control 2015, 33, 69-76. [CrossRef]

85. Brunetti, A.; Caravella, A.; Fernandez, E.; Tanaka, D.A.P.; Gallucci, F.; Drioli, E.; Curcio, E.; Viviente, J.L.; Barbieri, G. Syngas upgrading in a membrane reactor with thin Pd-alloy supported membrane. Int. J. Hydrog. Energy 2015, 40, 10883-10893. [CrossRef]

86. Helmi, A.; Fernandez, E.; Melendez, J.; Tanaka, D.A.P.; Gallucci, F.; Annaland, M.V. Fluidized Bed Membrane Reactors for Ultra Pure H2 Production-A Step forward towards Commercialization. Molecules 2016, 21, 376-393. [CrossRef] [PubMed]

87. Iulianelli, A.; Ribeirinha, P.; Mendes, A.; Basile, A. Methanol steam reforming for hydrogen generation via conventional and membrane reactors: A review. Renew. Sustain. Energy Rev. 2014, 29, 355-368. [CrossRef]

88. Bion, N.; Duprez, D. Bioethanol reforming for H 2 production. A comparison with hydrocarbon reforming. Phys. Rep. 2015, 302, 1-65.

89. Bion, N.; Duprez, D.; Epron, F. Design of nanocatalysts for green hydrogen production from bioethanol. ChemSusChem 2012, 5, 76-84. [CrossRef] [PubMed]

90. Aupr, F.; Descorme, C.; Duprez, D. Bio-ethanol catalytic steam reforming over supported metal catalysts. Catal. Commun. 2002, 3, 263-267.

91. Mariño, F. Hydrogen production via catalytic gasification of ethanol. A mechanism proposal over copper-nickel catalysts. Int. J. Hydrog. Energy 2004, 29, 67-71. [CrossRef]

92. Can, F.; le Valant, A.; Bion, N.; Epron, F.; Duprez, D. New Active and Selective Rh-REOx-Al2O3 Catalysts for Ethanol Steam Reforming. J. Phys. Chem. C 2008, 112, 14145-14153. [CrossRef]

93. Fatsikostas, A.N.; Verykios, X.E. Reaction network of steam reforming of ethanol over Ni-based catalysts. J. Catal. 2004, 225, 439-452. [CrossRef]

94. Haga, F.; Nakajima, T.; Yamashita, K.; Mishima, S. Effect of crystallite size on the catalysts of alumina-supported cobalt catalysts for steam reforming of ethanol. React. Kinet. Catal. Lett. 1998, 63, 253-259. [CrossRef]

95. García-García, F.R.; León, M.; Ordóñez, S.; Li, K. Studies on water-gas-shift enhanced by adsorption and membrane permeation. Catal. Today 2014, 236, 57-63. [CrossRef]

96. Soria, M.A.; Tosti, S.; Mendes, A.; Madeira, L.M. Enhancing the low temperature water-gas shift reaction through a hybrid sorption-enhanced membrane reactor for high-purity hydrogen production. Fuel 2015, 159, 854-863. [CrossRef]

97. Anderson, D.M.; Nasr, M.H.; Yun, T.M.; Kottke, P.A.; Fedorov, A.G. Sorption-Enhanced Variable-Volume Batch-Membrane Steam Methane Reforming at Low Temperature: Experimental Demonstration and Kinetic Modeling. Ind. Eng. Chem. Res. 2015, 54, 8422-8436. [CrossRef] 
98. Yun, T.M.; Kottke, P.A.; Anderson, D.M.; Fedorov, A.G. Experimental investigation of hydrogen production by variable volume membrane batch reactors with modulated liquid fuel introduction. Int. J. Hydrog. Energy 2015, 40, 2601-2612. [CrossRef]

99. Reijers, H.T.J.; Valster-schiermeier, S.E.A.; Cobden, P.D. Hydrotalcite as $\mathrm{CO}_{2}$ Sorbent for Sorption-Enhanced Steam Reforming of Methane. Ind. Eng. Chem. Res. 2006, 45, 2522-2530. [CrossRef]

100. $\mathrm{Wu}, \mathrm{X}$; $\mathrm{Wu}, \mathrm{C}$; $\mathrm{Wu}, \mathrm{S}$. Dual-enhanced steam methane reforming by membrane separation of $\mathrm{H}_{2}$ and reactive sorption of $\mathrm{CO}_{2}$. Chem. Eng. Res. Des. 2015, 96, 150-157. [CrossRef]

101. Medrano, J.A.; Spallina, V.; Annaland, M.V.; Gallucci, F. Thermodynamic analysis of a membrane-assisted chemical looping reforming reactor concept for combined $\mathrm{H}_{2}$ production and $\mathrm{CO}_{2}$ capture. Int. J. Hydrog. Energy 2013, 39, 4725-4738. [CrossRef]

102. Caravella, A.; Scura, F.; Barbieri, G.; Drioli, E. Sieverts law empirical exponent for Pd-based membranes: Critical analysis in pure $\mathrm{H}_{2}$ permeation. J. Phys. Chem. B 2010, 114, 6033-6047. [CrossRef] [PubMed]

103. Sieverts, A.; Krumbhaar, W. Über die löslichkeit von gasen in metallen und legierungen. Ber. Deutsch. Chem. Ges. 1910, 43, 893-900. [CrossRef]

104. Callister, W.D.; Rethwisch, D.G. Thermal Properties. In Fundamentals of Materials Science and Engineering: An Integrated Approach, 3rd ed.; Jonh Wiley ans Sons: Hoboken, NJ, USA, 2007.

105. Ryi, S.-S.; Ahn, H.-S.; Park, J.-S.; Kim, D.-W. Pd-Cu alloy membrane deposited on $\mathrm{CeO}_{2}$ modified porous nickel support for hydrogen separation. Int. J. Hydrog. Energy 2014, 39, 4698-4703. [CrossRef]

106. Lide, D.R.; Data, S.R.; Board, E.A.; Baysinger, G.; Chemistry, S.; Library, C.E.; Berger, L.I.; Goldberg, R.N.; Division, B.; Kehiaian, H.V.; et al. CRC Handbook of Chemistry and Physics; CRC Press: Boca Raton, FL, USA, 1997; Volume 257, p. 1438.

107. Ryi, S.-K.; Lee, S.-W.; Oh, D.-D.; Seo, B.-S.; Park, J.-W.; Park, J.-S.; Lee, D.-W. Electroless plating of Pd after shielding the bottom of planar porous stainless steel for a highly stable Hydrogen selective membrane. J. Membr. Sci. 2014, 467, 93-99. [CrossRef]

108. Uemiya, S. State-of-the-Art of Supported Metal Membranes for Gas Separation. Sep. Purif. Rev. 1999, 28, 51-85. [CrossRef]

109. McCool, B.; Xomeritakis, G.; Lin, Y. Composition control and hydrogen permeation characteristics of sputter deposited palladium-silver membranes. J. Membr. Sci. 1999, 161, 67-76. [CrossRef]

110. Tanaka, D.A.P.; Llosa, M.A.T.; Nagase, T.; Okazaki, J.; Wakui, Y.; Mizukami, F.; Suzuki, T.M. Fabrication of Hydrogen-Permeable Composite Membranes Packed with Palladium Nanoparticles. Adv. Mater. 2006, 18, 630-632. [CrossRef]

111. Thoen, P.M.; Roa, F.; Way, J.D. High flux palladium-copper composite membranes for hydrogen separations. Desalination 2006, 193, 224-229. [CrossRef]

112. Checchetto, R.; Patel, N.; Miotello, A.; Brusa, R.S. Nanolayers on nanochannels for hydrogen purification. J. Appl. Phys. 2009, 105, 034502. [CrossRef]

113. Pan, X.L.; Xiong, G.X.; Sheng, S.S.; Stroh, N.; Brunner, H. Thin dense Pd membranes supported on $\alpha-\mathrm{Al}_{2} \mathrm{O}_{3}$ hollow fibers. Chem. Commun. 2001, 24, 2536-2537. [CrossRef]

114. Wu, L.-Q.; $\mathrm{Xu}, \mathrm{N}$.; Shi, J. Novel method for preparing palladium membranes by photocatalytic deposition. AIChE J. 2000, 46, 1075-1083. [CrossRef]

115. Li, X.; Fan, Y.; Jin, W.; Huang, Y.; Xu, N. Improved photocatalytic deposition of palladium membranes. J. Membr. Sci. 2006, 282, 1-6. [CrossRef]

116. Tanaka, D.A.P.; Tanco, M.A.L.; Okazaki, J.; Wakui, Y.; Mizukami, F.; Suzuki, T.M. Preparation of 'pore-fill' type Pd-YSZ- $\gamma-\mathrm{Al}_{2} \mathrm{O}_{3}$ composite membrane supported on $\alpha-\mathrm{Al}_{2} \mathrm{O}_{3}$ tube for hydrogen separation. J. Membr. Sci. 2008, 320, 436-441. [CrossRef]

117. Okazaki, J.; Ikeda, T.; Tanaka, D.A.P.; Tanco, M.A.L.; Wakui, Y.; Sato, K.; Mizukami, F.; Suzuki, T.M. Strong Interaction at the Palladium/Alumina Interface of Membrane during Hydrogen Permeation at Elevated Temperature. Chem. Lett. 2008, 37, 1004-1005. [CrossRef]

118. Paglieri, S.N.; Foo, K.Y.; Way, J.D.; Collins, J.P.; Harper-Nixon, D.L. A New Preparation Technique for Pd/Alumina Membranes with Enhanced High-Temperature Stability. Ind. Eng. Chem. Res. 1999, 38, 1925-1936. [CrossRef]

119. Huang, Y.; Dittmeyer, R. Preparation and characterization of composite palladium membranes on sinter-metal supports with a ceramic barrier against intermetallic diffusion. J. Membr. Sci. 2006, 282, 296-310. [CrossRef] 
120. Okazaki, J.; Ikeda, T.; Tanaka, D.A.P.; Tanco, M.A.L.; Wakui, Y.; Sato, K.; Mizukami, F.; Suzuki, T.M. Importance of the support material in thin palladium composite membranes for steady hydrogen permeation at elevated temperatures. Phys. Chem. Chem. Phys. 2009, 11, 8632-8638. [CrossRef] [PubMed]

121. Gharibi, H.; Saadatinasab, M.; Zolfaghari, A. Hydrogen permeability and sulfur tolerance of a novel dual membrane of PdAg/PdCu layers deposited on porous stainless steel. J. Membr. Sci. 2013, 447, 355-361. [CrossRef]

122. Tardini, A.; Gerboni, C.; Cornaglia, L. PdAu membranes supported on top of vacuum-assisted $\mathrm{ZrO}_{2}$-modified porous stainless steel substrates. J. Membr. Sci. 2013, 428, 1-10. [CrossRef]

123. Braun, F.; Tarditi, A.M.; Miller, J.B.; Cornaglia, L.M. Pd-based binary and ternary alloy membranes: Morphological and perm-selective characterization in the presence of $\mathrm{H}_{2}$ S. J. Membr. Sci. 2014, 450, $299-307$. [CrossRef]

124. Calles, A.; Alique, D.; Furones, L. Thermal stability and effect of typical water gas shift reactant composition on $\mathrm{H}_{2}$ permeability through a Pd-YSZ-PSS composite membrane. Int. J. Hydrog. Energy 2014, 39, 1398-1409. [CrossRef]

125. Peters, T.A.; Stange, M.; Bredesen, R. On the high pressure performance of thin supported Pd-23\%Ag membranes-Evidence of ultrahigh hydrogen flux after air treatment. J. Membr. Sci. 2011, 378, 28-34. [CrossRef]

126. Lewis, A.E.; Zhao, H.; Syed, H.; Wolden, C.A.; Way, J.D. PdAu and PdAuAg composite membranes for hydrogen separation from synthetic water-gas shift streams containing hydrogen sulfide. J. Membr. Sci. 2014, 465, 167-176. [CrossRef]

127. Hatlevik, Ø.; Gade, S.K.; Keeling, M.K.; Thoen, P.M.; Davidson, A.P.; Way, J.D. Palladium and palladium alloy membranes for hydrogen separation and production: History, fabrication strategies, and current performance. Sep. Purif. Technol. 2010, 73, 59-64. [CrossRef]

128. el Hawa, H.W.A.; Paglieri, S.N.; Morris, C.C.; Harale, A.; Way, J.D. Identification of thermally stable Pd-alloy composite membranes for high temperature applications. J. Membr. Sci. 2014, 466, 151-160. [CrossRef]

129. Straczewski, G.; Völler-Blumenroth, J.; Beyer, H.; Pfeifer, P.; Steffen, M.; Felden, I.; Heinzel, A.; Wessling, M.; Dittmeyer, R. Development of thin palladium membranes supported on large porous 310L tubes for a steam reformer operated with gas-to-liquid fuel. Chem. Eng. Process. Process Intensif. 2014, 81, 13-23. [CrossRef]

130. Lee, C.-B.; Lee, S.-W.; Park, J.-S.; Ryi, S.-K.; Lee, D.-W.; Hwang, K.-R.; Kim, S.-H. Ceramics used as intermetallic diffusion barriers in Pd-based composite membranes sputtered on porous nickel supports. J. Alloys Compd. 2013, 578, 425-430. [CrossRef]

131. Fernandez, E.; Medrano, J.A.; Melendez, J.; Parco, M.; Viviente, J.L.; Annaland, M.V.; Gallucci, F.; Tanaka, D.A.P. Preparation and characterization of metallic supported thin Pd-Ag membranes for hydrogen separation. Chem. Eng. J. 2015, 305, 182-190. [CrossRef]

132. Zhao, H.; Pflanz, K.; Gu, J.; Li, A.; Stroh, N.; Brunner, H.; Xiong, G. Preparation of palladium composite membranes by modified electroless plating procedure. J. Membr. Sci. 1998, 142, 147-157. [CrossRef]

133. Iaquaniello, G.; Borruto, A.; Lollobattista, E.; Narducci, G.; Katsir, D. Hydrogen Palladium Selective Membranes: An Economic Perspective. In Membrane Reactor for Hydrogen Production Processes; de Falco, M., Marrelli, L., Iaquaniello, G., Eds.; Springer: London, UK, 2011.

134. Roa, F.; Way, J.D. The effect of air exposure on palladium-copper composite membranes. Appl. Surf. Sci. 2005, 240, 85-104. [CrossRef]

135. Zhang, K.; Gade, S.K.; Way, J.D. Effects of heat treatment in air on hydrogen sorption over Pd-Ag and Pd-Au membrane surfaces. J. Membr. Sci. 2012, 403-404, 78-83. [CrossRef]

136. Ayturk, M.E.; Engwall, E.E.; Ma, Y.H. Microstructure Analysis of the Intermetallic Diffusion-Induced Alloy Phases in Composite Pd/Ag/Porous Stainless Steel Membranes. Ind. Eng. Chem. Res. 2007, 46, 4295-4306. [CrossRef]

137. Broglia, M.; Pinacci, P.; Radaelli, M.; Bottino, A.; Capannelli, G.; Comite, A.; Vanacore, G.; Zani, M. Synthesis and characterization of Pd membranes on alumina-modified porous stainless steel supports. Desalination 2009, 245, 508-515. [CrossRef]

138. Li, A.; Grace, J.R.; Lim, C.J. Preparation of thin Pd-based composite membrane on planar metallic substrate. J. Membr. Sci. 2007, 298, 175-181. [CrossRef]

139. Chi, Y.-H.; Yen, P.-S.; Jeng, M.-S.; Ko, S.-T.; Lee, T.-C. Preparation of thin Pd membrane on porous stainless steel tubes modified by a two-step method. Int. J. Hydrog. Energy 2010, 35, 6303-6310. [CrossRef] 
140. Ryi, S.-K.; Park, J.-S.; Hwang, K.-R.; Lee, C.-B.; Lee, S.-W. Repair of Pd-based composite membrane by polishing treatment. Int. J. Hydrog. Energy 2011, 36, 13776-13780. [CrossRef]

141. Chotirach, M.; Tantayanon, S.; Tungasmita, S.; Kriausakul, K. Zr-based intermetallic diffusion barriers for stainless steel supported palladium membranes. J. Membr. Sci. 2012, 405-406, 92-103. [CrossRef]

142. Wang, D.; Tong, J.; Xu, H.; Matsumura, Y. Preparation of palladium membrane over porous stainless steel tube modified with zirconium oxide. Catal. Today 2004, 93-95, 689-693. [CrossRef]

143. Gao, H.; Slin, J.; Li, Y.; Zhang, B. Electroless plating synthesis, characterization and permeation properties of Pd-Cu membranes supported on $\mathrm{ZrO}_{2}$ modified porous stainless steel. J. Membr. Sci. 2005, 265, 142-152. [CrossRef]

144. Zhang, K.; Gao, H.; Rui, Z.; Liu, P.; Li, Y.; Lin, Y.S. High-Temperature Stability of Palladium Membranes on Porous Metal Supports with Different Intermediate Layers. Ind. Eng. Chem. Res. 2009, 48, 1880-1886. [CrossRef]

145. Tong, J.; Su, C.; Kuraoka, K.; Suda, H.; Matsumura, Y. Preparation of thin Pd membrane on $\mathrm{CeO}_{2}$-modified porous metal by a combined method of electroless plating and chemical vapor deposition. J. Membr. Sci. 2006, 269, 101-108. [CrossRef]

146. Manchester, F.D.; San-Martin, A.; Pitre, J.M. The H-Pd (Hydrogen-Palladium) System. J. Phase Equilib. 1994, 15, 62-83. [CrossRef]

147. Maeland, B.A.; Flanagan, T.B. The Hydrogen-Palladium System. Platinum Met. Rev. 1966, 10, $20-23$.

148. Okazaki, J.; Tanaka, D.; Tanco, M.; Wakui, Y.; Mizukami, F.; Suzuki, T. Hydrogen permeability study of the thin Pd-Ag alloy membranes in the temperature range across the $\alpha-\beta$ phase transition. J. Membr. Sci. 2006, 282, 370-374. [CrossRef]

149. Knapton, B.A.G. Palladium Alloys for Hydrogen Diffusion Membranes. Platin. Met. Rev. 1977, 21, 44-50.

150. Barbieri, G.; Scura, F.; Lentini, F.; de Luca, G.; Drioli, E. A novel model equation for the permeation of hydrogen in mixture with carbon monoxide through Pd-Ag membranes. Sep. Purif. Technol. 2008, 61, 217-224.

151. Khan, N.A.; Uhl, A.; Shaikhutdinov, S.; Freund, H.-J. Alumina supported model Pd-Ag catalysts: A combined STM, XPS, TPD and IRAS study. Surf. Sci. 2006, 600, 1849-1853. [CrossRef]

152. Sakamoto, Y.; Chen, F.L.; Kinari, Y.; Sakamoto, F. Effect of carbon monoxide on hydrogen permeation alloy membranes. Int. J. Hydrog. Energy 1996, 210, 1017-1024. [CrossRef]

153. Kulprathipanja, A.; Alptekin, O.; Falconer, J.L.; Way, J.D. Pd and Pd-Cu membranes: Inhibition of $\mathrm{H}_{2}$ permeation by $\mathrm{H}_{2}$ S. J. Membr. Sci. 2005, 254, 49-62. [CrossRef]

154. Gade, S.K.; Payzant, E.A.; Park, H.J.; Thoen, P.M.; Way, J.D. The effects of fabrication and annealing on the structure and hydrogen permeation of Pd-Au binary alloy membranes. J. Membr. Sci. 2009, 340, 227-233. [CrossRef]

155. Okazaki, J.; Tanaka, D.A.P.; Tanco, M.A.L.; Wakui, Y.; Ikeda, T.; Mizukami, F.; Suzuki, T.M. Preparation and Hydrogen Permeation Properties of Thin Pd-Au Alloy Membranes Supported on Porous $\alpha$-Alumina Tube. Mater. Trans. 2008, 49, 449-452. [CrossRef]

156. Meléndez, J.; Fernandez, E.; Sanchez-García, J.A.; Arias, P.L.; Tanaka, D.A.P. Preparation and Characterization of Pd-Ag-Au Alloy Membranes for Hydrogen Separation; European Hydrogen Energy Conference: Seville, Spain, 2014.

157. Morreale, B. Effect of hydrogen-sulfide on the hydrogen permeance of palladium-Copper alloys at elevated temperatures. J. Membr. Sci. 2004, 241, 219-224. [CrossRef]

158. Zhao, L.; Goldbach, A.; Bao, C.; Xu, H. Sulfur inhibition of PdCu membranes in the presence of external mass flow resistance. J. Membr. Sci. 2015, 496, 301-309. [CrossRef]

159. Pomerantz, N.; Hua, M.Y. Effect of $\mathrm{H}_{2} \mathrm{~S}$ on the performance and long-term stability of Pd/Cu membranes. Ind. Eng. Chem. Res. 2009, 48, 4030-4039. [CrossRef]

160. Zhao, L.; Goldbach, A.; Xu, H. Tailoring palladium alloy membranes for hydrogen separation from sulfur contaminated gas streams. J. Membr. Sci. 2016, 507, 55-62. [CrossRef]

161. Nayebossadri, S.; Speight, J.; Book, D. Novel Pd-Cu-Zr hydrogen separation membrane with a high tolerance to sulphur poisoning. Chem. Commun. 2015, 51, 15842-15845. [CrossRef] [PubMed]

162. Lee, S.W.; Oh, D.K.; Park, J.W.; Lee, C.B.; Lee, D.W.; Park, J.S.; Kim, S.H.; Hwang, K.R. Effect of a Pt-ZrO 2 protection layer on the performance and morphology of $\mathrm{Pd}-\mathrm{Au}$ alloy membrane during $\mathrm{H}_{2} \mathrm{~S}$ exposure. J. Alloys Compd. 2015, 641, 210-215. [CrossRef] 
163. Peters, T.A.; Stange, M.; Veenstra, P.; Nijmeijer, A.; Bredesen, R. The performance of Pd-Ag alloy membrane films under exposure to trace amounts of $\mathrm{H}_{2}$ S. J. Membr. Sci. 2016, 499, 105-115. [CrossRef]

164. Coulter, K.E.; Way, J.D.; Gade, S.K.; Chaudhari, S.; Alptekin, G.O.; DeVoss, S.J.; Paglieri, S.N.; Pledger, B. Sulfur tolerant PdAu and PdAuPt alloy hydrogen separation membranes. J. Membr. Sci. 2012, 405-406, 11-19. [CrossRef]

165. Gryaznov, V. Metal Containing Membranes for the Production of Ultrapure Hydrogen and the Recovery of Hydrogen Isotopes. Sep. Purif. Methods 2000, 29, 171-187. [CrossRef]

166. Tripathi, S.N.; Bharadway, S.R.; Dharwadkar, S.R. The Pd-Ru System (Palladium-Ruthenium). J. Phase Equilibr. 1993, 14, 638-642. [CrossRef]

167. Didenko, L.P.; Savchenko, V.I.; Sementsova, L.A.; Bikov, L.A. Hydrogen flux through the membrane based on the Pd-In-Ru foil. Int. J. Hydrog. Energy 2016, 41, 307-315. [CrossRef]

168. Dolan, M.D. Non-Pd BCC alloy membranes for industrial hydrogen separation. J. Membr. Sci. 2010, 362, 12-28. [CrossRef]

169. Basile, A.; Gallucci, F.; Tosti, S. Synthesis, Characterization and Applications of Palladium Membranes. In Inorganic Membranes: Synthesis, Characterization and Applications; Mallada, R., Menendez, M., Eds.; Elsevier: Amsterdam, The Netherlands, 2008.

170. Nambu, T.; Shimizu, K.; Matsumoto, Y.; Rong, R.; Watanabe, N.; Yukawa, H.; Morinaga, M.; Yasuda, I. Enhanced hydrogen embrittlement of Pd-coated niobium metal membrane detected by in situ small punch test under hydrogen permeation. J. Alloys Compd. 2007, 446-447, 588-592. [CrossRef]

171. Alimov, V.N.; Busnyuk, A.O.; Notkin, M.; Livshits, A.I. Pd-V-Pd composite membranes: Hydrogen transport in a wide pressure range and mechanical stability. J. Membr. Sci. 2014, 457, 103-112. [CrossRef]

172. Kim, K.H.; Park, H.C.; Lee, J.; Cho, E.; Lee, S.M. Vanadium alloy membranes for high hydrogen permeability and suppressed hydrogen embrittlement. Scr. Mater. 2013, 68, 905-908. [CrossRef]

173. Viano, D.M.; Dolan, M.D.; Weiss, F.; Adibhatla, A. Asymmetric layered vanadium membranes for hydrogen separation. J. Membr. Sci. 2015, 487, 83-89. [CrossRef]

174. Oh, J.-Y.; Ko, W.-S.; Suh, J.-Y.; Lee, Y.-S.; Lee, B.-J.; Yoon, W.Y.; Shim, J.-H. Enhanced high temperature hydrogen permeation characteristics of $\mathrm{V}-\mathrm{Ni}$ alloy membranes containing a trace amount of yttrium. Scr. Mater. 2016, 116, 122-126. [CrossRef]

175. Watanabe, N.; Yukawa, H.; Nambu, T.; Matsumoto, Y.; Zhang, G.X.; Morinaga, M. Alloying effects of Ru and $\mathrm{W}$ on the resistance to hydrogen embrittlement and hydrogen permeability of niobium. J. Alloys Comp. 2009, 477, 851-854. [CrossRef]

176. Paglieri, S.N.; Pal, N.K.; Dolan, M.D.; Kim, S.-M.; Chien, W.-M.; Lamb, J.; Chandra, D.; Hubbard, K.M.; Moore, D.P. Hydrogen permeability, thermal stability and hydrogen embrittlement of $\mathrm{Ni}-\mathrm{Nb}-\mathrm{Zr}$ and $\mathrm{Ni}-\mathrm{Nb}-\mathrm{Ta}-\mathrm{Zr}$ amorphous alloy membranes. J. Membr. Sci. 2011, 378, 42-50. [CrossRef]

177. Iwahara, H.; Yajima, T.; Ushida, H. Effect of ionic radii of dopants on mixed ionic conduction $\left(\mathrm{H}^{+}+\mathrm{O}^{2-}\right)$ in $\mathrm{BaCeO}_{3}$-based electrolytes. Solid State Ion. 1994, 1, 267-271. [CrossRef]

178. Iwahara, H. Technological challenges in the application of proton conducting ceramics. Solid State Ion. 1995, 77, 289-298. [CrossRef]

179. Liub, M.; Guan, J.; Dorris, S.E.; Balachardran, U. Transport properties of $\mathrm{BaCeO}_{0.95} \mathrm{Y}_{0.05} \mathrm{O}_{3-\alpha}$ mixed conductors for hydrogen separation. Solid State Ion. 1997, 100, 45-52.

180. Guan, I. The Effects of Dopants and A:B Site Nonstoichiometry on Properties of Perovskite-Type Proton Conductors. J. Electrochem. Soc. 1998, 145, 1780-1786. [CrossRef]

181. Guan, J.; Dorris, S.E.; Balachandran, U.; Liu, M. Development of Mixed-Conducting Ceramic Membranes for Hydrogen Separation. Electr. Glass Ceram. 1998, 92, 265-276.

182. Balachandran, U.B.; Lee, T.H.; Wang, S.; Zhang, G.; Dorris, S.E. Recent advances in the development of dense ceramic membranes for hydrogenseparation 2002. In Processings of the ACS meeting, Boston, MA, USA, 18 August 2002.

183. Balachandran, U.; Lee, T.H.; Chen, L.; Song, S.J.; Picciolo, J.J.; Dorris, S.E. Hydrogen separation by dense cermet membranes. Fuel 2006, 85, 150-155. [CrossRef]

184. Hoon, J.; Il, S.; Jong, W.; Hyun, I.; Hyun, S. Stability of Ta/YSZ cermet membrane for hydrogen separation. Energy Procedia 2011, 4, 756-762.

185. Jeon, S.; Choi, M.; Park, C.; Wachsman, E.D.; Song, S. High sulfur tolerance dual-functional cermet hydrogen separation membranes. J. Membr. Sci. 2011, 382, 323-327. [CrossRef] 
186. Jeon, S.; Lim, D.; Choi, M.; Wachsman, E.D.; Song, S. Hydrogen separation by $\mathrm{Pd}-\mathrm{CaZr}_{0.9} \mathrm{Y}_{0.1} \mathrm{O}_{3-\delta}$ cermet composite membranes. Sep. Purif. Technol. 2011, 79, 337-341. [CrossRef]

187. Jeon, S.; Choi, M.; Singh, B.; Song, S. Hydrogen separation by dual functional cermet membranes with self-repairing capability against the damage by $\mathrm{H}_{2}$ S. J. Membr. Sci. 2013, 428, 46-51. [CrossRef]

188. Yan, L.; Sun, W.; Bi, L.; Fang, S.; Tao, Z.; Liu, W. Influence of fabrication process of Ni-BaCe ${ }_{0.7} \mathrm{Zr}_{0.1} \mathrm{Y}_{0.2} \mathrm{O}_{3}-\mathrm{d}$ cermet on the hydrogen permeation performance. J. Alloys Compd. 2010, 508, L5-L8. [CrossRef]

189. Zuo, C.; Lee, T.H.; Dorris, S.E.; Balachandran, U.; Liu, M. Composite Ni-Ba $\left(\mathrm{Zr}_{0.1} \mathrm{Ce}_{0.7} \mathrm{Y}_{0.2}\right) \mathrm{O}_{3}$ membrane for hydrogen separation. J. Power Source 2006, 159, 1291-1295. [CrossRef]

190. Zhu, Z.; Sun, W.; Yan, L.; Liu, W.; Liu, W. Synthesis and hydrogen permeation of Ni-Ba $\left(\mathrm{Zr}_{0.1} \mathrm{Ce}_{0.7} \mathrm{Y}_{0.2}\right) \mathrm{O}_{3}-\mathrm{d}$ metal e ceramic asymmetric membranes. Int. J. Hydrog. Energy 2011, 36, 6337-6342. [CrossRef]

191. Kim, H.; Kim, B.; Lee, J.; Ahn, K.; Kim, H.; Joong, K.; Kim, B.; Whan, Y.; Lee, H.; Lee, J. Microstructural adjustment of $\mathrm{Ni}-\mathrm{BaCe}_{0.9} \mathrm{Y}_{0.1} \mathrm{O}_{3-\delta}$ cermet membrane for improved hydrogen permeation. Ceram. Int. 2014, 40, 4117-4126. [CrossRef]

192. Liu, M.; Sun, W.; Li, X.; Feng, S.; Ding, D.; Chen, D.; Liu, M.; Cheol, H. High-performance $\mathrm{Ni}-\mathrm{BaZr}_{0.1} \mathrm{Ce}_{0.7} \mathrm{Y}_{0.1} \mathrm{Yb}_{0.1} \mathrm{O}_{3-\mathrm{d}}(\mathrm{BZCYYb})$ membranes for hydrogen separation. Int. J. Hydrog. Energy 2013, 8, 3-9. [CrossRef]

193. Meng, X.; Song, J.; Yang, N.; Meng, B.; Tan, X.; Ma, Z.; Li, K. Ni-BaCe $e_{0.95} \mathrm{~Tb}_{0.05} \mathrm{O}_{3-\mathrm{d}}$ Cermet Membranes for Hydrogen Permeation. J. Membr. Sci. 2012, 402, 300-305. [CrossRef]

194. Balachandran, U.B.; Lee, T.H.; Park, C.Y.; Emerson, J.E.; Picciolo, J.J.; Dorris, S.E. Dense cermet membranes for hydrogen separation. Sep. Purif. Technol. 2014, 121, 54-59. [CrossRef]

195. Sato, K.; Nishioka, M.; Higashi, H.; Inoue, T.; Hasegawa, Y.; Wakui, Y.; Suzuki, T.M.; Hamakawa, S. Influence of $\mathrm{CO}_{2}$ and $\mathrm{H}_{2} \mathrm{O}$ on the separation of hydrogen over two types of Pd membranes: Thin metal membrane and pore-filling-type membrane. J. Membr. Sci. 2012, 415-416, 85-92. [CrossRef]

196. Nair, B.K.R.; Harold, M.P. Pd encapsulated and nanopore hollow fiber membranes: Synthesis and permeation studies. J. Membr. Sci. 2007, 290, 182-195. [CrossRef]

197. Israni, S.H.; Nair, B.K.R.; Harold, M.P. Hydrogen generation and purification in a composite Pd hollow fiber membrane reactor: Experiments and modeling. Catal. Today 2009, 139, 299-311. [CrossRef]

198. Arratibel, A.; Astobieta, U.; Tanaka, D.A.P.; Annaland, M.V.; Gallucci, F. N 2 , He and $\mathrm{CO}_{2}$ diffusion mechanism through nanoporous $\mathrm{YSZ} / \gamma-\mathrm{Al}_{2} \mathrm{O}_{3}$ layers and their use in a pore-filled membrane for hydrogen membrane reactors. Int. J. Hydrog. Energy 2016, 41, 8732-8744. [CrossRef]

199. Shgau, K.; Verweij, H. Stable Supported Pd-Alloy Membranes. U.S. Patent US20100071556 A1, 25 Mar 2010.

200. Yogo, K.; Takeyama, H.; Nagata, K. Pore-fill-type Palladium Porous Alumina Composite Membrane for Hydrogen Separation. Energy Procedia 2013, 37, 1104-1108. [CrossRef]

201. Bonanos, N.; Knight, K.S.; Ellis, B. Perovskite solid electrolytes: Structure, transport properties and fuel cell applications. Solid State Ion. 1995, 79, 161-170. [CrossRef]

202. Zakowsky, N.; Williamson, S.; Irvine, J. Elaboration of $\mathrm{CO}_{2}$ tolerance limits of $\mathrm{BaCe}_{0.9} \mathrm{Y}_{0.1} \mathrm{O}_{3-\delta}$ electrolytes for fuel cells and other applications. Solid State Ion. 2005, 176, 3019-3026. [CrossRef]

203. Kreuer, K.D. Aspects of the formation and mobility of protonic charge carriers and the stability of perovskite-type oxides. Solid State Ion. 1999, 125, 285-302. [CrossRef]

204. Zuo, C.; Dorris, S.E.; Balachandran, U.; Liu, M. Effect of Zr-Doping on the Chemical Stability and Hydrogen Permeation of the Ni-BaCe ${ }_{0.8} \mathrm{Y}_{0.2} \mathrm{O}_{3-\alpha}$ Mixed Protonic-Electronic Conductor. Chem. Mater. 2006, 18, 4647-4650. [CrossRef]

205. Kang, W.R.; Lee, K.B. Development of rare earth element-doped Ni-Ba(Ce/ $\mathrm{Zr}) \mathrm{O}_{3}$ cermets for hydrogen-permeable membranes. J. Ind. Eng. Chem. 2015, 29, 194-198. [CrossRef]

206. Zhu, Z.; Sun, W.; Dong, Y.; Wang, Z.; Shi, Z.; Zhang, Q.; Liu, W. Evaluation of hydrogen permeation properties of $\mathrm{Ni}-\mathrm{Ba}\left(\mathrm{Zr}_{0.7} \mathrm{Pr}_{0.1} \mathrm{Y}_{0.2}\right) \mathrm{O}_{3-\delta}$ cermet membranes. Int. J. Hydrog. Energy 2014, 39, 11683-11689. [CrossRef]

207. Wei, Y.; Xue, J.; Fang, W.; Chen, Y.; Wang, H.; Caro, J. Enhanced stability of Zr-doped Ba(CeTb) $\mathrm{O}_{(3-\delta)}-\mathrm{Ni}$ cermet membrane for hydrogen separation. Chem. Commun. (Camb. Engl.) 2015, 51, 11619-11621. [CrossRef] [PubMed]

208. Zhu, Z.; Sun, W.; Wang, Z.; Cao, J.; Dong, Y.; Liu, W. A high stability Ni-La ${ }_{0.5} \mathrm{Ce}_{0.5} \mathrm{O}_{2-\delta}$ asymmetrical metal-ceramic membrane for hydrogen separation and generation. J. Power Source 2015, 281, 417-424. [CrossRef] 
209. Lee, M.J.; Lee, Y.S.; Jang, M.H.; Hong, T.W. Evaluations of hydrogen permeability on $\mathrm{Ti}_{4} \mathrm{Cr}_{3} \mathrm{Nb}_{3} \mathrm{O}_{2}(\mathrm{TCN})-$ 20 wt. \%Ni composite membrane by hot press sintering. J. Alloys Compd. 2015, 645, S325-S328. [CrossRef]

210. Balachandran, U. Use of mixed conducting membranes to produce hydrogen by water dissociation. Int. J. Hydrog. Energy 2004, 29, 291-296. [CrossRef]

211. Kim, J.; Lin, Y.S. Synthesis and oxygen-permeation properties of thin YSZ/Pd composite membranes. AIChE J. 2000, 46, 1521-1529. [CrossRef]

212. Suzuki, T.; Tanaka, D.A.P.; Tanco, M.L. Method for Purifing/Separating Hydrogen. Patent JP4572385 (B2), 4 November 2010.

213. Gora, A.; Tanaka, D.A.P.; Mizukami, F.; Suzuki, T.M. Lower Temperature Dehydrogenation of Methylcyclohexane by Membrane-assisted Equilibrium Shift. Chem. Lett. 2006, 35, 1372-1373. [CrossRef]

214. Zhao, T.; Okazaki, J.; Tanaka, D.A.P.; Suzuki, T.M.; Wakui, Y. Hydrogen separation with 'pore-fill' type palladium membrane. In Proceedings of the AIChE Annual Meeting, New York, NY, USA, 16-21 October 2011.

215. Wakui, Y.; Tanaka, D.A.P.; Suzuki, T.; Fujio, M. High-Durability Hydrogen Separation Membrane and Its Manufacturing Method. U.S. Patent JP 4998881 (B2), 15 August 2012.

(C) 2017 by the authors; licensee MDPI, Basel, Switzerland. This article is an open access article distributed under the terms and conditions of the Creative Commons Attribution (CC-BY) license (http://creativecommons.org/licenses/by/4.0/). 